INSTITUTO DE PESQUISAS ENERGÉTICAS E NUCLEARES

Autarquia associada à Universidade de São Paulo

DESENVOLVIMENTO DE UM SOFTWARE DE ESPECTROMETRIA GAMA

PARA ANÁLISE POR ATIVAÇÃO COM NÊUTRONS UTILIZANDO O CONCEITO DE CÓDIGO LIVRE

SÍLVIO ROGÉRIO DE LÚCIA

Dissertação apresentada como parte dos requisitos para obtenção do Grau de Mestre em Ciências na Área de Tecnologia Nuclear - Aplicações.

Orientadora:

Dra. Vera Akiko Maihara

SÃO PAULO

2008 
Dedico esse trabalho em especial à minha esposa $e$ aos meus filhos pelo estímulo e paciência. 


\section{AGRADECIMENTOS}

Muitas pessoas, de forma direta ou indireta, contribuíram para a realização deste trabalho e a todas elas quero expressar meu reconhecimento e minha gratidão. Agradeço em especial,

À Dra. Vera Akiko Maihara, pela orientação dada a este trabalho, e pela confiança em mim depositada.

Ao Dr. Mario Olímpio Menezes, que me apoiou e contribuiu para a realização deste trabalho.

Ao IPEN/CNEN-SP, pela oportunidade de realizar este trabalho.

À Maria Aparecida H. Trezza, pelo apoio e oportunidade de realizar este trabalho. 


\title{
DESENVOLVIMENTO DE UM SOFTWARE DE ESPECTROMETRIA GAMA \\ PARA ANÁLISE POR ATIVAÇÃO COM NÊUTRONS UTILIZANDO O CONCEITO DE CÓDIGO LIVRE.
}

\section{SÍLVIO ROGÉRIO DE LÚCIA}

\begin{abstract}
RESUMO
O Laboratório de Análise por Ativação com Nêutrons (LAN) do Instituto de Pesquisas Energéticas e Nucleares (IPEN), utiliza esta técnica analítica multielementar, baseada na irradiação de uma amostra por um feixe de nêutrons oriundos de um reator nuclear, que induz a radioatividade; que é medida em um espectrômetro de raios gama, para a obtenção dos espectros de raios gama. Neste trabalho é implementado um software denominado de "SAANI" (Software Análise por Ativação com Nêutrons Instrumental) para análise de espectros de raios gama, desenvolvido para os usuários do laboratório LAN-IPEN, com a filosofia de software livre, para a substituição do software existente VISPECT/VERSÃO 2, e tem como características principais: tornar a interface mais amigável; facilitar a padronização dos procedimentos realizados pelos pesquisadores, estudantes e técnicos; ser extensível com a utilização da tecnologia de plugins; multiplataforma; código livre. O software foi desenvolvido utilizando a linguagem de programação Python, a biblioteca gráfica Trolltech Qt e algumas de suas extensões científicas. Os resultados preliminares obtidos utilizando o software "SAANI" foram comparados aos obtidos com o software existente e foram considerados bons. Algumas diferenças encontradas foram verificadas oriundas de erros de precisão na implementação do software. 0 software SAANI está instalado nos computadores de usuários selecionados para a execução de rotinas de análise para uma maior verificação de sua robustez, precisão e usabilidade.
\end{abstract}




\title{
DEVELOPMENT OF A GAMMA RAY SPECTROMETRY \\ SOFTWARE FOR NEUTRON ACTIVATION ANALYSIS \\ USING THE OPEN SOURCE CONCEPT
}

\author{
SÍLVIO ROGÉRIO DE LÚCIA
}

\begin{abstract}
This study developed a specific software for gamma ray spectra analysis for researchers of the Neutron Activation Laboratory (LAN), which was named SAANI (Instrumental Neutron Activation Analysis Software). The LAN laboratory of the Institute for Research and Nuclear Energy (IPEN-CNEN/SP), uses a multielementar analytical technique, based on irradiation of a sample by a flux of neutrons from a nuclear reactor, which induces radioactivity. The sample is then placed in a gamma-ray spectrometer, to obtain the spectrum. With free software philosophy in mind, this software will replace the existing software VISPECT / VERSION 2. The new software's main features are: a friendlier interface; easier standardization procedure carried out by LAN staff and researchers; adapted to the use of plug technology; multiplatform and code free. The software was developed using the programming Python language, the library Trolltech Qt graphics and some of their scientific extensions. Preliminary results using the SANNI software were compared to those obtained with the existing software and were considered good. There were some errors in accuracy during the implementation of the software. The SAANI software has been installed in selected computers to be used for routine analysis in order to verify its strength, accuracy and usability.
\end{abstract}




\section{SUMÁRIO}

CAPÍTULO 1 - INTRODUÇÃO

1.1 - Objetivo 12

1.2 - Estrutura do trabalho 13

CAPÍTULO 2 - METODOLOGIAS $\quad 14$

2.1 - Análise por Ativação com Nêutrons - AAN 14

2.1.1 - Princípio de Análise por Ativação com Nêutrons 14

2.1.2 - Detector e Geometria $\quad 16$

2.1.3 - Radiação de fundo - Background (BG) 16

$\begin{array}{ll}\text { 2.1.4 - Calibração do sistema de detecção } & 17\end{array}$

2.1.5 - Medição da Radiação Gama 17

2.2 - Processo de Desenvolvimento de Software $\quad 19$

2.2.1 - Metodologia de Desenvolvimento de Software 21

2.2.2 - Metodologia de Desenvolvimento de Software Livre 24

2.2.3 - Modelo de Qualidade de Software 26

CAPÍTULO 3 - MODELAGEM DO SOFTWARE 28

3.1 - Software VISPECT/VERSÃO 2

3.2 - Requisitos Levantados do Software Desenvolvido 33

3.3 - Propostas do Projeto do Software SAANI 33

3.4 - Especificação $\quad 34$

3.4.1 - Diagrama de Caso de Uso 34

3.4.1.1 - Caso de Uso: Acessar Software $\quad 35$

3.4.1.2 - Caso de Uso: Abrir Projeto 36

3.4.1.3 - Caso de Uso: Recuperar Espectro 36

3.4.1.4 - Caso de Uso: Configurar Arquivo $\quad 37$

3.4.1.5 - Caso de Uso: Verificar Cálculo 37

3.4.1.6 - Caso de Uso: Verificar Concentrações 38

3.4.2 - Modelo de Classes 38

CAPÍTULO 4 - IMPLEMENTAÇÃO DO SOFTWARE 41

4.1 - Técnicas e Ferramentas Utilizadas $\quad 41$

4.1.1 - Python $\quad 41$

4.1.2-QT $\quad 42$

4.2 - Implementação do Software SAANI 43

4.2.1 - Leitura do Arquivo de Espectro 43

4.2.2 - Apresentação do gráfico $\quad 45$

4.2.3 - Configuração do Espectro $\quad 45$

4.2.4 - Identificação dos picos $\quad 46$

$\begin{array}{ll}4.2 .5 \text { - Cálculos dos resultados } & 47\end{array}$ 
CAPÍTULO 5 - MANUAL DE USO DO SOFTWARE

5.1 - Projeto

5.2 - Inserir Arquivo do Espectro no Projeto

5.3 - Configurando Arquivo de Espectro

5.4 - Verificando Resultado dos Cálculos

55

5.5 - Verificando Resultado das Concentrações $\quad 55$

5.6 - Salvando Projeto $\quad 55$

CAPÍTULO 6 - RESULTADOS E DISCUSSÕES 56

6.1 - Comparação entre o softwares VISPECT/VERSÃO 2 e o SAANI 56

6.2 - Resultados Obtidos 63

6.2.1 - Resultados do processamento dos espectros 63

6.2.2 - Resultados do cálculo das concentrações 66

CAPÍTULO 7 - CONCLUSÕES $\quad 68$

$\begin{array}{lr}\text { ANEXOS } & 69\end{array}$

Anexo A - Listagem do software SAANI: espectro MT4-B.CHN 70

Anexo B - Listagem do software VISPECT/VERSAO 2: espectro MT4-B.CHN 72

Anexo C - Listagem do software SAANI: espectro 112-1B.CHN

Anexo D - Listagem do software VISPECT/VERSAO 2: espectro 112-1B.CHN 76

REFERÊNCIAS BIBLIOGRÁFICAS 


\section{LISTA DE TABELAS}

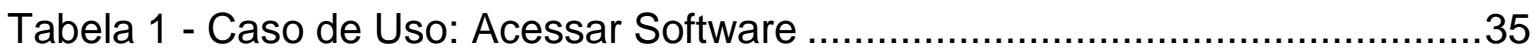

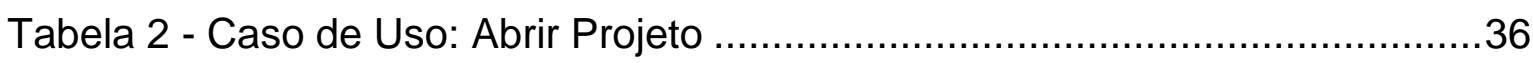

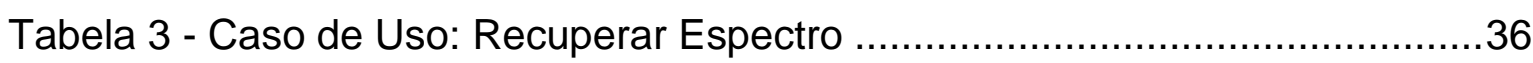

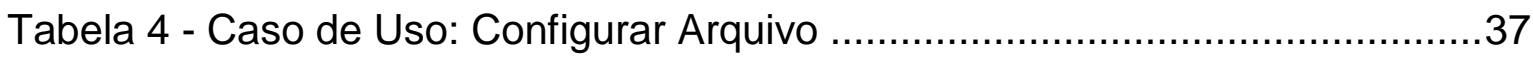

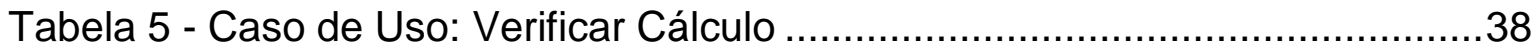

Tabela 6 - Caso de Uso: Verificar Concentrações ..............................................38

Tabela 7 - Lay-out dos arquivos de espectros: "CHN" e "MCA".............................43

Tabela 8 - Código fonte para ler o arquivo de espectro ......................................44

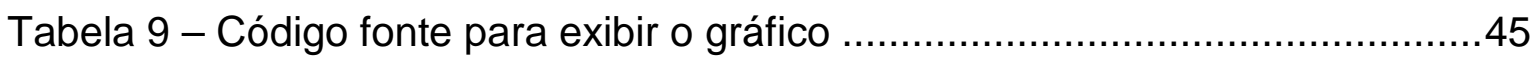

Tabela 10 - Código fonte para chamar o cálculo dos resultados ...........................48

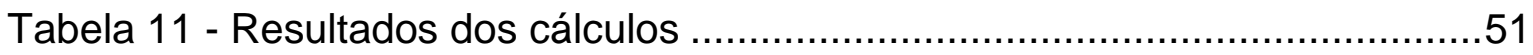

Tabela 12 - Comparação do espectro: 112-1B.CHN............................................64

Tabela 13 - Comparação do espectro: MT4-B.CHN ………………....................65

Tabela 14 - Comparação das concentrações dos elementos ...............................66 


\section{LISTA DE FIGURAS}

Figura 1 - Seqüência de eventos do mecanismo da reação nuclear tipo $(\mathrm{n}, \gamma) \ldots . .15$

Figura 2 - Desenvolvimento de sistemas - modelo cascata .................................22

Figura 3 - Desenvolvimento de sistemas - modelo interativo incremental ............24

Figura 4 - Etapas do processo da análise de espectros de raios gamas..............29

Figura 5 - Tela do software VISPECT/VERSÃO 2 ………...............................

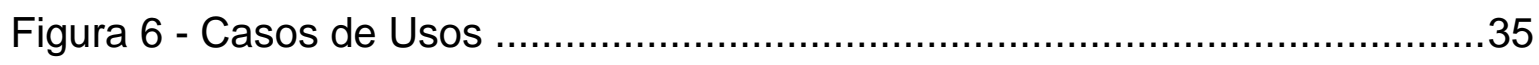

Figura 7 - Exemplificando janelas para busca dos picos no espectro ....................47

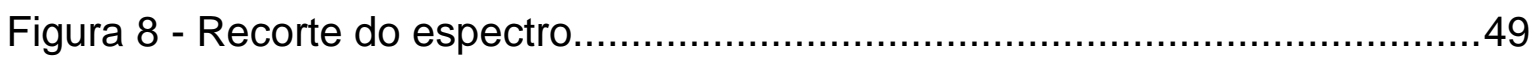

Figura 9 - Tela da apresentação dos resultados das concentrações .....................52

Figura 10 - Parâmetros do arquivo de espectro de um padrão ...............................54

Figura 11 - VISPECT/VERSÃO 2: Seleção tipo formato arquivo ..........................56

Figura 12 - VISPECT/VERSÃO 2: Digitando nome do arquivo e extensão ...........57

Figura 13 - SAANI: Tela Principal opção de abrir arquivo de espectro .................57

Figura 14 - VISPECT/VERSÃO 2: Tela da apresentação do gráfico ….................58

Figura 15 - SAANI: Tela da apresentação do gráfico ........................................59

Figura 16 - SAANI: Seleção de uma área do gráfico .........................................59

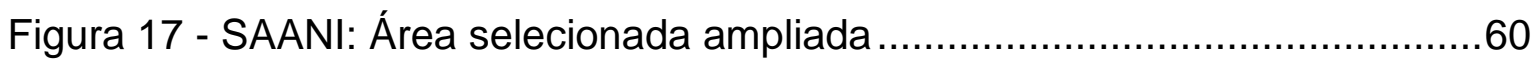

Figura 18 - VISPECT/VERSÃO 2: Relatório impresso dos resultados...................61

Figura 19 - SAANI: Resultados apresentados no vídeo ......................................61

Figura 20 - SAANI: Resultados das concentrações apresentados no vídeo ..........62 


\section{CAPÍTULO 1 - INTRODUÇÃO}

O Laboratório de Análise por Ativação Neutrônica (LAN-IPEN) é um dos principais laboratórios no país que realiza análises multielementares utilizando o método de ativação neutrônica e está situado no Centro do Reator Nuclear de Pesquisas (CRPq) do Instituto de Pesquisas Energéticas e Nucleares (IPENCNEN/SP).

O método de Análise por Ativação com Nêutrons (AAN) é conhecido por sua sensibilidade para detecção e determinação de um grande número de elementos químicos. O método consiste basicamente da produção de radionuclídeos artificiais a partir de elementos estáveis por meio da irradiação de uma amostra sob um fluxo de nêutrons e medida das radiações emitidas pelos radionuclídeos formados.

Dentre os diversos materiais (amostras) que podem ser analisados utilizando a Análise por Ativação com Nêutrons, podem-se citar: amostras geológicas (solos, rochas, carvão, minérios, concentrados minerais); plásticos, resinas e outros produtos industriais; catalisadores; petróleo; amostras arqueológicas; metais e ligas: aços, silício metálico, ligas nióbio-tântalo; amostras agropecuárias (pêlos de animais, solos, subprodutos agro-industriais); tecidos animais e humanos (cabelos, ossos, unhas, etc.); plantas e vegetais; alimentos e dietas e amostras ambientais.

O LAN-IPEN utiliza o método de Análise por Ativação Comparativo, onde amostras e padrões são irradiados juntos sob as mesmas condições de tempo de irradiação e fluxo de nêutrons. A concentração de um elemento particular de interesse é obtida comparando-se as taxas de contagens dos espectros de amostra e padrão, obtidas a partir das mesmas condições de geometria de contagem.

Como cada radioisótopo tem suas próprias características de meia-vida e energia (ou energias) de raios gama, é possível, em geral, identificar os isótopos dos elementos. A quantidade desse elemento na amostra é considerada como diretamente proporcional à taxa de contagens de raios gama. 
Para análise dos espectros de raios gama utiliza-se uma série de rotinas para localizar e quantificar os picos, calcular os resultados como energia dos picos, área líquida, área do BG, resolução em energia, canal da mediana, canal inicial, largura do pico em número de canais, atividades em contagens/segundos, desvio padrão da atividade em porcentagem. Estes cálculos são realizados para todos os espectros de amostra e padrão, que fazem parte de uma análise gerando as matrizes contendo os resultados dos cálculos.

Para a realização dessas análises, o LAN-IPEN conta com um conjunto de softwares. Esses softwares, apesar de utilizarem praticamente o mesmo conjunto de dados, são independentes e executados em seqüência, requerendo a entrada de um mesmo conjunto de dados em cada uma das diferentes fases de análise.

Existem diversos softwares para a análise de dados de espectrometria gama (IAEA, 1998). Alguns disponíveis comercialmente, alguns disponíveis gratuita e livremente e outros distribuídos com os equipamentos de espectroscopia do fabricante.

Dentre os vários softwares podem-se citar: GammaVision-32 feito pela Ortec (ORTEC, 2006), Genie-2000, feito pela Canberra (CAMBERRA, 2006), Hypermet-PC, feito pelo "Institute of Isotopes, Budapest, Hungary" e HyperLab (SIMONITS,2003).

Estes softwares são distribuídos sob a forma de "códigos executáveis" e "fechados", ou seja, não permitem que se desenvolvam novas funcionalidades ou mesmo que sejam integrados a outros softwares para ampliação de suas capacidades.

O LAN-IPEN, utiliza para a análise dos espectros 0 software VISPECT/VERSÃO 2, desenvolvido na linguagem TURBO BASIC, pelo Dr. Denis Piccot, do Laboratório Pierre Sue, do Centro de Estudos Nucleares de Saclay. Apesar de se possuir o código fonte deste software, a linguagem utilizada no seu desenvolvimento é bastante limitada, só pode ser executada em ambiente Windows ${ }^{\mathrm{TM}}$; a interface do usuário do VISPECT/VERSÃO 2 é também bastante limitada, o que propicia maior probabilidade de erro na entrada de dados. Para o cálculo das concentrações dos elementos são utilizados outros softwares, como o desenvolvido no próprio laboratório chamado de espectro ou a planilha do Excel.

A proposta deste trabalho é o desenvolvimento de um software, para Análise de Espectros de Raios Gama, com a filosofia de software livre, para a 
substituição do software existente VISPECT/VERSÃO 2, e tem como características principais: 1) tornar a interface mais amigável; 2) facilitar a padronização dos procedimentos realizados pelos pesquisadores, estudantes e técnicos; 3) ser extensível com a utilização da tecnologia de plugins; 4) multiplataforma; 5) código livre.

O desenvolvimento de software de modo organizado, planejado e controlado é objeto da Engenharia de Software, que tem suas atividades bem definidas de acordo com Pressman (PRESSMAN, 2002).

Este trabalho visa o desenvolvimento de um software de espectrometria gama para análise por ativação com nêutrons utilizando o conceito de software livre integrando processos e sistemas, desenvolvido para os usuários do laboratório LAN-IPEN.

Para o desenvolvimento deste software, denominado SAANI (Software para Análise por Ativação com Nêutrons Instrumental) foi efetuado um levantamento detalhado dos procedimentos executados pelos usuários do LANIPEN, bem como dos softwares utilizados e dos processos da análise dos materiais.

Para a validação dos resultados e das rotinas implementadas no novo software foi realizada uma série de testes com espectros reais e comparados com os resultados dos procedimentos adotados de forma rotineira pelo LAN-IPEN para as análises dos materiais.

\section{1 - Objetivo}

O objetivo deste trabalho é desenvolver um software livre, multiplataforma, para Análise de Espectros de Raios Gama, aplicado especificamente a Análise por Ativação com Nêutrons que é realizada no Laboratório de Análise por Ativação Neutrônica (LAN) do IPEN-CNEN/SP, facilitando a obtenção dos resultados de análise, de modo que os dados obtidos no espectrômetro sejam diretamente processados pelo aplicativo, eliminando os erros causados pela entrada manual nos softwares para os cálculos das concentrações (Excel e/ou Espectro) atualmente utilizados. 


\section{2 - Estrutura do trabalho}

O trabalho está estruturado em 7 capítulos. O primeiro é esta Introdução; o segundo capítulo, Fundamentação Teórica, apresenta os conceitos básicos sobre Análise por Ativação com Nêutrons; o terceiro capítulo, Desenvolvimento do Software, apresenta conceitos sobre o processo de desenvolvimento de software - engenharia de software, metodologias e a descrição das etapas realizadas. $O$ capítulo quatro, Implementação, apresenta os detalhes da implementação do software, descrevendo as ferramentas utilizadas. No quinto capítulo, Etapas para uso do Software SAANI, é apresentado um "manual resumido do usuário", que servirá de base para a documentação do software. No sexto capítulo, Resultados e Discussões, são apresentados os principais resultados obtidos e algumas discussões pertinentes a estes resultados. O capítulo sete, Conclusões, apresenta as principais conclusões deste trabalho e também algumas sugestões para trabalhos futuros. 


\section{CAPÍTULO 2 - METODOLOGIAS}

Neste capítulo são apresentados alguns conceitos que fundamentam o projeto do software de espectrometria gama para o laboratório de análises por ativação com nêutrons.

\section{1 - Análise por Ativação com Nêutrons - AAN}

A Análise por Ativação com Nêutrons (AAN) originou-se com os trabalhos de Hevesy e Levi em 1936, mas não se tornou um método prático de análise até o desenvolvimento do reator nuclear como uma fonte de nêutrons de alta intensidade. A introdução dos detectores de raios gama por cintilação $\mathrm{Nal}(\mathrm{TI})$ e o de alta resolução $\mathrm{Ge}(\mathrm{Li})$ estabeleceram a AAN como uma técnica analítica sensível e de boa precisão e exatidão, útil para análises multielementares quali e quantitativas dos elementos principais, elementos menores e elementos traço, em amostras dos mais variados campos de aplicação (ALFASSI, 1990).

\subsection{1 - Princípio de Análise por Ativação com Nêutrons}

O princípio da análise por ativação com nêutrons é a interação de um núcleo alvo com nêutrons, que induz uma reação nuclear em um núcleo de um elemento alvo. O produto da reação é detectado e quantificado por um fóton pronto ou emissão de uma partícula ou, mais comumente, por suas propriedades de decaimento (meia-vida).

A reação nuclear do tipo $(n, \gamma)$, conforme mostra a Figura 1, produz 0 radionuclídeo de interesse para a realização de uma análise, por meio do método de ativação com nêutrons, que ocorre quando um feixe de partículas ativadoras (nêutrons) interage com o núcleo alvo, por meio de colisão inelástica, originando um núcleo composto de alta energia de excitação. Rapidamente este núcleo instável passa para uma configuração mais estável, emitindo raios gama "prontos" e transformando-se em um núcleo radioativo. Esse núcleo radioativo emitirá raios 
gama e partículas beta, com uma meia-vida característica, formando por fim um núcleo estável. Por meio da energia da radiação gama de decaimento e da meiavida, o radioisótopo formado na reação nuclear pode ser identificado, permitindo assim realizar análises qualitativas e quantitativas do elemento contido na amostra.

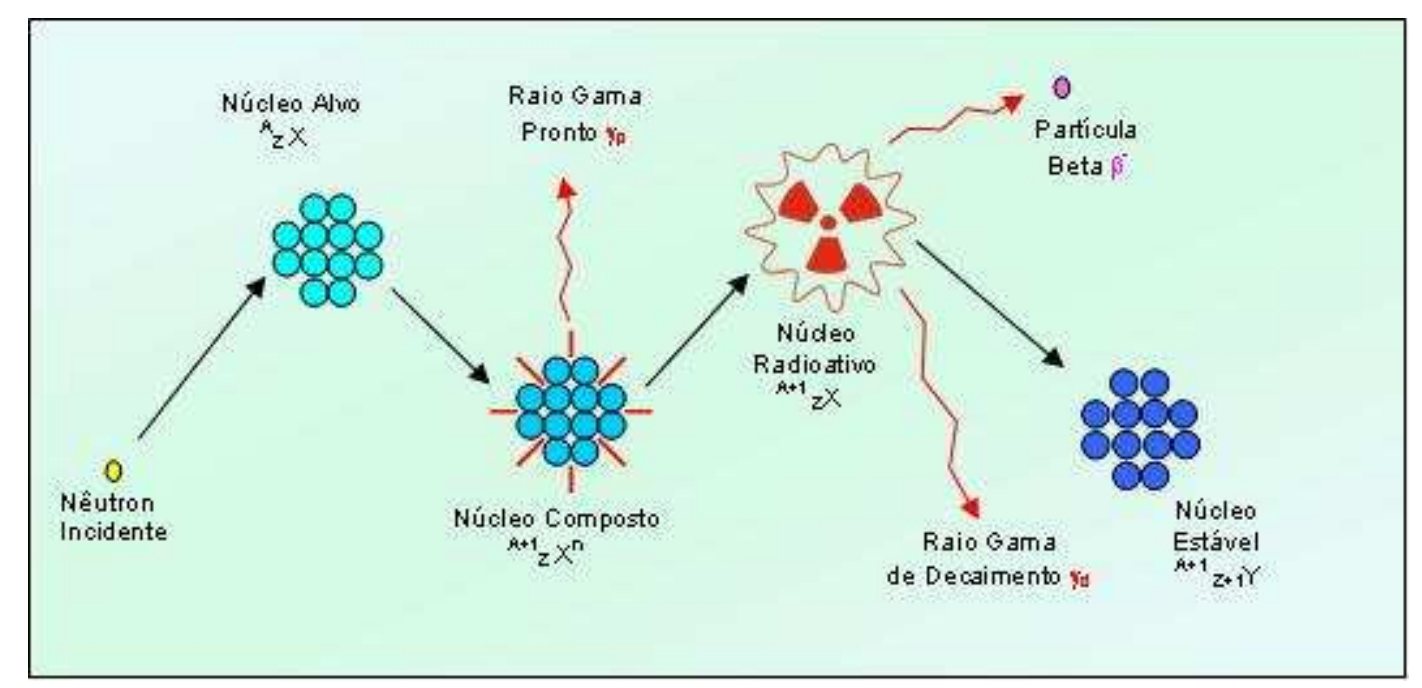

Figura 1 - Seqüência de eventos do mecanismo da reação nuclear tipo $(n, \gamma)$.

Cada fóton de raio gama tem uma energia discreta e esta energia é característica do isótopo fonte. Isto forma a base da espectrometria de raios gama; através da medição das energias dos fótons de raios gama, pode-se determinar a fonte da radiação (IAEA, 2003).

O espectro de energia dos raios gama representa a distribuição de energia dos fótons emitidos na fonte. Cada linha do espectro (ou espectro de "emissão") mostra a energia e a intensidade relativa das emissões de raios gama nas séries de decaimento nuclear.

Cada radioisótopo gera um pico definido, representando a energia dos fótons diretamente transmitida. Isto é superposto no espectro dos fótons espalhados por efeito Compton que mostram um "continuum" de energias até a máxima energia dos fótons emitidos pelo isótopo. Este "continuum" é devido a eventos de espalhamentos simples e múltiplos entre a fonte e o detector.

Na prática, o espectro do fluxo de raios gama registrado sempre terá as contribuições dos espalhamentos e também a influência da resposta do detector. 


\subsection{2 - Detector e Geometria}

Detectores semicondutores e cintiladores são os tipos mais comuns utilizados em espectrometria gama, em particular os de germânio hiperpuro (HPGe), germânio-lítio $(\mathrm{Ge}(\mathrm{Li}))$, $\mathrm{Nal}(\mathrm{TI})$. Estes detectores modificam o espectro consideravelmente.

Os principais aspectos da resposta do detector são:

- A eficiência do detector

- A resolução em energia

- O tempo morto

A eficiência do detector está relacionada à quão bem o detector absorve os raios gama que o atingem. A resolução em energia é a medida da habilidade do detector em distinguir entre dois raios gama de energias próximas.

O tempo morto refere-se ao tempo finito requerido para o espectrômetro processar fótons individuais. Outros fatores como eventos de escape, soma acidental e o "joelho" Compton característico podem afetar a forma do espectro de amplitude de pulso. Espectros de fotopicos têm formas Gaussianas.

A espessura da fonte tem um efeito significante na forma do espectro observado. Com o aumento da espessura da fonte há um aumento no "continuum" Compton devido ao espalhamento na fonte. Os fotopicos são, assim, reduzidos relativamente ao fundo Compton. Como fótons de baixa energia são mais facilmente atenuados do que os de alta energia, este efeito é mais pronunciado em baixas energias.

\subsection{3 - Radiação de fundo - Background (BG)}

Os espectros de raios gama que são analisados têm sua origem em um espectro da radiação de fundo ou "background" (BG) de um dos sistemas detectores.

Os espectrômetros de raios gama utilizados no LAN-IPEN consistem de um detector de Ge hiperpuro (marca Canberra e/ou Ortec), que está ligado a um microcomputador $\mathrm{PC}$, no qual tem o software de aquisição de dados e a uma eletrônica associada. 
O espectro do BG mostra as radiações que estão presentes no ambiente do sistema detector e às quais ele é sensível e que, desse modo, também estarão presentes quando da contagem de uma amostra e farão parte do espectro da mesma, sem ter origem nela.

\subsection{4 - Calibração do sistema de detecção}

A calibração é feita através de fontes radioativas conhecidas, certificadas que emitem radiações gama, com energias bem definidas. Normalmente fontes de ${ }^{152} \mathrm{Eu}$ e ${ }^{60} \mathrm{Co}$ são utilizadas para fazer a calibração do sistema detector de raios gama, uma vez que possuem radioisótopos que apresentam fotopicos em toda a faixa de energia do espectro, desde baixas energias até altas energias.

O espectro de calibração do sistema para o software tem o intuito de conseguir uma relação canal-energia.

A calibração de um sistema de detecção se divide na calibração em energia e na calibração em resolução.

Para a calibração em energia basta fornecer a energia de pelo menos dois canais do espectro e uma regressão linear da energia em função do número do canal é obtido, ao passo que a calibração em resolução é feita em função da energia, e são os coeficientes destas retas que ficam guardados nos arquivos de calibração, de forma que, quando se faz uma nova análise sob as mesmas condições em que foi feita a calibração, não é necessário refazer a calibração e sim recuperar as informações a partir do arquivo de calibração já existente.

\subsection{5 - Medição da Radiação Gama}

Por meio dos detectores semicondutores e cintiladores, utilizados em espectrometria gama, ocorre a detecção de raios gama por cristais semicondutores de $\mathrm{Ge}(\mathrm{Li})$ ou de Ge hiperpuro, que se dá através dos modos pelos quais a radiação gama interage com a matéria, gerando impulsos elétricos proporcionais à energia da radiação incidente. Desse modo, o detector efetua a contagem dos raios gama por canais, gerando o espectro que pode ser salvo em arquivo de computador. 
Levando-se em conta a eficiência do detector, a atividade induzida $A_{t}$ em um elemento após determinado tempo de irradiação $t_{i}$, que pode ser medida por detector adequado, é dada pela seguinte equação (2.1):

$$
A_{t}=\frac{\varepsilon \sigma \Phi N_{A} m_{a} f\left(1-e^{-\lambda t i}\right)}{M}
$$

onde:

$$
\begin{array}{ll}
\varepsilon & \text { Eficiência do detector; } \\
\sigma & \text { Seção de choque; } \\
\Phi & \text { Fluxo de nêutrons; } \\
\mathrm{N}_{\mathrm{A}} & \text { Número de Avogadro; } \\
\mathrm{m}_{\mathrm{a}} & \text { Massa do elemento, em gramas; } \\
\mathrm{f} & \text { Abundância isotópica do nuclídeo alvo; } \\
\mathrm{M} & \text { Massa atômica do elemento. }
\end{array}
$$

Na AAN não destrutiva ou instrumental (AANI), técnica mais comumente utilizada no LAN do IPEN/CNEN-SP, o radionuclídeo é normalmente quantificado sem que a amostra irradiada sofra um processo químico anterior a espectroscopia de raios gama.

Em princípio, a AANI é um método absoluto de análise e a concentração $C_{a}$ de um elemento pode ser calculada se a taxa de desintegração absoluta, $A_{t}$, é medida e se $\Phi$ e $\sigma$ são conhecidos. A análise absoluta é mais difícil de ser utilizada porque $\Phi$ e $\sigma$ variam com a energia do nêutron.

Como o método absoluto tem sua aplicação restrita, a determinação da concentração $C_{a}$ do elemento na amostra é realizada pelo método comparativo, no qual a amostra desconhecida tem sua massa determinada e é irradiada simultaneamente com um padrão (material de concentração conhecida do elemento a ser determinado), e após determinado período de tempo, a intensidade e energia dos picos de raios gama são medidos. A comparação entre as atividades específicas induzidas nos padrões e nas amostras desconhecidas é a base para o cálculo da concentração do elemento na amostra. 
Estas atividades resultantes, $A_{a}$ e $A_{p}$, respectivamente, são expressas pelas equações (2.2) e (2.3):

$$
\begin{gathered}
A_{a}=\frac{\varepsilon \sigma \Phi N_{A} m_{a} f\left(1-e^{-\lambda t i}\right)}{M} \\
A_{p}=\frac{\varepsilon \sigma \Phi N_{A} m_{p} f\left(1-e^{-\lambda t i}\right)}{M}
\end{gathered}
$$

Onde os índices a e p se referem à amostra e ao padrão, respectivamente. A razão entre as equações (2.2) e (2.3) resulta em:

$$
\frac{A_{a}}{A_{p}}=\frac{m_{a}}{m_{p}}
$$

A concentração $C_{a}$ do elemento na amostra é, então, expressa por:

$$
C_{a}=\frac{A_{a} C_{p} m_{p} e^{\lambda(t a-t p)}}{A_{p} m_{a}}
$$

onde:

$\mathrm{C}_{\mathrm{p}}$ concentração do elemento no padrão;

ta tempo de decaimento da amostra;

tp tempo de decaimento do padrão.

O termo exponencial na equação (2.5) leva em consideração o decaimento da amostra e do padrão, uma vez que estes não são medidos simultaneamente.

\section{2 - Processo de Desenvolvimento de Software}

Engenharias de software compreendem tecnologias e práticas utilizadas para criar software para computadores melhorando a produtividade e qualidade. Estas tecnologias e práticas englobam linguagens de programação, bases de dados, ferramentas, plataformas, bibliotecas, padrões e processos. 
Esses métodos e técnicas consistem na investigação e especificação da solução de problemas, a partir dos requisitos (dados) levantados.

O desenvolvimento de software de modo organizado, planejado e controlado é objeto da Engenharia de Software. Termos como Processo, Modelo, Método e Metodologia são muitas vezes utilizados para descreverem a atividade de desenvolvimento de software. Embora haja alguma sobreposição nas definições destes termos, eles não são sinônimos (BONA, 2004).

Vários autores definem o Processo de desenvolvimento de software, conforme citado a seguir:

- O Processo de Software é definido por SOMMERVILLE (2003) como: "O processo é um conjunto de atividades e resultados associados que produzem um produto de software".

- PRESSMAN (2002) oferece a seguinte definição: “...definimos um processo de software como um framework para as tarefas que são necessárias para a construção de software de alta qualidade".

- De acordo com COSTA (2001), o processo de software tem a seguinte definição: "O processo define quem irá fazer o quê e como será atingido o objetivo. O objetivo é construir um software ou melhorar um existente".

Estas definições oferecem uma idéia mais clara do que é considerado um processo, diretamente destas, pode-se retirar os seguintes pontos:

- O processo reúne um conjunto de atividades. Como existem atividades que englobam outras atividades, pode-se usar o termo fase para descrever atividades no nível mais alto;

- A definição contempla na prática: procedimentos e métodos, ferramentas e equipamentos, comunicação e pessoas;

- O processo tem como objetivo desenvolver um produto de software. PRESSMAN (2002) restringe o termo a processos que geram "produtos de alta qualidade", mas se esta restrição for ignorada, pode-se aplicar o termo a qualquer conjunto de atividades que é aplicada com o objetivo de desenvolver software. 
O processo direciona as tarefas individuais e do grupo como um todo. $\mathrm{O}$ nível de detalhamento de cada processo depende da equipe envolvida no desenvolvimento do software. REZENDE (2002) usa a metáfora da receita de bolo para representar o processo. Quem segue uma receita tem a liberdade de adicionar ou suprir partes, assim também pode ocorrer com o processo, estabelecendo um dinamismo na execução.

Não há processo correto ou incorreto; dependendo da sua aplicação, ambiente e objetivo, o uso de um processo específico pode ser vantajoso ou não. Um ponto importante a ressaltar é que, cada autor e organização colocam e classificam processos e atividades de forma diferente, tornando difícil uma uniformidade completa.

Os processos de desenvolvimento de softwares podem ser realizados utilizando diversas metodologias (GUSTAFSON, 2003). Neste trabalho, foi utilizada uma mescla das metodologias existentes, apropriando-se das melhores partes de cada uma delas, tornando o desenvolvimento um processo ágil e eficiente.

Desta forma, são apresentados simplificadamente abaixo, alguns tópicos da metodologia de desenvolvimento, para que se tenha uma linha mestra de trabalho. Outras metodologias são utilizadas, visando flexibilidade na abordagem do problema.

\subsection{1 - Metodologia de Desenvolvimento de Software}

O processo clássico de desenvolvimento de sistemas chamado waterfall (ou cascata) (PRESSMAN, 2002) possui uma seqüência de fases bem definidas que guiam o desenvolvimento de um sistema, conforme mostra a Figura 2. Para que uma fase seja iniciada, é necessário que a fase anterior seja totalmente concluída.

Mesmo com a execução rigorosa das fases de engenharia de requisitos e de análise, a experiência na construção de sistemas mostra que ainda existe uma lacuna de informações a serem especificadas, para prosseguir com a fase de projeto. Isto significa que especificar e modelar o que o sistema deve fazer não é 
suficiente para saber como o sistema deve ser estruturado e organizado, para satisfazer os requisitos funcionais e os atributos de qualidade.

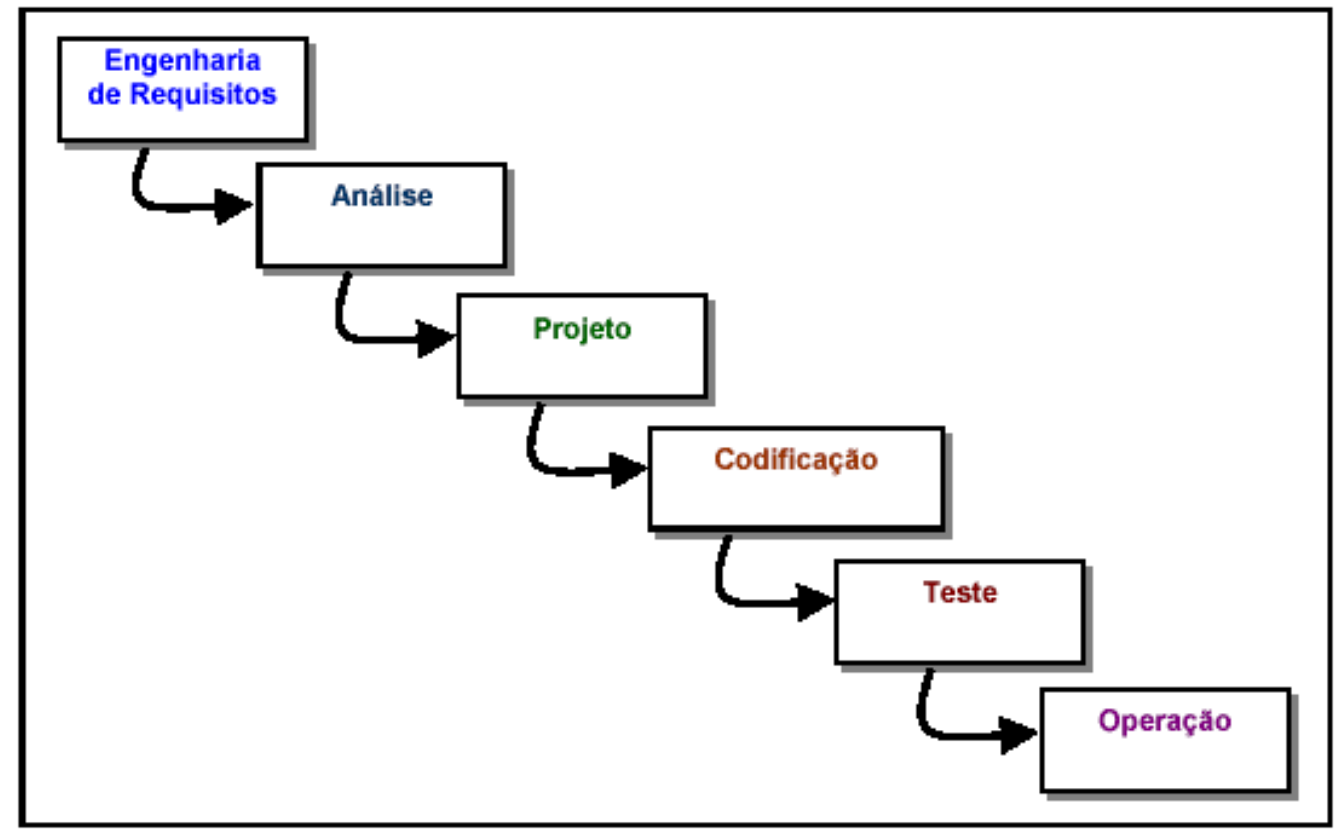

Figura 2 - Desenvolvimento de sistemas - modelo cascata

O processo de desenvolvimento considera as seguintes fases, conforme Figura 2 (PRESSMAN, 2002):

Engenharia de requisitos/informações: fase que estabelece os requisitos necessários, conforme a estratégia e a área de atuação do negócio e identifica a interação do sistema com outros elementos externos, tais como hardware, pessoas, base de dados ou outros sistemas.

Análise de requisitos: fase que estabelece o entendimento da natureza do sistema a ser construído, o domínio de informações, as funcionalidades solicitadas e o comportamento em relação ao negócio;

Projeto: fase na qual se transforma requisitos em uma representação do software, que pode ter medidas de qualidade antes da codificação do software iniciar;

Codificação: fase na qual se transforma o projeto em código legível por máquina; 
Teste: fase na qual se testa o código gerado, com foco tanto na lógica interna do software quanto nas funcionalidades externas;

Operação: fase na qual se identificam as mudanças e manutenções (corretivas, evolutivas ou adaptativas) necessárias no software.

A arquitetura de software propõe várias atividades que tentam suprir esta distância entre as fases de análise e projeto, dentre elas a elaboração de um modelo de domínio com o objetivo de ressaltar o escopo do sistema, a identificação das dependências de construção e o mapeamento dos requisitos não funcionais, que o sistema deve atender e que não foram totalmente especificados na fase de engenharia dos requisitos.

As atividades da arquitetura são mais visíveis dentro do processo de desenvolvimento de sistemas. A diferença entre as fases de análise e de projeto, com as atividades de arquitetura são mais evidentes quando se trata de sistemas grandes e complexos.

Para sistemas pequenos, a transição entre as fases de engenharia de requisitos, análise e projeto é tranqüila, pois os modelos gerados nestas fases são suficientes para representar os requisitos necessários, satisfazendo a construção do sistema.

Apesar de o modelo de processo adotado para explicação do esquema conceitual ser linearmente seqüencial, o desenvolvimento não implica que, ao final, o software estará completamente pronto. O processo, para fornecer versões rápidas e cada vez mais robustas, deve ser interativo e incremental, como ocorre na Figura 3, aliando-se às fases do modelo cascata. 


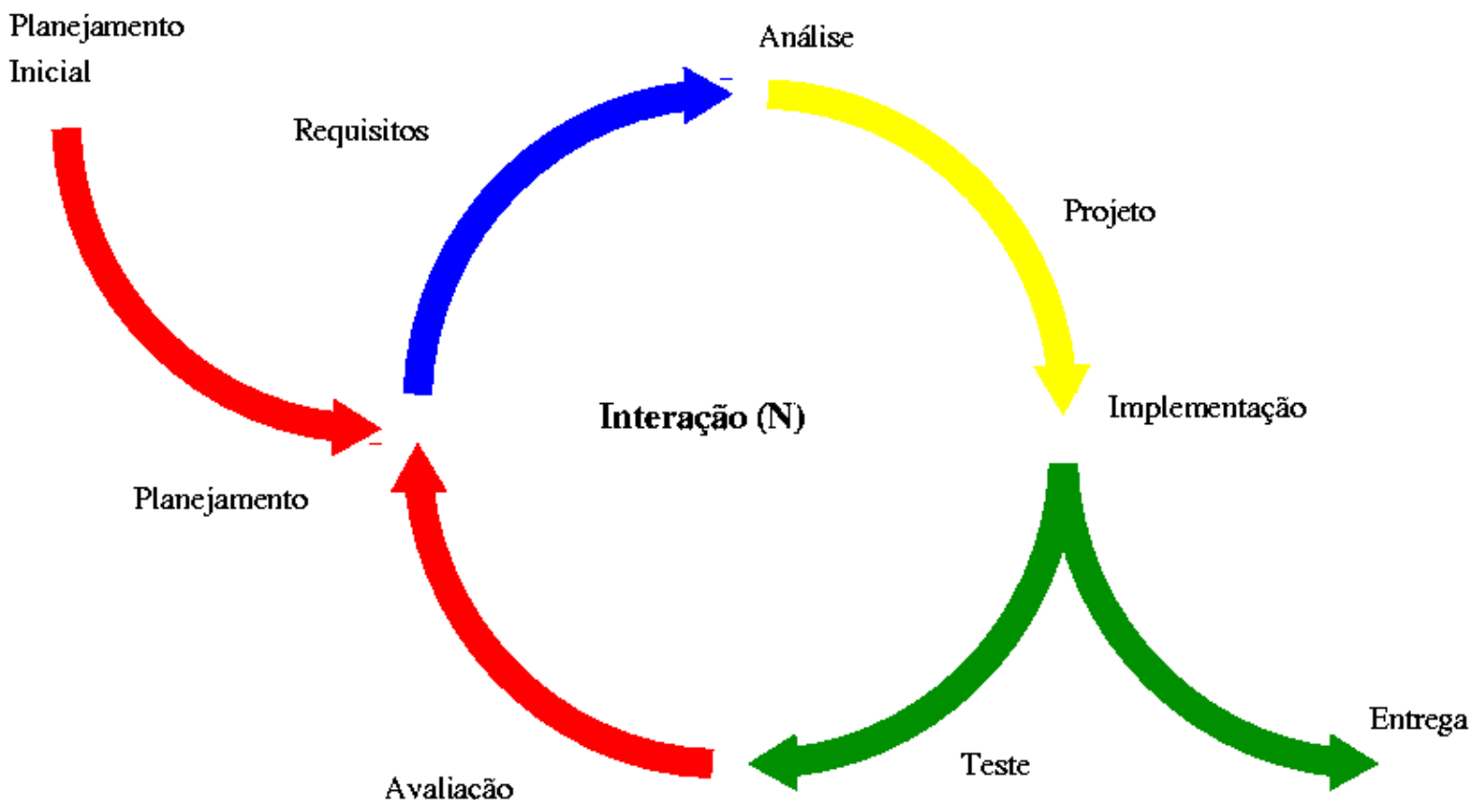

Figura 3 - Desenvolvimento de sistemas - modelo interativo incremental

A arquitetura deve considerar que requisitos são mutáveis, por natureza. Sendo assim, várias versões podem ser estabelecidas considerando que 0 modelo cascata é repetido em cada ciclo que finaliza uma versão (PRESSMAN, 2002).

\subsection{2 - Metodologia de Desenvolvimento de Software Livre}

O desenvolvimento de software de modo organizado, planejado e controlado é objeto da Engenharia de Software, que tem suas atividades bem definidas de acordo com PRESSMAN (2002).

O desenvolvimento e distribuição de softwares (programas) livres estão relacionados com a liberdade das pessoas em utilizar o software da maneira como achar necessário. É ter a liberdade de executar o software para qualquer propósito, acessar o código fonte para modificar o software para adequá-lo às suas necessidades, redistribuir de graça ou cobrando e distribuir versões modificadas do software de modo que outros possam se beneficiar das suas melhorias. 
Não existe uma definição exata do termo "Software Livre", mas geralmente a definição usada é a de que "Software Livre é um tipo de software que é distribuído de acordo com os termos estabelecidos pelo Open Source Definition" (JOSEPH, 2002).

Este documento é mantido pela Open Source Initiative(OSI), e não deve ser entendido como uma definição de licença, e sim uma especificação de como o software deve ser distribuído. Para o produto ser considerado Software Livre, e capaz de receber um certificado OSI, este deve estar de acordo com todos os critérios da especificação, sem exceção.

O movimento de software livre tem crescido expressivamente, conseguindo inclusive o apoio de universidades e órgãos governamentais, que enxergam no software livre um caminho economicamente viável para a democratização do acesso aos recursos da informática no país.

Não existe um processo de desenvolvimento de software livre que seja considerado "padrão", diferentes desenvolvedores e comunidades empregarão técnicas, métodos e ferramentas diferentes.

Embora estas diferenças existam, ainda assim é possível delinear nos diferentes projetos várias características comuns. Descrevem-se aqui estas características, lembrando que mesmo estas, podem vir a sofrer alterações significativas em alguns projetos mais específicos.

Um projeto de software livre pode ter várias formas, mas dois estilos de desenvolvimento são considerados dominantes na comunidade:

- A catedral: os sistemas desenvolvidos neste estilo são normalmente fruto do trabalho de um grupo pequeno de programadores ou mesmo de um único programador. Contribuições de código ou idéias vindas da comunidade são aceitas, mas estas não são as principais preocupações dos autores originais. Estes monopolizam grande parte das decisões de design, implementação e a data de liberação de determinada versão, o que faz com que o tempo entre o lançamento de versões se torne maior e a contribuição por parte da comunidade diminua.

- O bazar: ao contrário da catedral, este estilo é bem menos conservador, e trabalha com ciclos de desenvolvimento bem menores. Muitos projetos deste tipo ainda são controlados por um pequeno grupo de 
desenvolvedores, mas a contribuição de código é muito encorajada e inclusive esse fato é um dos motivos que leva o ciclo de desenvolvimento a ser tão pequeno. Este estilo de desenvolvimento faz uso intensivo de ferramentas de Groupware (bate-papos, listas de discussão, IRC) entre seus participantes como uma forma de estimular a troca de idéias. É comum também a existência de um repositório global de código no qual as contribuições são feitas.

A forma de desenvolvimento de software livre tem dois métodos: a catedral refere-se àquela que descreve projetos desenvolvidos por grupos fechados, com pequena abertura para participação externa e o bazar que engloba projeto colaborativo aberto aos usuários, os quais são bem vindos para participar e opinar sobre o desenvolvimento de qualquer fase.

\subsection{3 - Modelo de Qualidade de Software}

A garantia da qualidade de um software depende da qualidade da arquitetura definida para este software. Para PRESSMAN (2002), há três pontos importantes relacionados à qualidade:

- Requisitos de software são a base para medidas de qualidade. Falta de aderência da arquitetura aos requisitos significa falta de qualidade;

- Padrões específicos estabelecem um conjunto de critérios que guiam a definição da arquitetura. Se os critérios não são seguidos, o resultado não terá qualidade;

- Há os atributos de qualidade (requisitos não funcionais) que nem sempre são mencionados. Se a arquitetura apresenta os requisitos explícitos, mas não apresenta algum dos requisitos implícitos, a qualidade será duvidosa.

A necessidade de se construir um sistema determina qualidades que devem ser acomodadas pela arquitetura. $O$ atendimento aos requisitos funcionais é a condição básica para os serviços e habilidades do sistema. Porém, muitos 
destes sistemas são re-projetados, não por causa de deficiências em suas funcionalidades, mas devido à dificuldade de serem mantidos, ou pela deficiência no desempenho e na segurança.

A arquitetura de software tem como objetivo melhorar a qualidade dos produtos de software que são construídos. Sua definição consiste em quebrar a complexidade do problema em partes menores, denominadas componentes ou subsistemas, explicitando o relacionamento entre estas partes. Os componentes podem ser pedaços de código, um sistema externo, elementos de hardware, protocolos de comunicação, entre outros. Isto significa que arquitetura de software representa muito mais do que a infra-estrutura técnica necessária para desenvolver sistemas. Sua importância surge, pois:

- Possui a abstração da complexidade do problema que facilita a comunicação entre os participantes do desenvolvimento do sistema;

- Antecipa decisões de projeto, estabelecendo as restrições do ponto de vista do negócio e do ponto de vista técnico;

- Incentiva o reuso através da utilização de componentes prontos e também através dos estilos e padrões arquiteturais.

Os estilos de arquitetura oferecem muitos recursos que orientam as atividades do arquiteto, descrevendo domínios de aplicação, tipos e padrões para o parcionamento dos componentes e motivações para o reuso. Estes recursos e também as definições relacionadas à arquitetura de referência e modelos de referência indicam que a definição de uma arquitetura não precisa partir do zero. Ela pode e deve utilizar tais recursos e técnicas como ponto de partida.

Dentre os requisitos, há aqueles que são identificados pelos participantes que são responsáveis pelo negócio e desejam uma solução computacional para o problema que enfrentam. Estes requisitos estão ligados às funcionalidades que 0 sistema deve atender.

Porém, há outros requisitos implícitos, denominados requisitos não funcionais ou atributos de qualidade que devem ser identificados e compreendidos pelos arquitetos, analistas e projetistas de sistemas. 


\section{CAPÍTULO 3 - MODELAGEM DO SOFTWARE}

Este trabalho visa o desenvolvimento de um software de espectrometria gama para análise por ativação com nêutrons utilizando o conceito de software livre, tendo como características principais fornecer informações da análise dos espectros relacionados à espectrometria de raios gama, referente às análises executadas no laboratório LAN do IPEN, integrando processos e sistemas.

Neste trabalho é implementado um software denominado de "SAANI" (Software Análise por Ativação com Nêutrons Instrumental) para análise de espectros de raios gama, desenvolvido para os usuários do laboratório LAN-IPEN, focados para os pesquisadores, estudantes e técnicos, que trabalham a maior parte do tempo com pesquisas e que necessitam de alta precisão, mobilidade e praticidade em suas ferramentas, que auxiliam no trabalho e que ao mesmo tempo precisam associar isto à necessidade de possuir um fluxo de trabalho ágil e com informações atualizadas.

No processo de análise de uma amostra identificou-se a necessidade de utilizar outro software para o cálculo das concentrações dos elementos encontrados na amostra, no qual o usuário tem que digitar os resultados gerados pelo software VISPECT/VERSÃO 2 em outro software para obter as concentrações dos elementos, durante o processo de digitação dos dados no segundo software podem ocorrer erros. O novo software irá eliminar este processo, pois os cálculos das concentrações são realizados no mesmo software, eliminando este possível erro.

A Figura 4 mostra as etapas do processo da análise de espectros de raios gamas. 


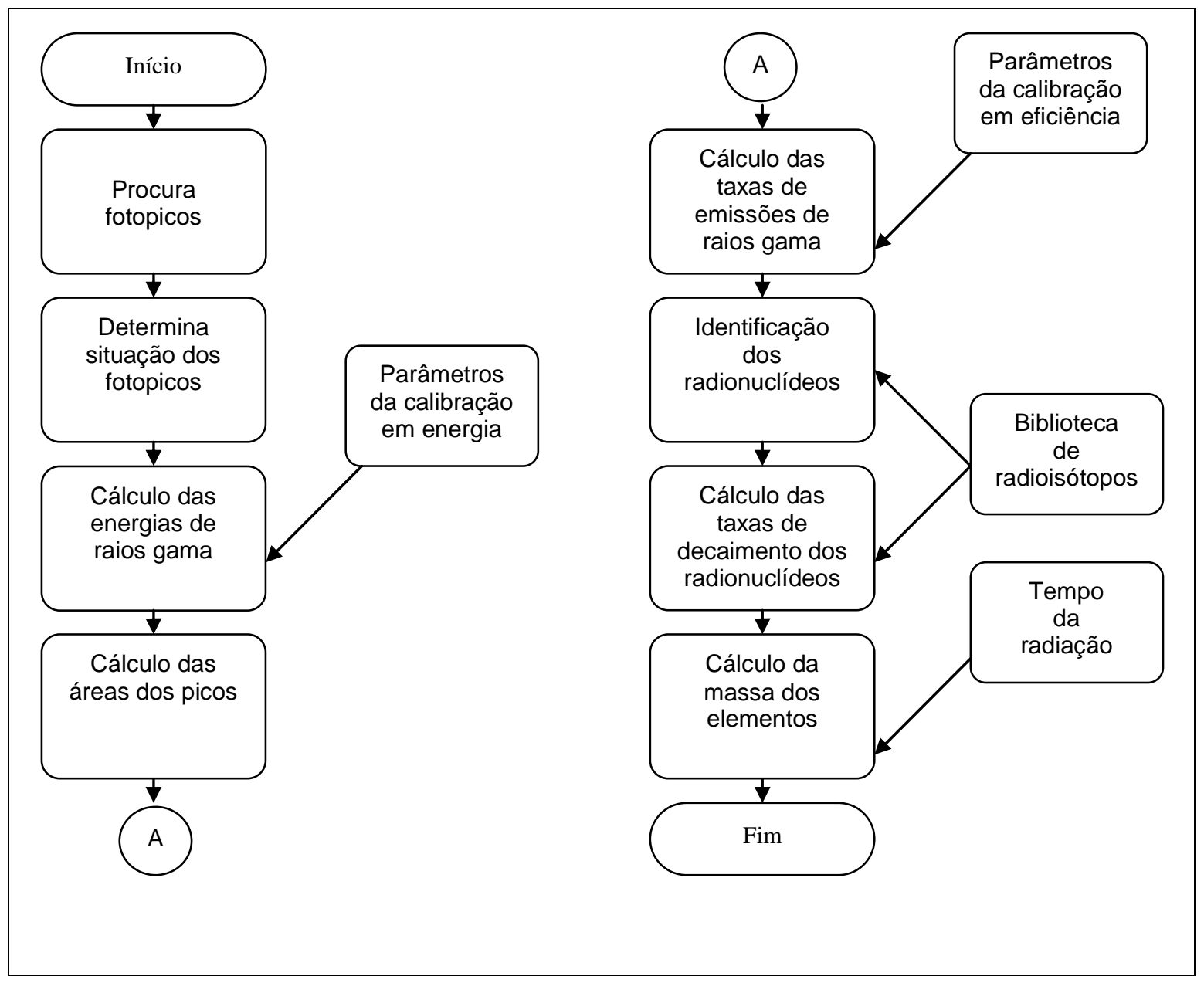

Figura 4 - Etapas do processo da análise de espectros de raios gamas.

O processo ocorre em várias etapas, como mostra a Figura 4. Após a contagem feita pelo equipamento, o software VISPECT/VERSÃO 2 processa o espectro e gera uma listagem com os resultados dos cálculos, que é posteriormente entrada para outro software, no qual são calculados as concentração dos elementos. O novo software vai agregar os dois processos em um único software, dando maior agilidade, melhorando a qualidade da informação, com uma menor possibilidade de erros.

Com o estudo das etapas e o processo que envolve a AANI - Análise por Ativação de Nêutrons Instrumental, tanto os manuais quanto os automatizados e as características e funcionalidades dos softwares que são utilizados no LANIPEN, foi feito o levantamento dos requisitos principais do software. 
Como o VISPECT/VERSÃO 2 foi desenvolvido utilizando uma linguagem conhecida, o TURBO BASIC, o seu código, que é disponível, é o ponto de partida

para o entendimento de várias funcionalidades, como leitura dos arquivos de espectros com origem de diferentes equipamentos, localização dos picos e os cálculos.

As rotinas gráficas do novo software SAANI foram baseadas no software PyMca que é um software para a Fluorescência de Raios-X (SOLÉ, 2007), apresenta uma estrutura e implementação muito próximas do que foi planejado para o novo software SAANI.

O PyMca tem em sua estrutura rotinas gráficas implementadas que foram estudas e portadas para dar suporte a montagem e manipulação dos gráficos no novo software SAANI.

\section{1 - Software VISPECT/VERSÃO 2}

O Laboratório de Análise por Ativação Neutrônica (LAN-IPEN), utiliza para a análise de espectros o software VISPECT/VERSÃO 2, desenvolvido na linguagem TURBO BASIC, pelo Dr. Denis Piccot, do Laboratório Pierre Sue, do Centro de Estudos Nucleares de Saclay.

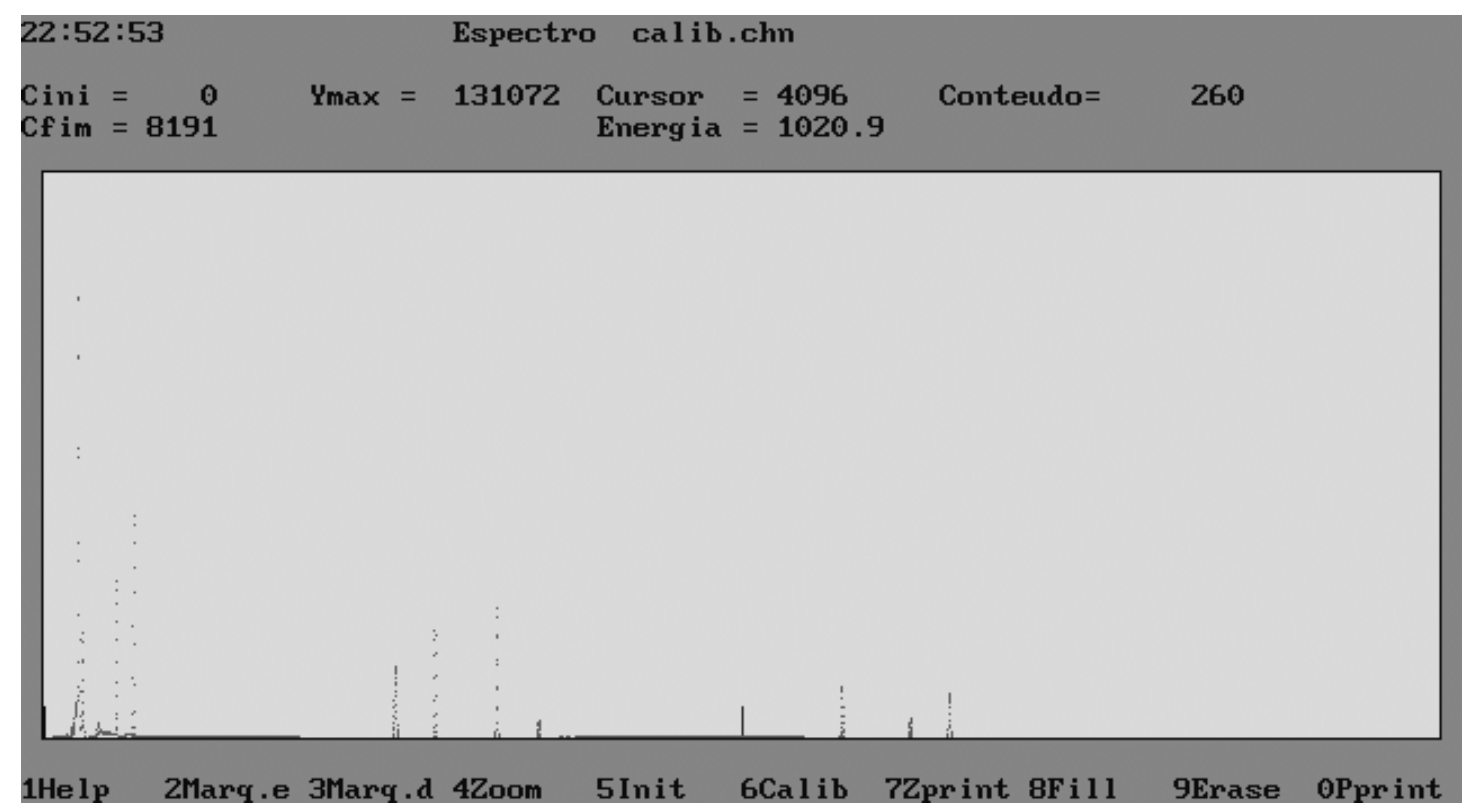

Figura 5 - Tela do software VISPECT/VERSÃO 2 
O software VISPECT/VERSÃO 2, conforme mostra a Figura 5, tem as seguintes características:

- Interface não gráfica;

- Efetua a leitura dos arquivos de espectros criados por sistemas detectores da EG\&G Ortec com a aquisição dos dados MAESTRO II com extensão “.CHN” e da Canberra com aquisição de dados $\mathrm{S} 100 \mathrm{com}$ extensão ".MCA";

- Lê o espectro e exibe os dados no vídeo como: canal inicial, canal final, fundo de escala em contagens, canal em que o cursor está posicionado, o número de contagens desse canal;

Esta tela possui dez funções:

F1 - ajuda;

F2 - marcar um canal como limite inferior de uma região;

F3 - marcar um canal como limite superior de uma região;

F4 - visualizar no vídeo apenas a região marcada;

F5 - voltar ao espectro original;

F6 - calibração - ativa uma lista de opções que permite fazer calibração em energia (fornece a energia de pelo menos dois canais do espectro) e em resolução do espectro (é necessário marcar pelo menos dois picos no espectro para que o software possa calcular função de resolução do detector). Pode-se salvar essa calibração em arquivo, ou chamar uma calibração já gravada;

F7 - imprimir uma lista com os números dos canais e suas contagens;

F8 - marcar uma região previamente selecionada;

F9 - desmarcar uma região previamente selecionada;

F10 - imprimir resultados. A impressão do relatório tem como informações: nome do arquivo, data e hora em que o espectro foi gravado (quando os espectros são obtidos nos sistemas EG\&G Ortec), tempo de detecção e as informações dos fotopicos são tabeladas na seguinte ordem: energia dos fotopicos, área líquida, área do BG, resolução em energia, canal da mediana, 
canal inicial, largura do fotopico em número de canais, atividades em contagens/segundos, desvio padrão da atividade em porcentagem;

Ctrl-P - para realizar a localização de fotopicos, informa-se qual o nível de sensibilidade, sendo o padrão 15, se for menor que este nível de sensibilidade localiza os fotopicos com poucas contagens acima da linha BG (Background) e se for maior localiza os fotopicos com maior número de contagens. Antes de localizar os fotopicos, é necessário fazer a calibração ou ler a calibração existente no sistema.

Para realizar a análise dos espectros, o software VISPECT/VERSÃO 2 utiliza uma série de rotinas para localizar e quantificar os fotopicos. Para entender como o software realiza estas tarefas, foi realizado um estudo de suas rotinas para o desenvolvimento do novo software referente a este trabalho.

Segundo os estudos efetuados sobre os softwares que fazem este tipo de análise, algumas características em comum são:

- Ter uma rotina para realizar uma análise automática dos dados;

- O método deve ser capaz de manipular os dados medidos sobre uma grande variedade de condições experimentais, incluindo estatística variável, ganho do sistema variável e detectores de diferentes tamanhos e qualidades;

- O método deve ser capaz de analisar espectros de alta complexidade e nenhum conhecimento prévio dos componentes do espectro deve ser necessário. Informações devem ser incluídas para o reconhecimento e análise de linhas espectrais próximas (multipletos);

- Os dados de calibração, se necessários, devem estar facilmente disponíveis;

- Os resultados da análise devem incluir as energias e as intensidades dos raios gama e as meias-vidas das linhas medidas;

- A análise deve incluir os procedimentos de calibração para a determinação da energia e eficiência;

- A exatidão dos resultados deve ser tão boa quanto a estatística dos dados e a exatidão das informações da calibração permitir; 
- O procedimento computacional deve ser eficiente o suficiente para tornar o método viável para as análises de rotina, usando as capacidades computacionais disponíveis.

Estas características são pertinentes aos softwares de análise e foram aplicadas no desenvolvimento do software SAANI.

\section{2 - Requisitos Levantados do Software Desenvolvido}

A seguir, são descritos os requisitos funcionais, não funcionais e as regras de negócio levantadas para a implementação do trabalho:

- Ler o arquivo de espectro, conforme a especificação do usuário;

- Apresentar o espectro graficamente no vídeo;

- Manipular o espectro, por região de interesse;

- Ler dados de calibração do sistema em que o espectro foi gerado;

- Realizar a calibração do sistema quando necessário, por energia ou resolução;

- Realizar a localização dos fotopicos de forma automática e/ou manual;

- Emitir relatório de resultado de análise realizada;

- Calcular as concentrações.

\section{3 - Propostas do Projeto do Software SAANI}

Desenvolver um software de análise de espectros de raios gama aplicado à Análise por Ativação com Nêutrons, que apresenta como características principais:

- A facilitação de padronização dos procedimentos realizados pelos pesquisadores, estudantes e técnicos;

- A fácil extensibilidade com a utilização da tecnologia de plugins; 
- Eliminar os erros causados pela entrada manual dos resultados gerados pelo VISPECT/VERSÃO 2 em outro software para o cálculo das concentrações.

Construir um aplicativo mais moderno, com mais facilidades do ponto de vista de interface com o usuário, sem, no entanto, estender em demasia as funcionalidades dos existentes com relação a:

- Métodos matemáticos e estatísticos;

- Execução em ambiente de rede, através de interface WEB ou modelo Cliente/Servidor;

- Deteç̧ão automática de fotopicos;

- Identificação automática de elementos através de base de dados nucleares.

O aplicativo, resultado deste trabalho, teve seu escopo inicial definido para substituir aquele que está sendo atualmente utilizado, o VISPECT/VERSÃO 2, servindo de base para desenvolvimentos futuros e extensões de funcionalidades.

Desta forma, a proposta do trabalho é lançar as bases para futuros desenvolvimentos, portanto obtendo ao final do trabalho um software moderno, de fácil utilização, com ganho de produtividade e eficiência para seus usuários.

\section{4 - Especificação}

$\mathrm{Na}$ especificação técnica do sistema, são apresentados modelos baseados na linguagem Unified Modeling Language (UML), que é uma linguagem para modelar softwares, descreve diagramas de classe, diagramas de caso de uso, especificando textualmente as funções do sistema e de seus principais módulos.

\subsection{1 - Diagrama de Caso de Uso}

Apresentam-se os casos de uso a seguir, explicando de maneira mais detalhada os casos de maior influência dentro do sistema. 


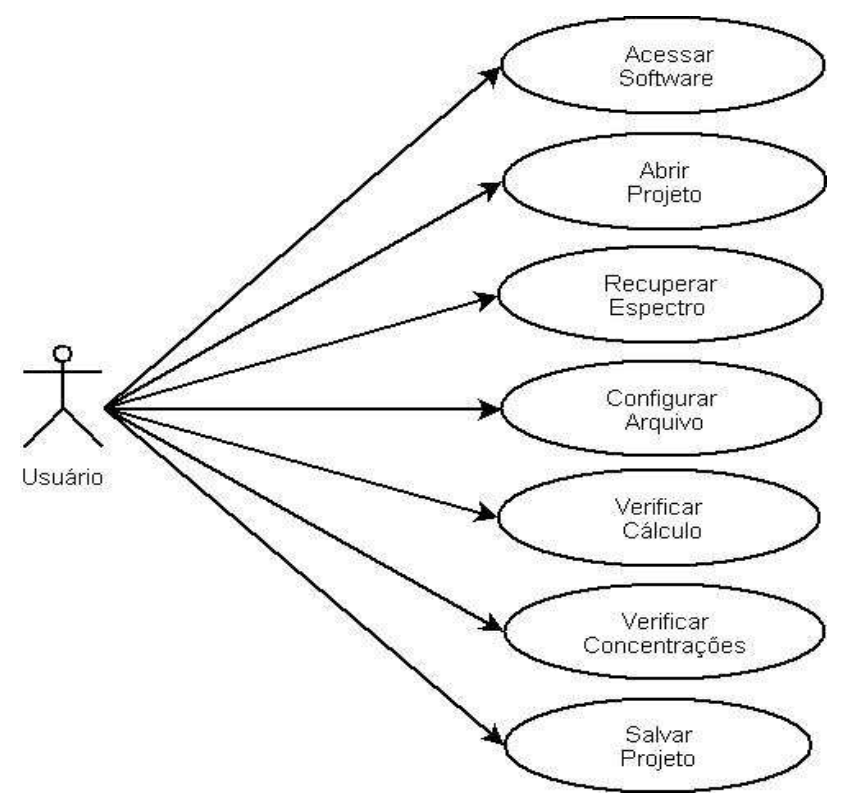

Figura 6 - Casos de Usos

Estes casos de usos, mostrados na Figura 6, representam graficamente as funcionalidades propostas para o sistema. A seguir, será detalhado cada caso de uso, para um melhor entendimento dos processos.

\subsubsection{1 - Caso de Uso: Acessar Software}

O usuário terá um ícone para o acesso ao sistema. Ao clicar no ícone, o sistema irá abrir a janela principal do aplicativo.

Tabela 1 - Caso de Uso: Acessar Software

\begin{tabular}{|l|l|}
\hline \multicolumn{2}{|c|}{ Caso de Uso - Acessar Software } \\
\hline Ator primário & Usuário (Pesquisador ou Bolsista). \\
\hline Ator secundário & Não há. \\
\hline Pré-condições & $\begin{array}{l}\text { O usuário deve possuir acesso ao sistema, ou seja, no } \\
\text { equipamento do usuário deve ter o software instalado. }\end{array}$ \\
\hline Fluxo principal & $\begin{array}{l}\text { - O usuário clica o ícone; } \\
\text { - Será aberto e apresentado o aplicativo no vídeo, na sua janela } \\
\text { principal. }\end{array}$ \\
\hline Fluxo alternativo & $\begin{array}{l}\text { - Caso não encontre o arquivo será dada mensagem de arquivo } \\
\text { não localizado. }\end{array}$ \\
\hline Pós-condições & Aplicativo aberto para uso. \\
\hline Regras de negócio & - O software deve estar instalado no equipamento do usuário. \\
\hline
\end{tabular}




\subsubsection{2 - Caso de Uso: Abrir Projeto}

O usuário deve clicar no botão "Abrir Projeto" para a localização do arquivo anteriormente gravado. Ao clicar neste botão, abre-se a janela padrão do sistema para localização do arquivo. Após localizar o arquivo, o sistema carrega todos os dados referentes ao projeto.

Tabela 2 - Caso de Uso: Abrir Projeto

\begin{tabular}{|l|l|}
\hline \multicolumn{2}{|c|}{ Caso de Uso - Abrir Projeto } \\
\hline Ator primário & Usuário (Pesquisador ou Bolsista). \\
\hline Ator secundário & Não há. \\
\hline Pré-condições & O sistema deve estar aberto. \\
\hline Fluxo principal & $\begin{array}{l}\text { - O usuário clica no botão “Abrir Projeto"; } \\
\text { - Será aberta janela padrão do sistema para localizar o arquivo; } \\
\text { - O sistema processa a leitura e efetua a leitura dos dados } \\
\text { referentes ao projeto. }\end{array}$ \\
\hline Fluxo alternativo & - Caso não encontre o arquivo retorna para a página principal. \\
\hline Pós-condições & Projeto aberto e carregado para uso. \\
\hline Regras de negócio & $\begin{array}{l}\text { - O software deve estar instalado no equipamento do usuário; } \\
\text { - Sistema deve estar aberto. }\end{array}$ \\
\hline
\end{tabular}

\subsubsection{3 - Caso de Uso: Recuperar Espectro}

O usuário pode ler arquivos de espectros com extensões ".CHN" e "MCA", originários de equipamentos de contagem diferentes. O sistema conta com reconhecimento automático do tipo de arquivo, no momento da abertura do arquivo, não sendo necessário o usuário diferenciar o tipo do arquivo, facilitando o processo.

Tabela 3 - Caso de Uso: Recuperar Espectro

\begin{tabular}{|l|l|}
\hline \multicolumn{2}{|c|}{ Caso de Uso - Recuperar Espectro } \\
\hline Ator primário & Usuário (Pesquisador ou Bolsista). \\
\hline Ator secundário & Não há. \\
\hline Pré-condições & Conhecer o local onde o arquivo de espectro está armazenado. \\
\hline Fluxo principal & $\begin{array}{l}\text { - O usuário acessa o sistema através da tela principal; } \\
\text { - Seleciona a opção do menu Arquivo e sub-menu Abrir ou } \\
\text { botão abrir; } \\
\text { - Será apresentada uma janela padrão do sistema para localizar } \\
\text { o arquivo de espectro a ser aberto; } \\
\text { - Seleciona a pasta, o arquivo e clica a opção do botão Abrir; }\end{array}$ \\
\hline Fluxo alternativo & $\begin{array}{l}\text { - Caso não encontre o arquivo exibe mensagem de arquivo não } \\
\text { localizado; } \\
\text { - Caso cancele operação de abertura, o sistema retorna a tela } \\
\text { principal. }\end{array}$ \\
\hline Pós-condições & Espectro obtido e apresentação do gráfico. \\
\hline Regras de negócio & $\begin{array}{l}\text { - Não importa o tipo de arquivo que será aberto ".CHN" ou } \\
\text { ".MCA", o software irá identificar e ler o arquivo. }\end{array}$ \\
\hline
\end{tabular}




\subsubsection{4 - Caso de Uso: Configurar Arquivo}

Para configuração do arquivo de espectro, o usuário deve clicar na aba "Parâmetros do Arquivo", que abre no vídeo a janela para entrada dos dados: tipo do arquivo (amostra ou padrão), massa, data e hora em que a contagem foi realizada, nível de sensibilidade para busca dos picos, desvio padrão para os cálculos. Quando o tipo do arquivo for o arquivo do padrão, é necessário informar dados adicionais sobre os elementos, concentrações e desvio padrão que estão presentes no padrão.

Tabela 4 - Caso de Uso: Configurar Arquivo

\begin{tabular}{|l|l|}
\hline \multicolumn{2}{|c|}{ Caso de Uso - Configurar Arquivo } \\
\hline Ator primário & Usuário (Pesquisador ou Bolsista). \\
\hline Ator secundário & Não há. \\
\hline Pré-condições & $\begin{array}{l}\text { - O usuário deve possuir os dados do arquivo de espectro para a } \\
\text { configuração; } \\
\text { - Deve ter o arquivo de espectro aberto e selecioná-lo da lista de } \\
\text { arquivos, para poder efetuar a configuração. }\end{array}$ \\
\hline Fluxo principal & $\begin{array}{l}\text { - O usuário seleciona arquivo de espectro na lista de arquivos; } \\
\text { - Clica na aba "Parâmetros do Arquivo", para abrir janela para } \\
\text { entrada dos dados; }\end{array}$ \\
$\begin{array}{l}\text { - Efetua a entrada dos dados: tipo do arquivo (amostra ou } \\
\text { padrão), massa, data e hora em que a contagem foi realizada, } \\
\text { calibração do sistema onde o arquivo foi gerado, nível de } \\
\text { sensibilidade, desvio padrão; } \\
\text { - Se o tipo do arquivo de espectro for o arquivo do padrão é } \\
\text { necessário dar entrada nos elementos e dados de concentrações, } \\
\text { que compõem o padrão. }\end{array}$ \\
\hline Fluxo alternativo & $\begin{array}{l}\text { - Se não tiver os dados para configuração, salvar o projeto e } \\
\text { localizar os dados para depois atualizá-lo. }\end{array}$ \\
\hline Pós-condições & Arquivo de espectro configurado e pronto para cálculo. \\
\hline Regras de negócio & - Se o arquivo for padrão, permitir entrada de dados adicionais. \\
\hline
\end{tabular}

\subsubsection{5 - Caso de Uso: Verificar Cálculo}

Para verificar os resultados dos cálculos, o usuário deve clicar a aba "Resultado dos Cálculos", onde serão exibidos os seguintes dados: energia dos picos, área líquida, área do BG, resolução em energia, canal da mediana, canal inicial, largura do pico em número de canais, atividades em contagens/segundos, desvio padrão da atividade em porcentagem. 
Tabela 5 - Caso de Uso: Verificar Cálculo

\begin{tabular}{|l|l|}
\hline \multicolumn{2}{|c|}{ Caso de Uso - Verificar Cálculo } \\
\hline Ator primário & Usuário (Pesquisador ou Bolsista) \\
\hline Ator secundário & Não há \\
\hline Pré-condições & - Arquivo de espectro deve estar selecionado e configurado. \\
\hline Fluxo principal & $\begin{array}{l}\text { - Seleciona a aba "Resultado dos Cálculos"; } \\
\text { - Será aberta a aba e apresentado os resultados. }\end{array}$ \\
\hline Fluxo alternativo & $\begin{array}{l}\text { - Caso tenha algum dado do arquivo não configurado, o sistema } \\
\text { apresenta mensagem e posiciona na tela de configuração. }\end{array}$ \\
\hline Pós-condições & - Obtém os resultados dos cálculos. \\
\hline Regras de negócio & - Têm que ser configurado os dados do arquivo de espectro. \\
\hline
\end{tabular}

\subsubsection{6 - Caso de Uso: Verificar Concentrações}

O cálculo das concentrações confronta cada amostra com todos os padrões que foram inseridos no projeto. Ao encontrar os elementos, através dos dados já configurados anteriormente, efetua o cálculo da concentração para cada elemento encontrado e seu respectivo desvio padrão. O usuário deve clicar a aba "Resultado das Concentrações", onde são mostrados os resultados.

Tabela 6 - Caso de Uso: Verificar Concentrações

\begin{tabular}{|l|l|}
\hline \multicolumn{2}{|l|}{ Caso de Uso - Verificar Concentrações } \\
\hline Ator primário & Usuário (Pesquisador ou Bolsista) \\
\hline Ator secundário & Não há \\
\hline Pré-condições & - Arquivo de espectro deve estar selecionado e configurado. \\
\hline Fluxo principal & $\begin{array}{l}\text { - Seleciona a aba "Resultado das Concentrações"; } \\
\text { - Será aberta a aba e apresentado os resultados; } \\
\text { - Selecionar a aba da amostra para verificar os resultados. }\end{array}$ \\
\hline Fluxo alternativo & $\begin{array}{l}\text { - Caso tenha algum dado do arquivo não configurado, o sistema } \\
\text { apresenta mensagem e posiciona na tela de configuração do } \\
\text { respectivo arquivo de espectro. }\end{array}$ \\
\hline Pós-condições & - Obtém os resultados das concentrações. \\
\hline Regras de negócio & - Têm que ser configurado os dados do arquivo de espectro. \\
\hline
\end{tabular}

\subsection{2 - Modelo de Classes}

O sistema é composto por vários objetos de negócio, nos quais cada um representa uma necessidade básica, que deverá ser comportada pelo sistema, controlando todas as ações que poderão ser tomadas por cada item. Dentro da implementação, a interface da aplicação apenas irá solicitar aos objetos de negócio as informações necessárias e, os objetos de negócio irão devolver 
apenas os dados já formatados e preparados para serem apresentados na interface da aplicação.

O acesso aos dados é feito com base em uma classe implementada apenas para este fim, na qual todos os métodos estão preparados para efetuarem as transações com os dados e devolverem apenas as informações solicitadas pela classe de negócio.

O modelo conta com 7 classes, nas quais 2 estarão focadas diretamente no negócio e uma classe estará disposta especialmente para prover acesso aos dados.

Explicando melhor as classes implementadas:

- Classe LerEspectro: é responsável pela leitura dos dados do espectro, e seus dados complementares se houver; permite a leitura de tipos de arquivos de espectros de diferente origem, retorna um dicionário (um DataObjetc) com os dados, valores das contagens para cada canal, nome do arquivo lido e outras informações.

- Classe QtBlissGraph: esta classe é encarregada pela apresentação do gráfico no vídeo e todas as rotinas que envolvem a manipulação do gráfico, como por exemplo, a seleção de uma parte do gráfico para análise (Zoom).

- Classe VispectFit: Efetua a busca dos fotopicos automaticamente e calcula a área dos fotopicos, estuda alguns casos de dupletos e gera uma saída com os resultados da energia dos fotopicos, área líquida, área do BG, resolução em energia, canal da mediana, canal inicial, largura do fotopico em número de canais, atividades em contagens/segundos, desvio padrão da atividade em porcentagem.

As classes que iniciam por "frm", como frmMenu, frmResultados, frmConcentracao, são lay-out das telas para exibição no vídeo dos resultados e operações do sistema, e são controladas pelos arquivos que iniciam por "crt", como crtResultados, crtConcentracao. 
Os principais métodos são listados a seguir:

- ler_MCAeCHN: Efetua a leitura do arquivo de espectro;

- lerCalibracao: Efetua a leitura da calibração do sistema (equipamento) no qual foi gerado o espectro (o software SAANI não efetua a calibração do sistema ainda, utiliza o arquivo de calibração já existente do software VISPECT/VERSÃO 2);

- VispectFit: Executa a busca dos fotopicos e calcula resultados;

- CalConcetra: Efetua o cálculo das concentrações, a partir das matrizes resultados dos cálculos, sendo confrontados as amostras com os padrões dos elementos cadastrados. 


\section{CAPÍTULO 4 - IMPLEMENTAÇÃO DO SOFTWARE}

Neste capítulo, são apresentados tópicos referentes à implementação do software deste trabalho.

A proposta é o desenvolvimento de um software que será liberado de acordo com a licença de código aberto (GPL) ou Licença Pública Geral, possibilitando liberdade de execução, estudo, modificação e redistribuição do código fonte. Na fase inicial, por se tratar de um trabalho acadêmico, foi utilizada uma metodologia mais voltada para o método "Catedral", pois está focado a um único programador. A intenção é que após a conclusão do projeto, este será liberado para a comunidade, quando então será aplicado o método "Bazar" (RAYMOND, 2007).

Este trabalho poderá ser explorado, tornando-se base para novas implementações ou extensões, entre outras melhorias que possam surgir, toda a documentação e programas fontes desenvolvidos estão disponíveis para este fim, Anexo "CD" com os fontes do software.

\section{1 - Técnicas e Ferramentas Utilizadas}

Nos tópicos a seguir, são apresentadas algumas das principais ferramentas e técnicas utilizadas para o desenvolvimento deste software. O principal destaque é o desenvolvimento de software livre com a implementação em Python e o ambiente de gráfico QT.

\subsection{1 - Python}

É uma linguagem de programação que foi criada por Guido van Rossum um programador de computador em 1991, enquanto trabalhava para o sistema operacional distribuído Amoeba no Instituto Nacional de Investigação de Matemática e Ciências da Computação em Amesterdã (PYTHON, 2004). 
O nome Python teve a sua origem no grupo humorístico britânico Monty Python, e não com animais selvagens e ferozes, que muitas pessoas fazem associação.

Algumas das características do Python são:

- fácil de utilizar;

- linguagem do tipo interpretada;

- contém uma vasta biblioteca de objetos e funções;

- é orientada a objetos;

- exceções, um moderno mecanismo para o tratamento de erros;

- módulos, uma forma inteligente de acessar e organizar código a ser reutilizado, coleta de lixo automática, sistema que elimina os erros causados pelo acúmulo de dados inúteis na memória do computador;

- recursos avançados de manipulação de textos, listas e outras estruturas de dados;

- multiplataforma, ou seja, possibilidade de executar o mesmo software sem modificações em várias plataformas de hardware e sistemas operacionais.

Por estas características apresentadas e com o objetivo de criar um software livre com metodologia orientada a objetos, foi adotada esta linguagem de programação para o desenvolvimento do novo software de espectrometria gama.

\subsection{2-QT}

QT é um sistema multiplataforma para o desenvolvimento de programas de interface gráfica. A empresa responsável pela criação é a norueguesa Trolltech, que lançou uma versão 4 da biblioteca sob as licenças GPL em todas as plataformas suportadas, incluindo a partir desta versão, a plataforma Windows (TROLLTECH, 2005), que foi utilizada para o desenvolvimento de toda a interface gráfica do software, através do PyQt (RIVERBANK, 2005), que é um pacote para o desenvolvimento em Python. 


\section{2 - Implementação do Software SAANI}

Nos tópicos a seguir, são apresentadas as implementações efetuadas e a operacionalização do software.

\subsection{1 - Leitura do Arquivo de Espectro}

Uma das preocupações iniciais foi com a leitura dos dados do espectro pois, o LAN-IPEN tem dois sistemas de detectores: 1) da Ortec da E\&G ORTEC com a aquisição dos dados utilizando o software MAESTRO II, gerando o arquivo de espectro com extensão ".CHN"; 2) da Canberra com aquisição de dados

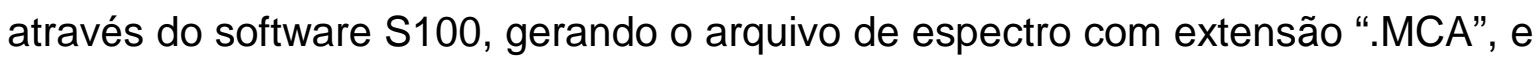
os arquivos gerados por estes sistemas são de diferentes formatos, conforme mostra o Tabela 7.

Tabela 7 - Lay-out dos arquivos de espectros: "CHN" e "MCA"

\begin{tabular}{|c|c|c|c|}
\hline \multicolumn{4}{|c|}{ Lay-Out } \\
\hline \multicolumn{2}{|r|}{$\mathrm{CHN}$} & \multicolumn{2}{|r|}{ MCA } \\
\hline Posição & Conteúdo & Posição & Conteúdo \\
\hline 1 a 8 & Espaços livres em branco & 1 a 48 & Espaços livres em branco \\
\hline 9 a 12 & Tempo total & 49 a 52 & Tempo vivo \\
\hline 13 a 16 & Tempo vivo & 53 a 56 & Tempo total \\
\hline 17 a 24 & Data inicio contagem & 57 a 138 & Espaços livres em branco \\
\hline 25 a 28 & Hora inicio contagem & \multirow{3}{*}{$\mid \begin{array}{l}139 \text { a } \\
\text { fim de } 4 \\
\text { em } 4 \\
\text { posições }\end{array}$} & \multirow{3}{*}{$\begin{array}{l}\text { Canal e contagem são } 8190 \\
\text { canais correndo as posições }\end{array}$} \\
\hline 29 a 32 & Espaços livres em branco & & \\
\hline $\begin{array}{l}33 \text { a fim de } \\
4 \text { em } 4 \\
\text { posições }\end{array}$ & $\begin{array}{l}\text { Canal e contagem são } \\
8190 \text { canais correndo as } \\
\text { posições }\end{array}$ & & \\
\hline
\end{tabular}

Para implementar a rotina da leitura dos arquivos de espectros, o software VISPECT/VERSÃO 2, que contém o código fonte na linguagem de programação BASIC, com base em suas rotinas os formatos dos arquivos foram identificados e, dessa forma, foi possível elaborar a rotina de leitura em Python, para o novo software desenvolvido.

Para a leitura dos espectros, foi desenvolvida a classe LerSpectro, que contém as rotinas de identificação do tipo de arquivo que deve ser lido e a leitura 
efetiva dos dados, que retorna um dicionário contendo o dados das contagens por canais e informações sobre o espectro. O trecho de código, na Tabela 8, demonstra a rotina de identificação do tipo de arquivo e a execução da rotina que realiza a leitura dos dados.

Tabela 8 - Código fonte para ler o arquivo de espectro

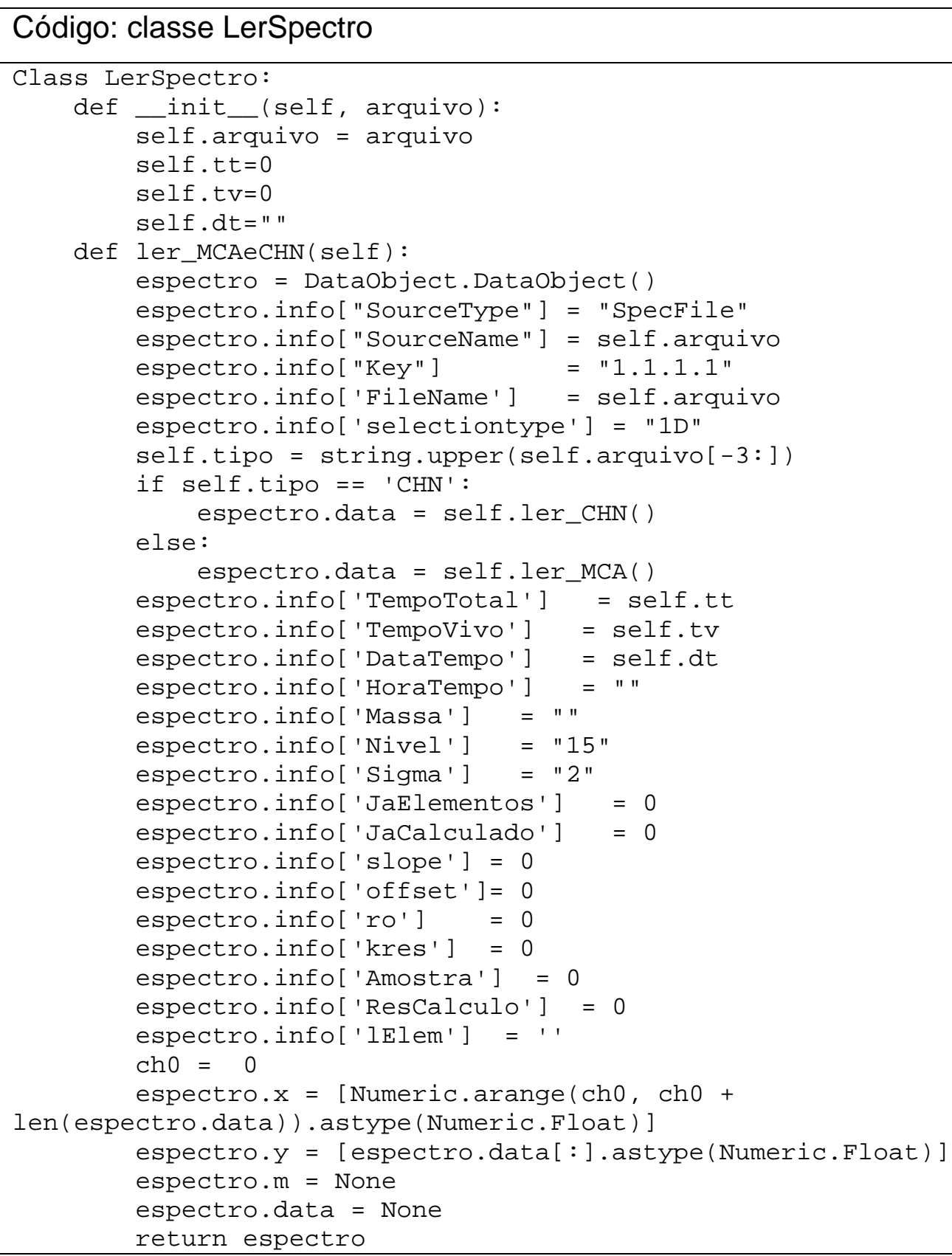




\subsection{2 - Apresentação do gráfico}

Para o desenvolvimento da apresentação dos gráficos no sistema, foi utilizada a classe "QtBlissGraph" do software PyMCA (SOLÉ, 2007) que contém varias rotinas com uma série de recursos para apresentação e manipulação dos gráficos.

Após a leitura dos dados do arquivo de espectro, o software armazena os dados em um dicionário para cada espectro e adiciona em uma lista o nome do arquivo de espectro, esta lista fica disponível para que o usuário do software selecione o espectro que deseja trabalhar.

Para a apresentação do gráfico após o usuário selecionar o espectro de interesse o software exibe o gráfico de conforme mostra a rotina na Tabela 9.

Tabela 9 - Código fonte para exibir o gráfico

\begin{tabular}{|c|}
\hline 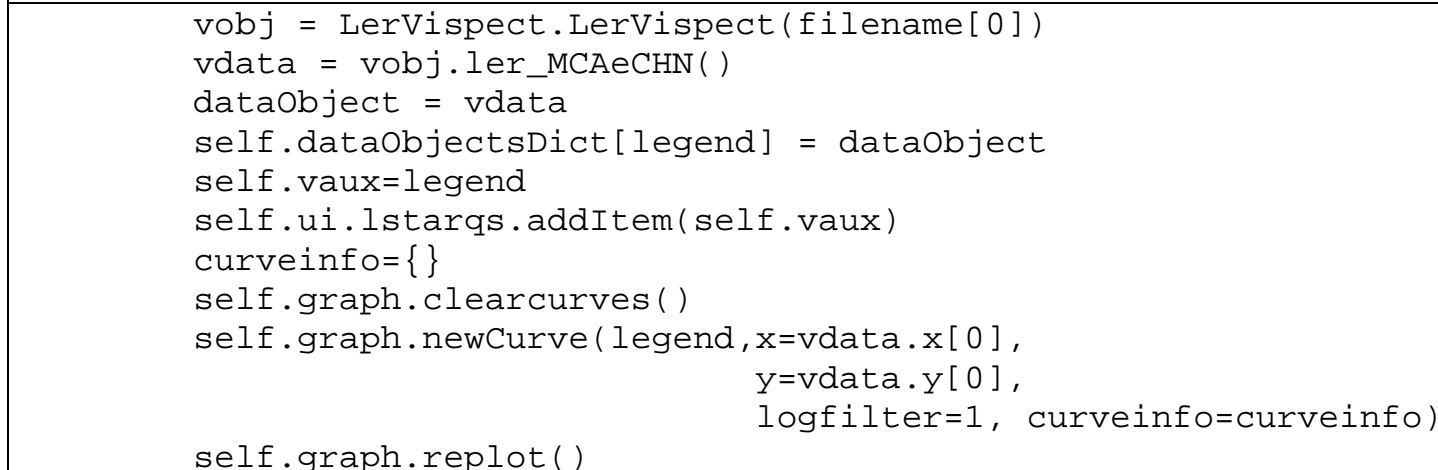 \\
\hline
\end{tabular}

\subsection{3 - Configuração do Espectro}

Para cada arquivo de espectro, o usuário deve fazer a configuração dos dados antes de efetuar o cálculo. Clicar na aba "Parâmetros do Arquivo" abre então a janela para entrada dos seguintes dados: tipo do arquivo (amostra ou padrão), massa, data e hora em que a contagem foi realizada, calibração do sistema, nível de sensibilidade para busca dos picos, desvio padrão para os cálculos.

Se o tipo do arquivo for o arquivo do padrão, é aberta uma nova entrada de dados na qual são informados os elementos e a concentrações que compõem o 
padrão. Existe um arquivo no software SAANI, que contém os dados dos elementos na seguinte ordem: energia referente ao elemento; descrição do elemento; a meia vida; tipo do tempo da meia vida em horas, dias, meses ou anos.

\subsection{4 - Identificação dos picos}

As rotinas de busca e identificação dos fotopicos foram implementadas para 0 novo software SAANI baseadas nas rotinas do software VISPECT/VERSÃO 2.

Com os dados do arquivo de calibração do sistema detector, em que os espectros foram gerados e, do parâmetro nível de sensibilidade, cujo valor padrão é 15, é possível realizar a localização dos picos.

O nível da sensibilidade padrão usado na procura de picos, significa que para localizar picos com poucas contagens acima da linha do BG é necessário diminuir esse valor, e ao contrário, se o objetivo for localizar somente os picos com um grande número de contagens deve-se aumentar esse valor.

A rotina de localização dos picos segue várias etapas, começando com a utilização de informações contidas no arquivo de calibração. Por isso, a calibração é obrigatoriamente chamada no início de um projeto. Posteriormente, são inseridos os espectros, identificando-os como amostra ou padrão. No padrão são inseridos os elementos com suas concentrações que são a base para identificação nas amostras e para os cálculos das concentrações.

A rotina de localização utiliza os coeficientes das calibrações para calcular o número de canais (NC) que a forma do sinal de procura irá ter.

Os pontos do espectro que têm valores maiores que o da sensibilidade escolhida quando se inicia o processo da procura dos picos no espectro, mostram a presença de picos nestas posições. São utilizadas as somas em quadratura das raízes quadradas das contagens para marcar as regiões do espectro em que existem os picos.

Para exemplificar através do NC, encontram-se as somatórias das raízes quadradas das contagens denominadas janela total (JT) e janela central (JC), conforme mostra a Figura 7. 


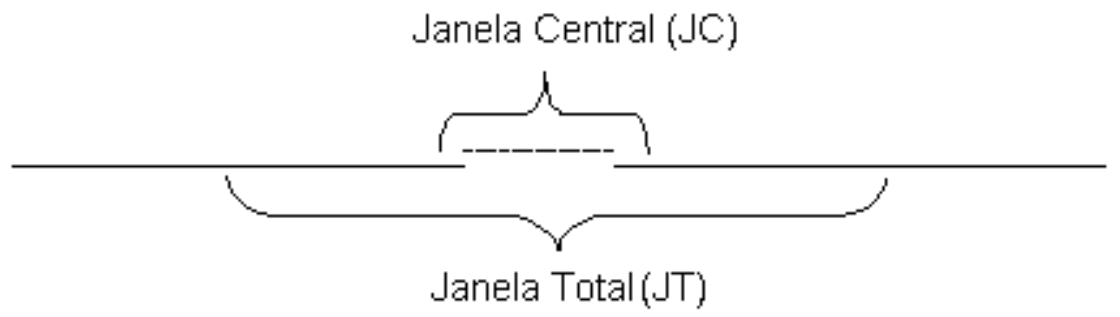

Figura 7 - Exemplificando janelas para busca dos picos no espectro

Estas janelas são deslizadas no espectro, e é testado se a subtração da JT menos 5 (cinco) vezes a JC é maior que a sensibilidade, se for indica que o canal faz parte de uma região do pico.

O software determina o canal inicial do pico ao primeiro canal que possui um valor maior que o da sensibilidade e após esta ocorrência encontra o final do pico quando o canal do espectro possuir um valor menor que o da sensibilidade, marca assim as regiões do espectro que foram encontrados os picos.

$\mathrm{Na}$ seqüência, é procurado dentro destas regiões encontradas o canal que possui a maior contagem, que indicam os picos no espectro.

O processo de busca dos picos, canal inicial, canal final e localização da maior contagem ocorrem para todo o espectro, identificando todos os picos existentes no espectro.

Após o processamento destas rotinas o software executa os cálculos para apresentar os resultados.

\subsection{5 - Cálculos dos resultados}

As rotinas de cálculo da energia do pico, área líquida, área do BG, resolução em energia, canal da mediana, canal inicial, largura do pico em número de canais, atividade em contagens/segundo e desvio padrão da atividade em porcentagem, foram extraídas do VISPECT/VERSÃO 2 e implementadas no novo software.

A classe VispectFit é a responsável pela busca dos picos, que é automática, e pelo cálculo da área dos picos, verifica alguns casos de dupletos e gera a saída com os resultados. 
Tabela 10 - Código fonte para chamar o cálculo dos resultados

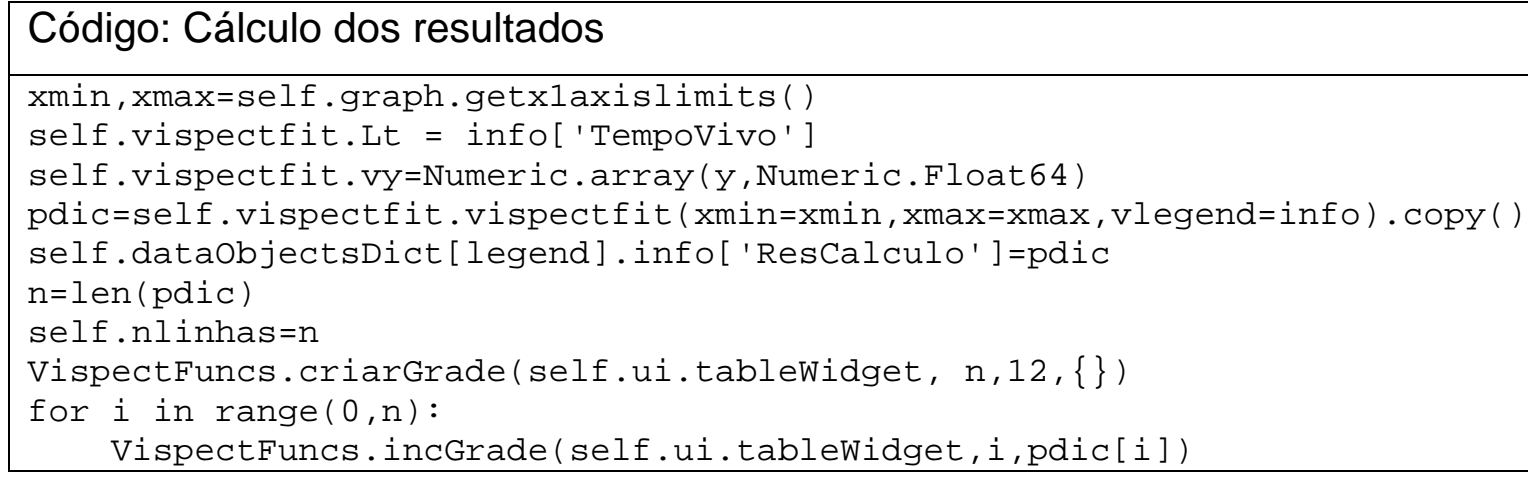

A Tabela 10 mostra o código que efetua a chamada da classe VispectFit, que é responsável por encontrar os picos e efetuar o cálculo dos resultados, que são exibidos no vídeo na aba "Resultados de Cálculos", através da função incGrade do arquivo VispectFuncs.

Com os canais iniciais e finais conhecidos, o software efetua o cálculo da área do pico, através do método da Área Total do Pico (Total Peak Area - TPA), segundo BAEDECKER (1971).

O método da Área Total do Pico utiliza o seguinte equacionamento:

sendo:

$$
A_{L}=A_{T}-A_{B g}
$$

$$
A_{T}=\sum_{i=i}^{f} C_{i}
$$

e

$$
A_{B G}=\frac{\left(Y_{i}+Y_{f}\right)}{2} \bullet L P
$$

ou seja, a área líquida $\left(A_{L}\right)$ é a diferença entre a área total $\left(A_{T}\right)$ e a área do $B G$ $\left(A_{B G}\right)$. $A$ área total é a somatória das contagens dos canais (xi) e a área do $B G$ é a média dos extremos do pico $\left(Y_{i} \in Y_{f}\right)$ multiplicado pelo número de canais que formam o pico (LP), mas Yi e Yf são calculados como é mostrado abaixo:

$$
Y_{i}=\frac{x_{i-1}+x_{i}+x_{i+1}}{3}
$$




$$
Y_{f}=\frac{x_{f-1}+x_{f}+x_{f+1}}{3}
$$

isto é: $Y_{i}$ é a média aritmética feita com as contagens do canal inicial do pico e das contagens dos dois canais vizinhos e $Y_{f}$ é a média aritmética feita com as contagens do canal final do pico e das contagens dos dois canais vizinhos.

A Figura 8 mostra um recorte de um espectro, denominado 283br5-2.chn, onde está marcada em negrito a área das contagens para exemplificar os cálculos.

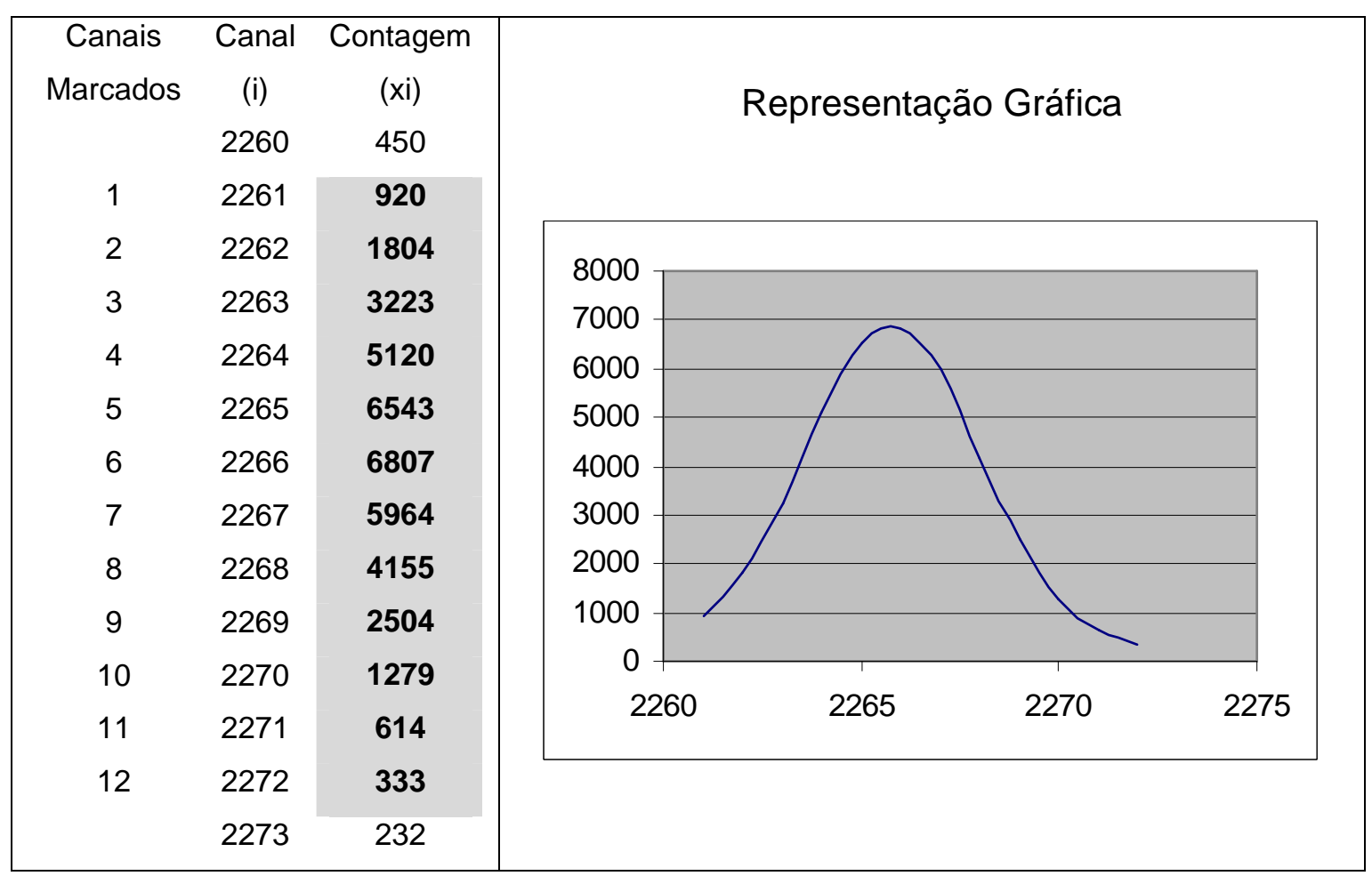

Figura 8 - Recorte do espectro

Através do recorte na Figura 8, serão exemplificados os cálculos e os resultados estão demonstrados na Tabela 11.

A área total do pico é a somatória das contagens do canal inicial 2261 até o canal final 2272, que neste exemplo é igual a 39.266.

O Bg é igual a 8.706, utilizam-se os canais dos extremos, que é a média dos extremos das três últimas contagens do pico dividido por 2 e multiplicado pelo 
número de canais que formam o pico (LP) da área marcada, que no caso são 12 canais.

Através dos dados de contagem do espectro e o tempo vivo, que é o tempo de contagem efetivo no sistema de detecção, é calculado a atividade $\left(A T_{c p s}\right)$ que é dada pela equação (4.6):

$$
A T_{C P S}=\frac{A_{L}}{T_{V}}
$$

onde:
$A_{L} \quad$ Área líquida;
TV Tempo vivo.

O erro ou desvio padrão da área liquida do pico é calculado de acordo com a equação (4.7):

$$
\sigma=\frac{\sqrt{2 A_{B G}+A_{L}}}{A_{L}} \times 100 \times p
$$

onde:

$A_{L} \quad$ Área líquida;

$\mathrm{A}_{\mathrm{Bg}}$ Área do $\mathrm{Bg}$;

p Valor inteiro (1,2 ou 3).

A energia é calculada utilizando a equação (4.8):

onde:

$$
E=\text { CM } x \text { Slope }+ \text { OffSet }
$$

CM Canal da mediana;

Slope Inclinação da reta (dado da calibração);

OffSet Intercept (dado da calibração);

Na Tabela 11 são apresentados os resultados dos cálculos referentes ao exemplo apresentado na Figura 8, para o pico encontrado no espectro entre o canal 2261 a 2272. 
Tabela 11 - Resultados dos cálculos

\begin{tabular}{|c|c|c|c|c|c|c|}
\hline $\begin{array}{c}\text { Energia } \\
E\end{array}$ & Área Total & Área Líquida & $\mathrm{Bg}$ & Atividade (cps) & Desvio Padrão & Tempo Vivo \\
& $A_{T}$ & $\mathrm{~A}_{\llcorner}$ & $A_{B G}$ & $A T_{C P S}$ & $\sigma$ & $T_{V}$ \\
\hline 554,15 & 39266 & 30560 & 8706 & 5,0792 & 0,716 & 6016,7 \\
\hline
\end{tabular}

Estes cálculos ocorrem para todas as regiões marcadas no espectro que contém os fotopicos. Assim, uma listagem com todos os resultados são exibidos no vídeo ou também podem ser impressos. São estes resultados de todos os espectros, que formam as matrizes para os cálculos das concentrações.

\subsection{6 - Cálculo das concentrações}

Através do levantamento de dados efetuado junto aos usuários, verificouse que existem dois procedimentos para o cálculo das concentrações: 1) Software Espectro2000 (desenvolvido para o cálculo de concentração);

2) Planilha do Excel, montada com as fórmulas necessárias para o cálculo.

Nos dois procedimentos, existe a necessidade da entrada dos dados, a data e a hora em que os arquivos de espectros foram processados, os resultados dos cálculos das atividades dos espectros obtidas pelo software VISPECT/VERSÃO 2. Neste momento, quando é necessário fazer a digitação dos dados, podem ocorrer erros de digitação no lançamento dos dados.

Alguns arquivos de espectros e uma planilha do Excel com as fórmulas foram coletados para o detalhamento do processo dos cálculos, permitindo efetuar alguns testes iniciais.

O método "calConcentra" foi desenvolvido para o cálculo das concentrações. No projeto, após os espectros das amostras e dos padrões serem inseridos, configurados e calculados as áreas e atividades, é possível efetuar o cálculo das concentrações. Cada amostra é confrontada com todos os padrões, quando é identificado o elemento através da energia na amostra e no padrão, são então recuperados os dados de concentração dos elementos nos padrões para o cálculo da concentração, o desvio padrão para o elemento e a energia localizada.

O software calcula as concentrações de todos os elementos de interesse presentes nas amostras. Após todos os espectros serem processados e as 
atividades calculadas, são realizados os cálculos das concentrações dos elementos nas amostras.

Utiliza-se a equação 2.5 do Capítulo 2 para o cálculo das concentrações. 0 cálculo da concentração ocorre para cada elemento que foi lançado no padrão e localizado na amostra, é assim, montada uma tabela de todos os resultados das concentrações por amostras.

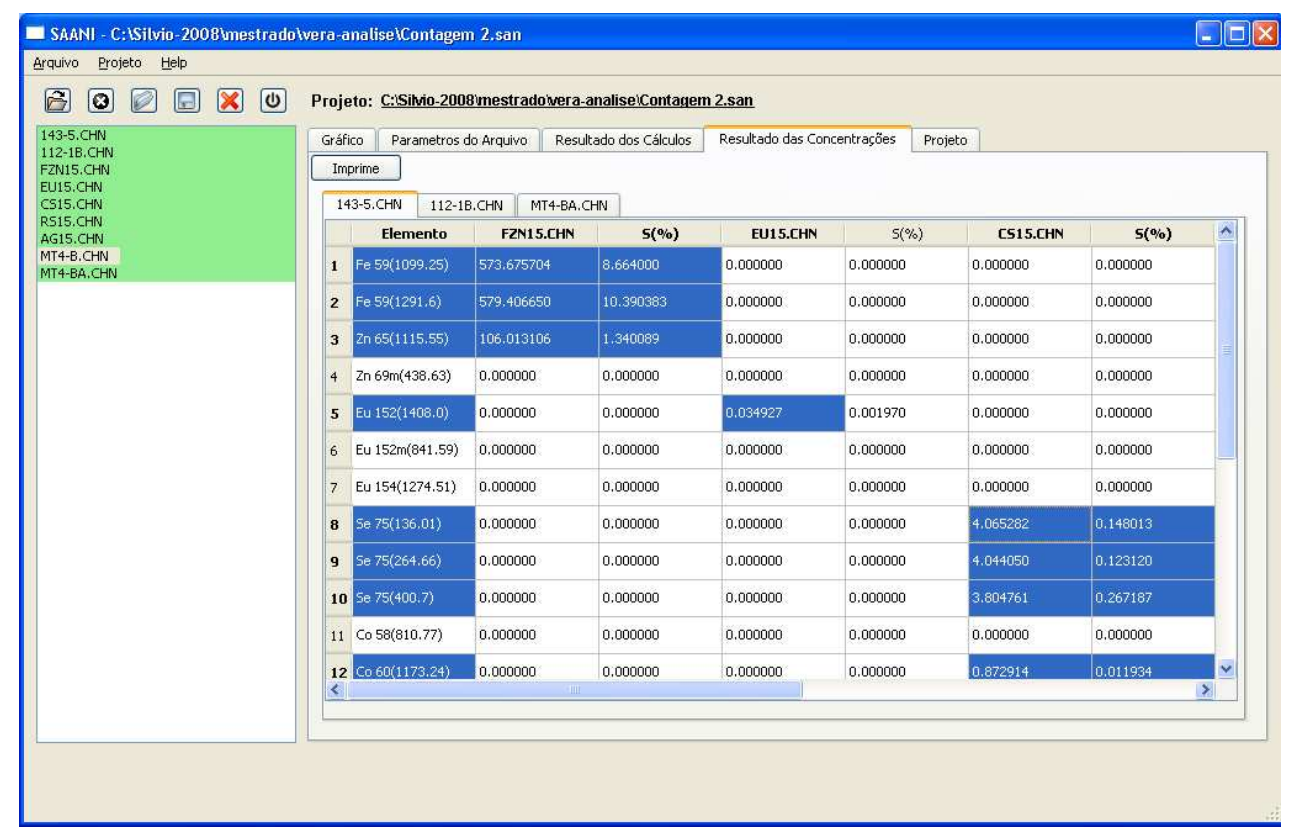

Figura 9 - Tela da apresentação dos resultados das concentrações

A Figura 9 mostra a janela do software SAANI com os resultados das concentrações, possibilitando a impressão dos dados. 


\section{CAPÍTULO 5 - MANUAL DE USO DO SOFTWARE}

Neste capítulo são apresentadas detalhadamente as etapas que compõem o SAANI.

\section{1 - Projeto}

O projeto é a forma utilizada para organizar o processo de análise, ou seja, agrupar todos os arquivos de espectros que são analisados. Pode-se criar um projeto novo e inserir os arquivos de espectros ou abrir um projeto, que já foi gravado anteriormente, com todos os arquivos de espectros e suas características.

Para iniciar um projeto, é necessário efetuar a leitura do arquivo de calibração, o software SAANI na aba projeto tem um botão chamado "Ler arquivo de calibração", que abre janela padrão do sistema para a abertura do arquivo com extensão "cal".

\section{2 - Inserir Arquivo do Espectro no Projeto}

$\mathrm{O}$ arquivo de espectro, que foi gerado por um dos dois sistemas detectores da Ortec ou da Canberra, localizados no laboratório do IPEN, é armazenado em uma pasta ou outro meio magnético. O software SAANI faz a abertura do arquivo, identifica o tipo do arquivo através de sua extensão ".CHN" ou ".MCA" , carrega os dados das contagens por canais, adiciona o nome do arquivo de espectro na lista de arquivos abertos e apresenta o gráfico do espectro no vídeo.

Ao clicar em outro arquivo de espectro da lista, este será selecionado e apresentado o respectivo gráfico, podendo alternar de um arquivo para outro, através de um clique do mouse. 


\section{3 - Configurando Arquivo de Espectro}

A configuração do arquivo de espectro é necessária para o processo da análise. Verifica se o arquivo do espectro que foi adicionado ao projeto é uma amostra ou um padrão (ou um material de referência). Digitam-se a massa utilizada, data e hora em que foi processada a leitura no sistema de detecção, o nível de sensibilidade de contagens por canais para a identificação dos picos é escolhido e o valor do desvio padrão que será utilizado. Se o arquivo de espectro for de um padrão, exige a entrada de mais alguns dados, como os elementos presentes no padrão para a análise e suas respectivas concentrações, permitindo incluir vários elementos para cada padrão.

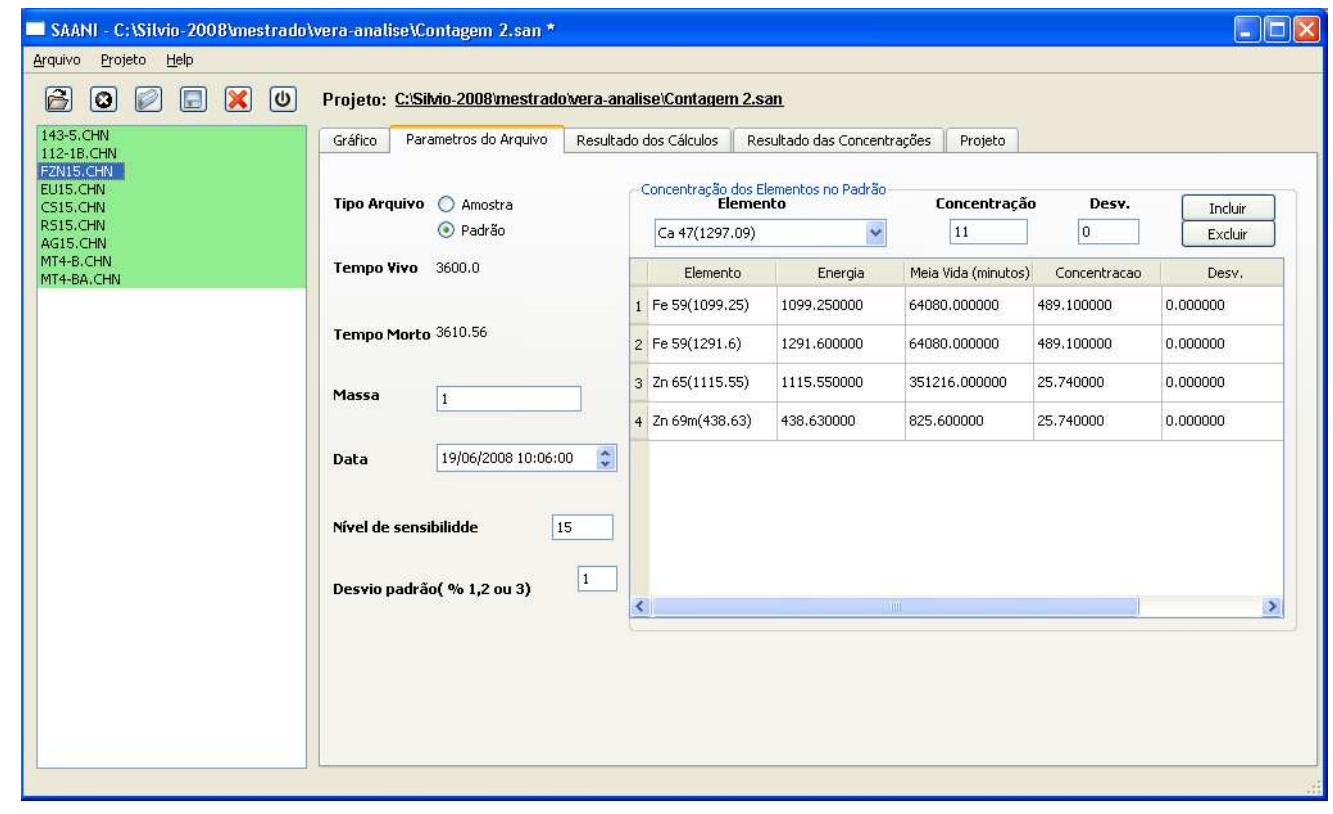

Figura 10 - Parâmetros do arquivo de espectro de um padrão

A Figura 10 mostra a janela dos parâmetros do arquivo de espectro; quando é de uma amostra, não exibe a janela para entrada da concentração dos elementos. Já no caso de arquivo de um padrão, é montada uma tabela com os elementos presentes no padrão, mostrando as energias dos elementos, meia vida. 


\section{4 - Verificando Resultado dos Cálculos}

Após a configuração do arquivo dos espectros das amostras e dos padrões e com os dados da calibração do sistema é possível calcular os resultados. Ao clicar na aba "Resultado dos Cálculos" na janela principal, são calculados os dados e são exibidos na seguinte ordem: energia do pico, área líquida, área do BG, resolução em energia, canal da mediana, canal inicial, largura do pico em número de canais, atividade em contagens/segundo e desvio padrão da atividade em porcentagem, elemento identificado e sua meia vida.

\section{5 - Verificando Resultado das Concentrações}

O resultado das concentrações dos elementos depende dos dados da configuração dos arquivos de espectros, previamente fornecidos ao software e o cálculo das concentrações é feito automaticamente. Para visualizar os resultados, deve-se clicar na aba "Resultado das Concentrações" na janela principal.

Os resultados das concentrações são calculados para cada amostra em função dos padrões utilizados e mostrados na tela, com a identificação de cada amostra analisada.

\section{6 - Salvando Projeto}

Para salvar o projeto, o software utiliza a janela padrão do sistema operacional, na qual é determinado o nome do arquivo a ser salvo. $O$ arquivo salvo terá a extensão ".SAN" para diferenciar dos demais arquivos do sistema.

Para o usuário salvar o projeto deve clicar no botão "Salvar Projeto" e ao abrir a janela padrão do sistema, informar o nome do arquivo e salvar o projeto. 


\section{CAPÍTULO 6 - RESULTADOS E DISCUSSÕES}

\section{1 - Comparação entre o softwares VISPECT/VERSÃO 2 e o SAANI}

Para proceder a leitura de um arquivo de espectro no software VISPECT/VERSÃO 2, inicialmente seleciona o tipo de arquivo onde o espectro foi gerado para identificar qual "lay-out" de leitura que será processado, conforme Figura 11. Logo após, é necessário digitar o nome do arquivo com sua extensão, conforme mostrado na Figura 12.

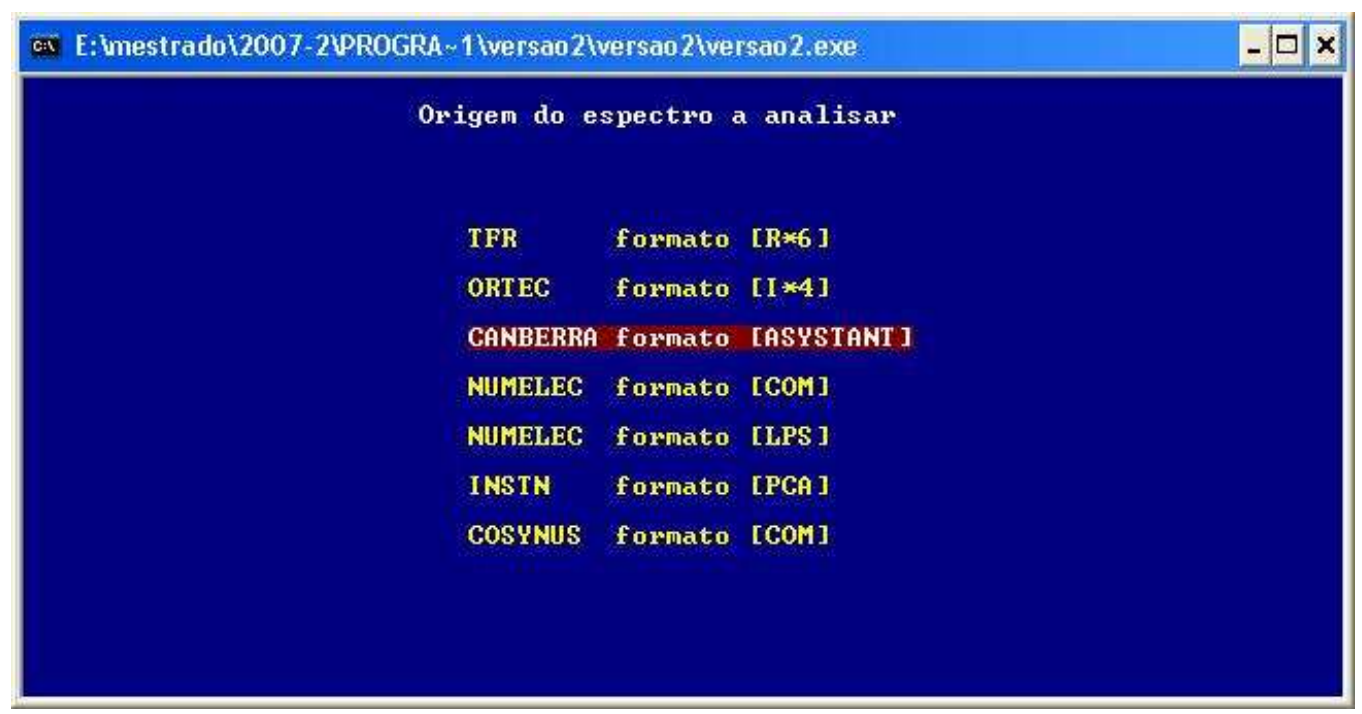

Figura 11 - VISPECT/VERSÃO 2: Seleção tipo formato arquivo 


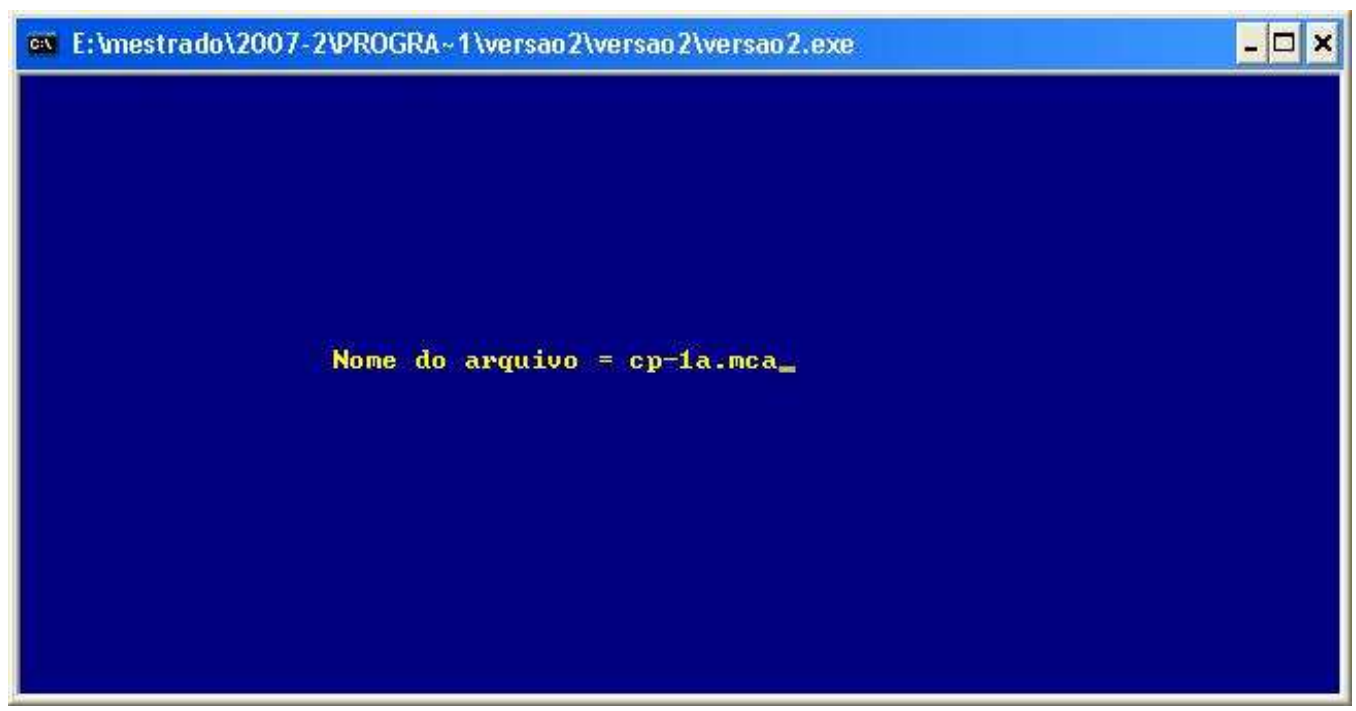

Figura 12 - VISPECT/VERSÃO 2: Digitando nome do arquivo e extensão

No software SAANI, para selecionar o arquivo do espectro, o usuário seleciona no menu "arquivo" a opção "abrir" ou simplesmente, clica no ícone "abrir espectro", conforme mostra a Figura 13. Em seguida, abre-se uma janela padrão do sistema para a seleção do arquivo.

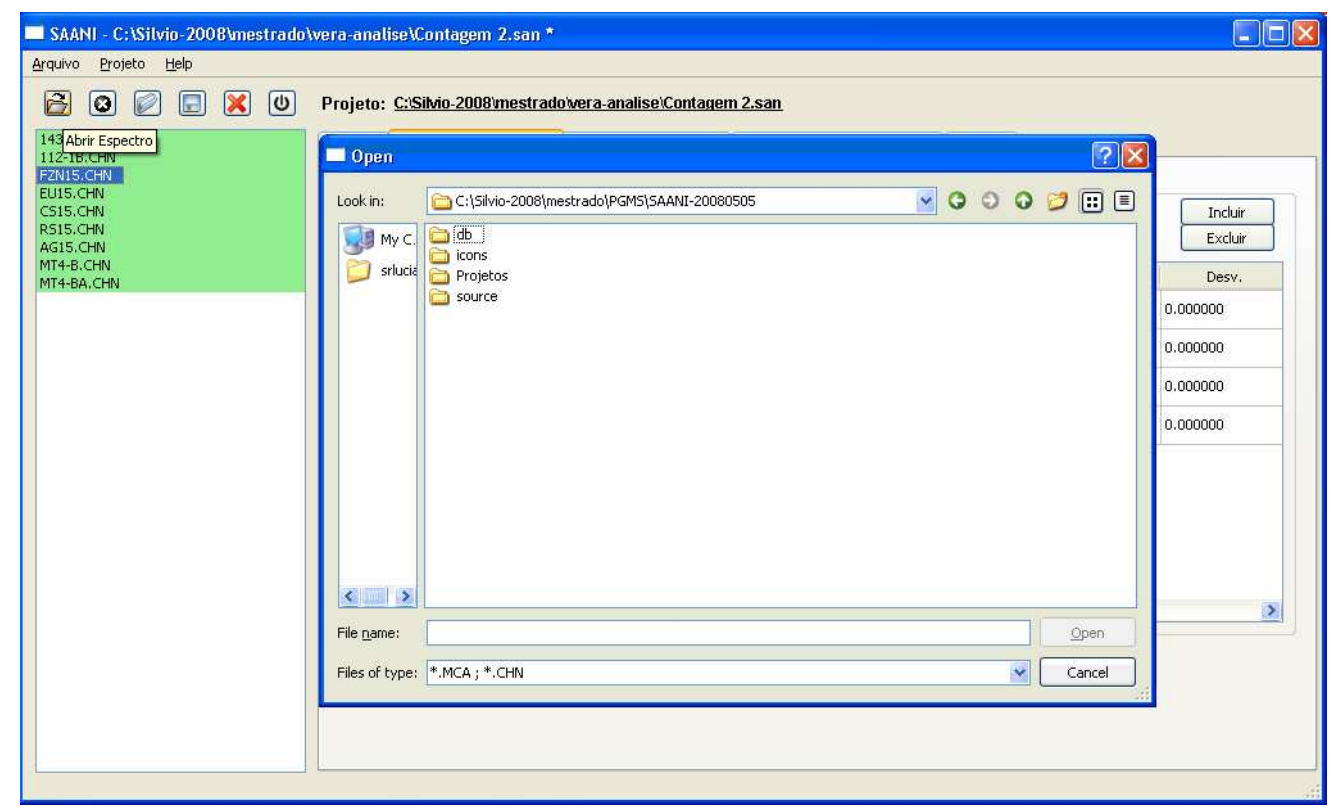

Figura 13 - SAANI: Tela Principal opção de abrir arquivo de espectro

No software VISPECT/VERSÃO 2 existe a necessidade de informar o tipo de arquivo e digitar o nome do arquivo para leitura do espectro, quando é feita a digitação do nome do arquivo e pressionado a tecla "Enter", o software lê o arquivo e se ele não existir ocorre um erro e aborta o software voltando para a 
tela principal. No SAANI, a identificação do tipo de arquivo não é efetuada e também não é digitado o nome do arquivo. Ao clicar o botão "abrir", o software exibe a janela de abertura padrão do sistema, permitindo a seleção do arquivo através do clique do mouse, facilitando o processo para o usuário e evitando erros de digitação do nome do arquivo.

O software VISPECT/VERSÃO 2 não tem interface gráfica bem definida. Utiliza o sistema "DOS". Assim, após a entrada do nome do arquivo o software mostra o gráfico de acordo com a Figura 14.

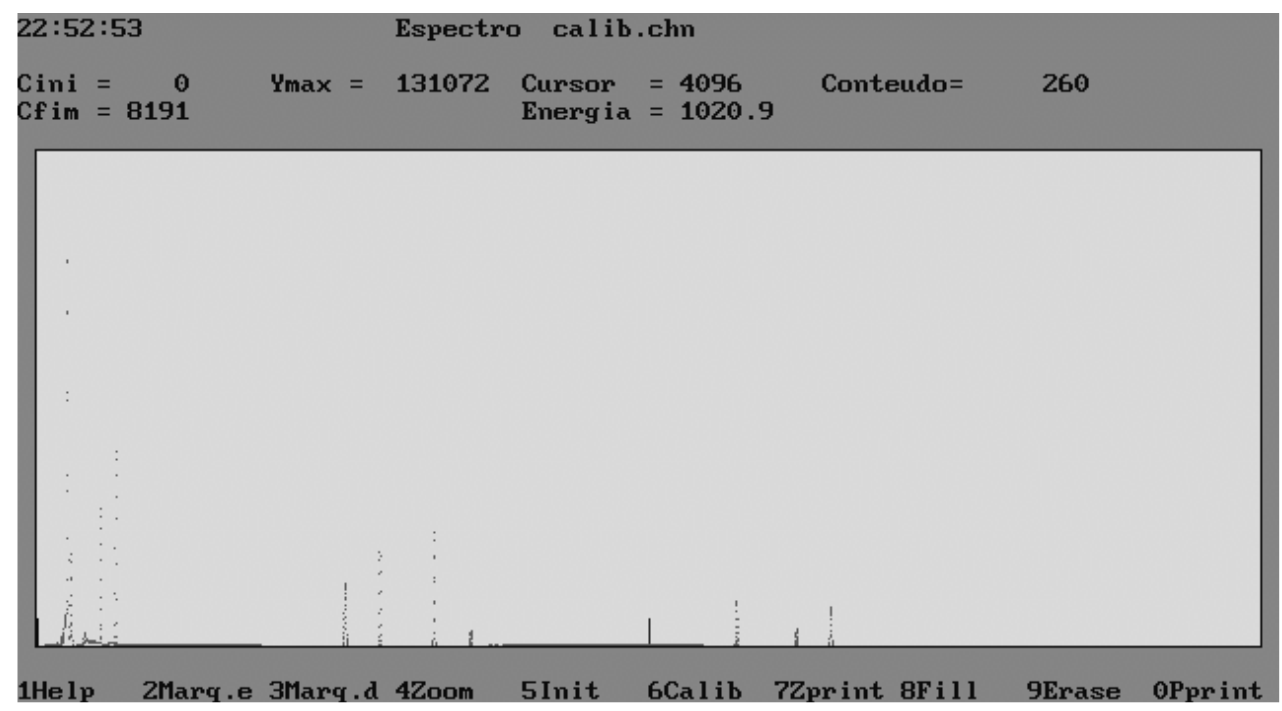

Figura 14 - VISPECT/VERSÃO 2: Tela da apresentação do gráfico

No software VISPECT/VERSÃO 2, como podemos verificar na Figura 14, a interface para a visualização do gráfico não é muito boa, devido à limitação da interface gráfica.

O software novo, SAANI, tem uma interface gráfica bem definida, é utilizada a biblioteca PyQt para a montagem do gráfico, como mostra a Figura 15. 


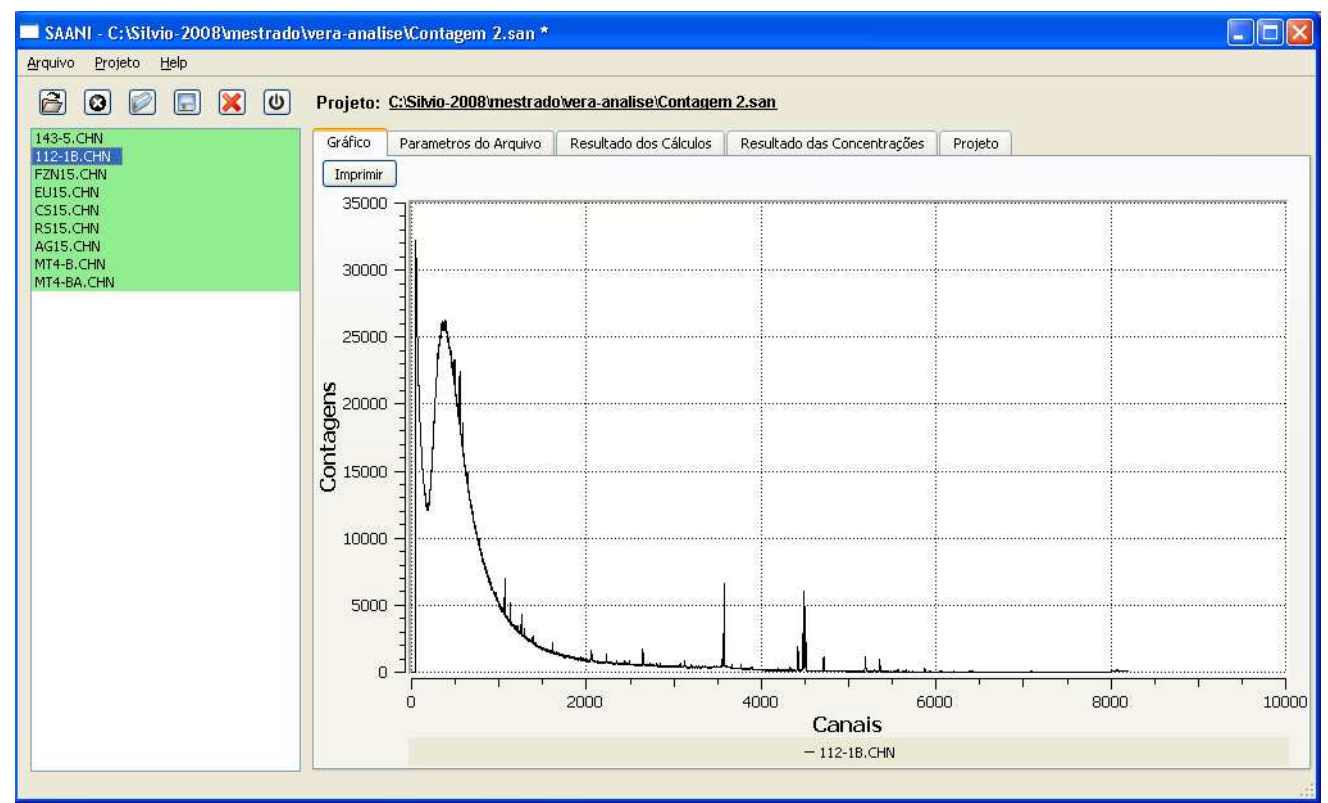

Figura 15 - SAANI: Tela da apresentação do gráfico

Com as rotinas gráficas definidas é possível, com o uso do mouse, selecionar regiões para ampliação, conforme mostram as Figuras 16 e 17.

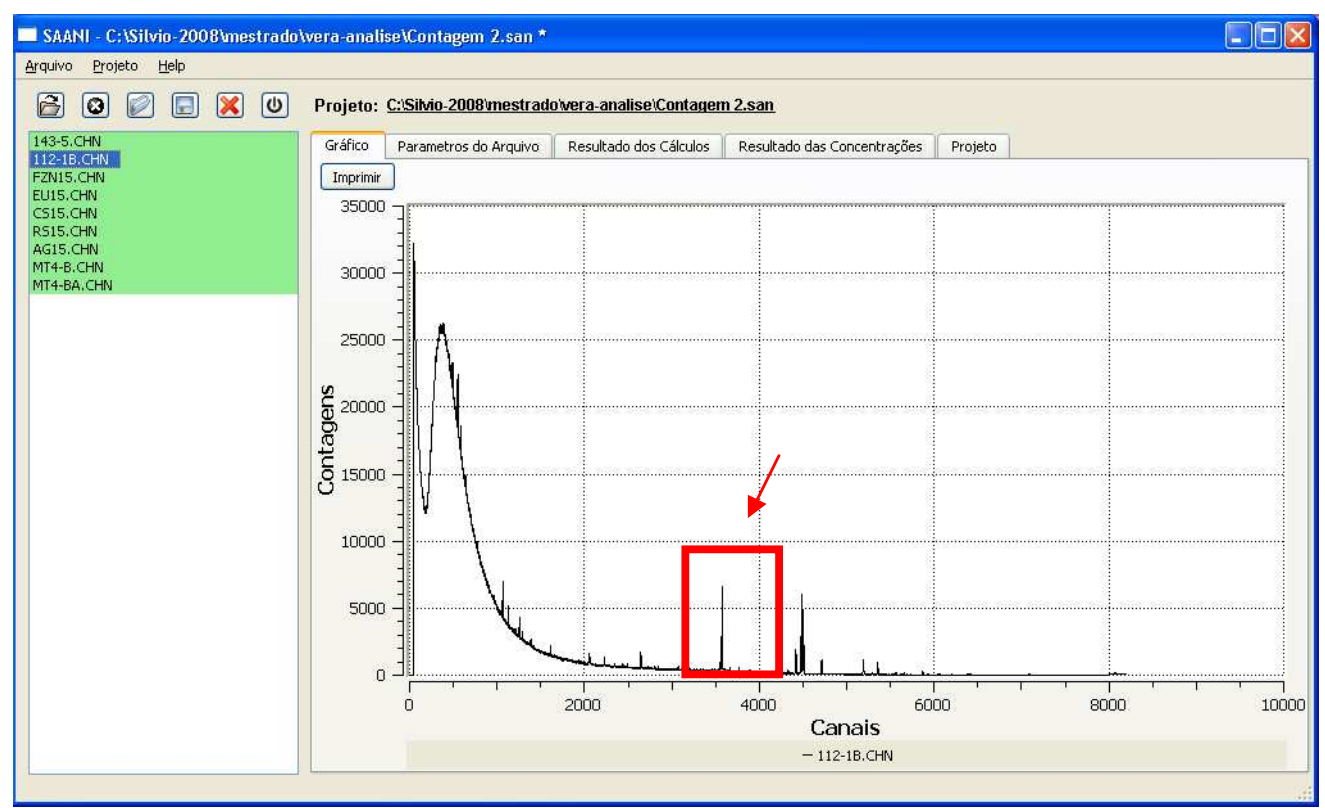

Figura 16 - SAANI: Seleção de uma área do gráfico 


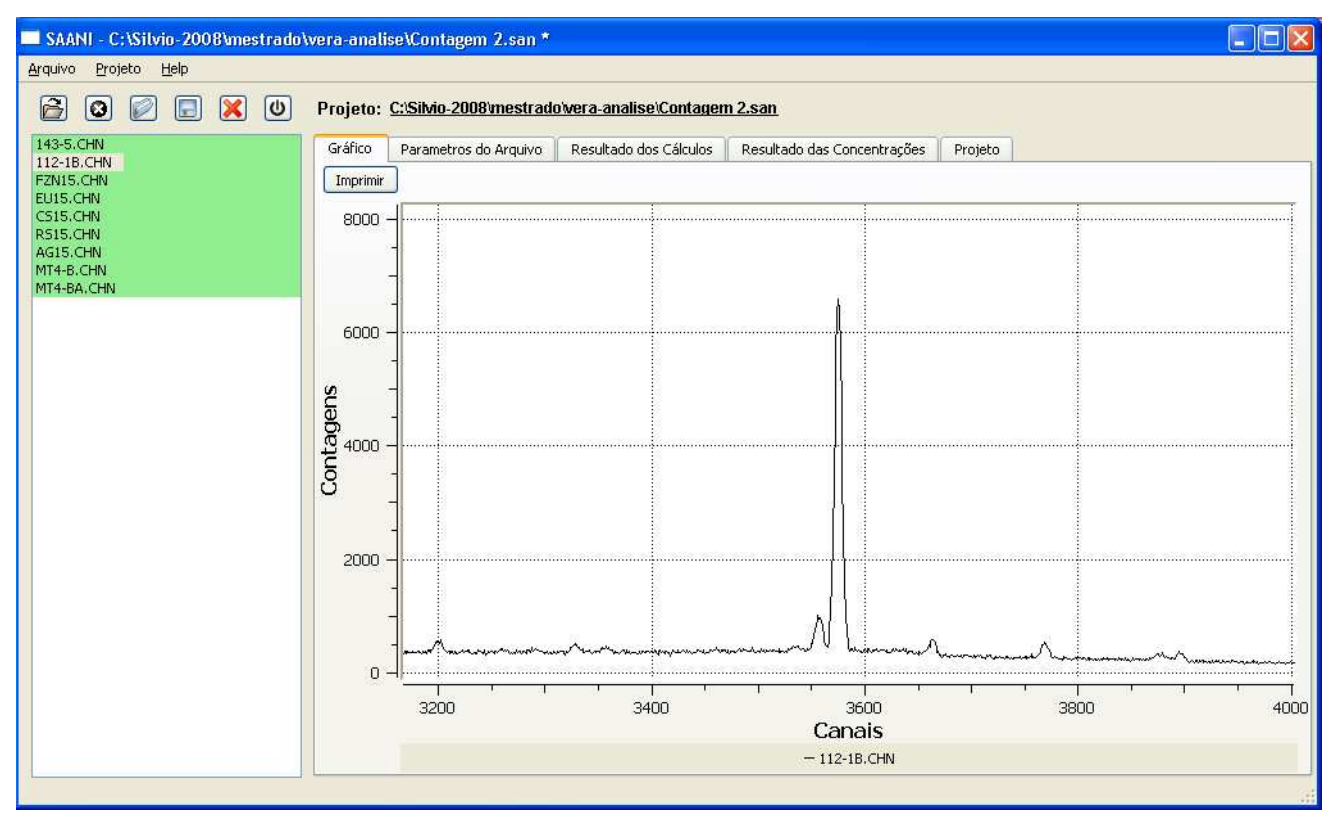

Figura 17 - SAANI: Área selecionada ampliada

No software VISPECT/VERSÃO 2, para efetuar a ampliação de parte do gráfico é necessário utilizar o teclado acionando as teclas F2 e F3 para marcar a região e F5 para executar a ampliação. As rotinas gráficas implementadas no SAANI facilitam a identificação e ampliação dos picos no espectro de forma rápida, simples e fácil.

O software VISPECT/VERSÃO 2 apresenta os resultados somente em relatório impresso, como mostra a Figura 18. Já o novo software apresenta os dados no vídeo, permitindo a impressão, caso necessário, conforme mostra Figura 19.

No novo software é permitida a entrada dos dados do espectro, ou seja, data e hora em que o espectro foi gravado e tempo de detecção. As informações sobre os picos são apresentadas e tabeladas na seguinte ordem: energia dos picos, área líquida, área do BG, resolução em energia, canal da mediana, canal inicial, largura do pico em número de canais, atividade em contagens/segundo e desvio padrão da atividade em porcentagem. 


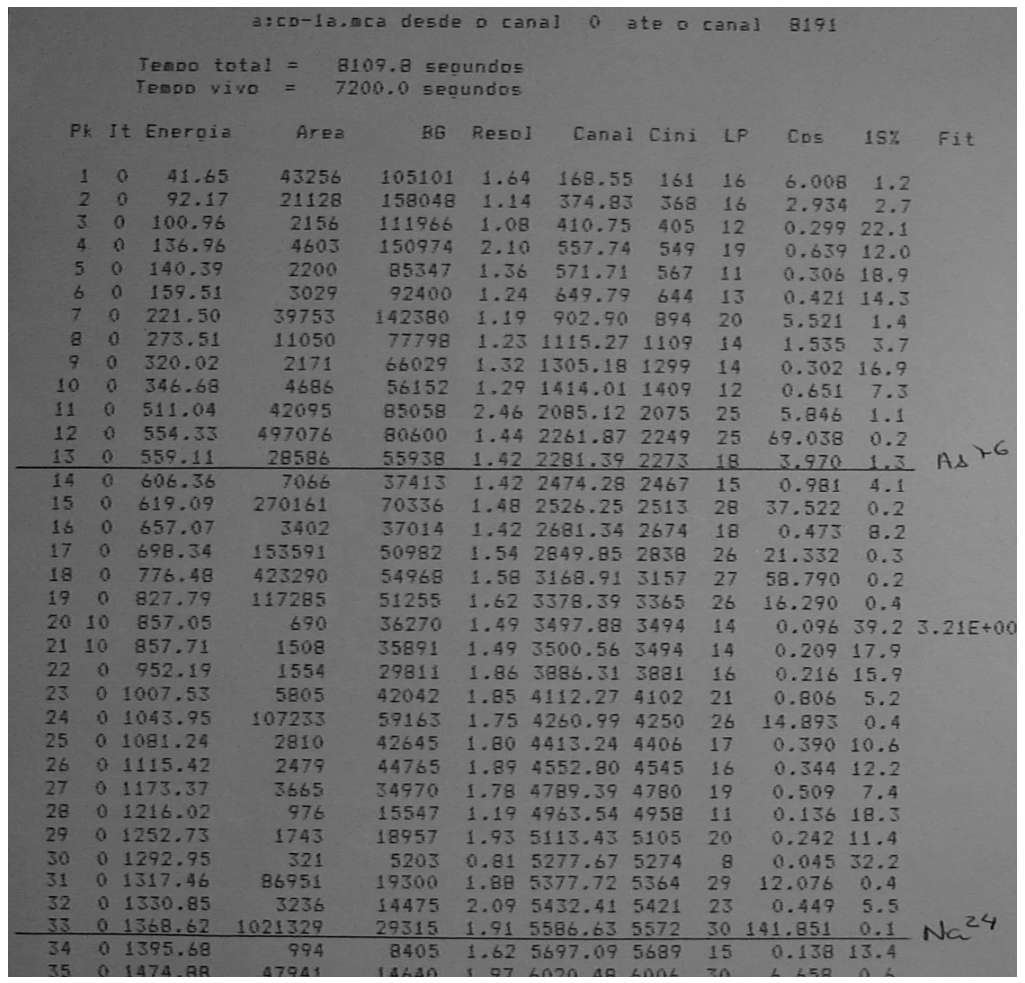

Figura 18 - VISPECT/VERSÃO 2: Relatório impresso dos resultados

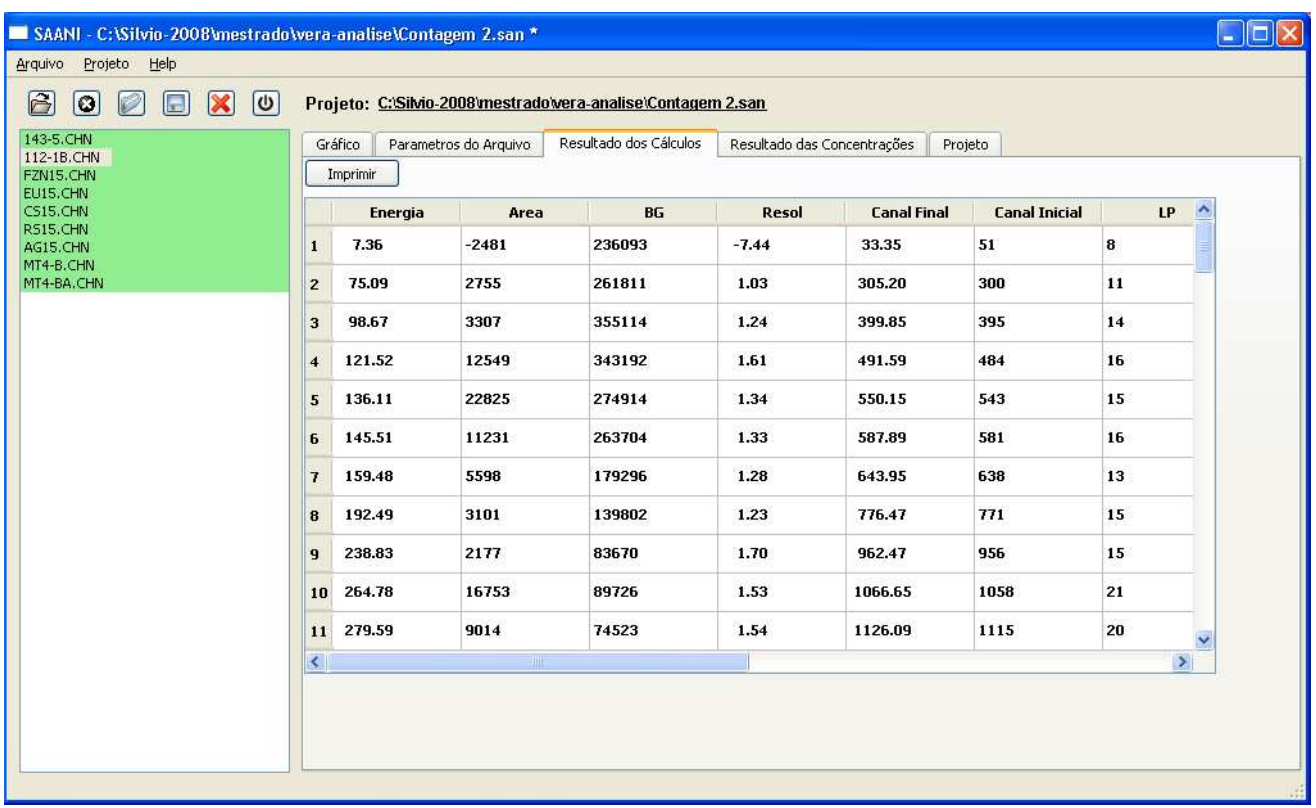

Figura 19 - SAANI: Resultados apresentados no vídeo

O VISPECT/VERSÃO 2 não executa o cálculo das concentrações, só emitindo o relatório impresso com os resultados dos cálculos das áreas, atividades e outras informações, conforme já relatado anteriormente. Há a necessidade de executar outro software ou utilizar uma planilha com as fórmulas para execução dos cálculos das concentrações. 


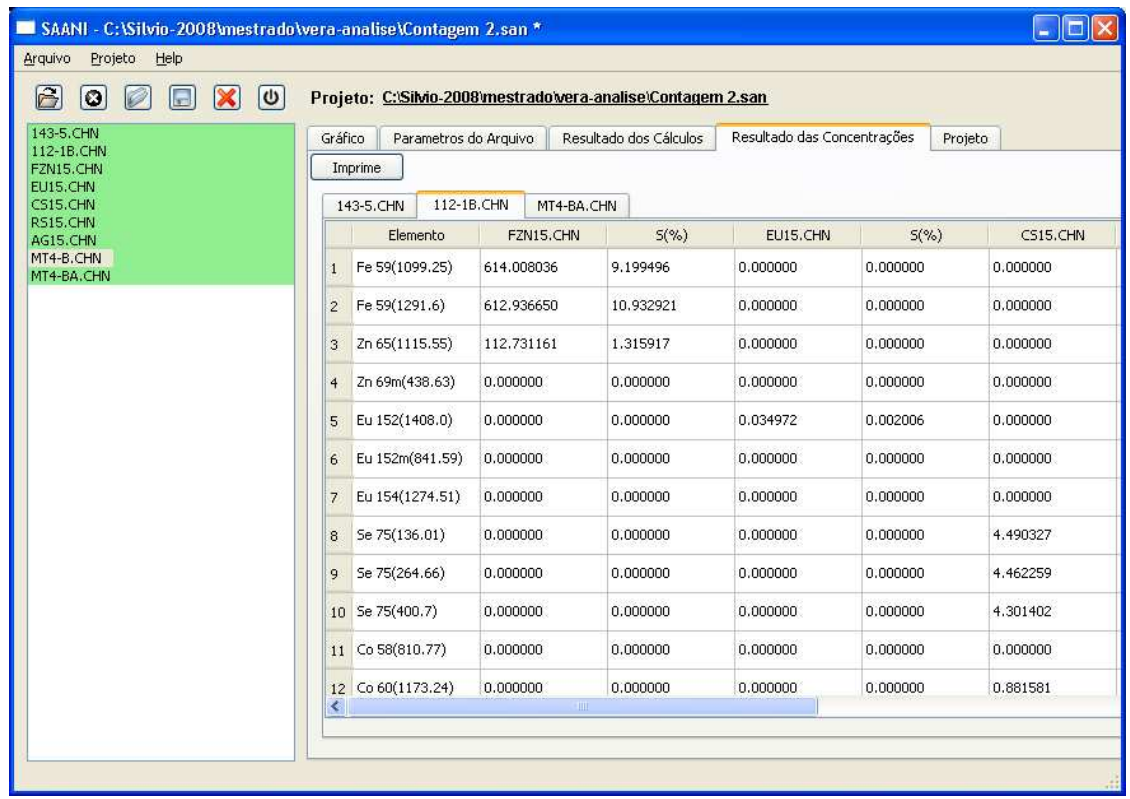

Figura 20 - SAANI: Resultados das concentrações apresentados no vídeo

O novo software elimina a entrada de dados, conforme mostra a Figura 20, recupera automaticamente os resultados e efetua o cálculo de todo o processo dentro do mesmo software SAANI. O usuário irá montar o projeto, inserir os arquivos de espectros, efetuar as configurações e o aplicativo resolve os cálculos das concentrações, através do clique na aba "Resultado Concentrações". 


\section{2 - Resultados Obtidos}

Para a análise dos dados dos espectros, o software SAANI utiliza uma série de rotinas para localizar e quantificar os picos, calcular os resultados como energia dos picos, área líquida, área do BG, resolução em energia, canal da mediana, canal inicial, largura do pico em número de canais, atividades em contagens/segundos, desvio padrão da atividade em porcentagem.

Para a determinação da concentração dos elementos presentes nas matrizes de interesse (resultados dos cálculos dos espectros) utiliza-se a análise por ativação comparativa, que é o procedimento empregado no Laboratório de Análise por Ativação Neutrônica -LAN-IPEN para a análise dos materiais (amostras).

Nesse método, padrões contendo conhecidas quantidades de elementos de interesse são submetidos ao fluxo de nêutrons juntos com as amostras e as atividades induzidas são medidas nas mesmas condições.

Como cada radioisótopo tem suas próprias características de meia-vida e energia (ou energias) de raios gama, é possível, em geral, identificar os isótopos dos elementos. A quantidade desse elemento na amostra é considerada como diretamente proporcional a taxa de contagens de raios gama.

Sendo, amostra e padrões irradiados juntos sob as mesmas condições de tempo de irradiação e fluxo de nêutrons, a concentração de um elemento particular de interesse é obtida comparando-se as taxas de contagens dos espectros de amostra e padrão.

Para apurar os resultados foram utilizados espectros reais que foram cedidos pelos usuários do LAN-IPEN, para efeito de comparação e validação dos resultados.

\subsection{1 - Resultados do processamento dos espectros}

Após o processamento dos espectros no sistema de contagem são gerados os arquivos contendo contagens por canais. 
Para efeito de comparação e validação dos cálculos efetuados pelo novo software SAANI, foram processados os espectros no software VISPECT/VERSÃO 2, que gerou os resultados impressos de cada espectro e os mesmos espectros foram processados no SAANI.

Após coleta dos resultados nos dois softwares foi feita a comparação entre os resultados obtidos. Nas Tabelas 12 e 13 são apresentados os resultados do processamento do espectro de uma amostra denominada "112-1B.CHN" e do espectro de um padrão denominado "MT4-B.CHN". Os dois arquivos foram escolhidos por apresentar uma boa quantidade de elementos para a comparação, mostrando as áreas e as atividades que foram calculadas pelos dois softwares.

Tabela 12 - Comparação do espectro: 112-1B.CHN

\begin{tabular}{|c|c|c|c|c|c|c|}
\hline \multirow{3}{*}{$\begin{array}{l}\text { Amostra:112-1B } \\
\text { Elementos }\end{array}$} & \multicolumn{3}{|c|}{ Área } & \multicolumn{3}{|c|}{ Atividade (CPS) } \\
\hline & Vispect/ & SAANI & Dif. & Vispect/ & SAANI & Dif. \\
\hline & Versão 2 & & $(\%)$ & Versão 2 & & $(\%)$ \\
\hline Eu-152(121,8) & 12549 & 12549 & $0,00 \%$ & 0,349 & 0,349 & $0,00 \%$ \\
\hline Se-75 $(136,01)$ & 22825 & 22825 & $0,00 \%$ & 0,634 & 0,634 & $0,00 \%$ \\
\hline Sc-47 $(159,4)$ & 5598 & 5598 & $0,00 \%$ & 0,156 & 0,156 & $0,00 \%$ \\
\hline Se-75 $(264,66)$ & 16753 & 16753 & $0,00 \%$ & 0,465 & 0,465 & $0,00 \%$ \\
\hline Cr-51 $(320,08)$ & 3357 & 3357 & $0,00 \%$ & 0,093 & 0,093 & $0,00 \%$ \\
\hline Eu-152(344,3) & 3001 & 3001 & $0,00 \%$ & 0,083 & 0,083 & $0,00 \%$ \\
\hline Se-75 $(400,7)$ & 4328 & 4520 & $4,25 \%$ & 0,120 & 0,126 & $4,76 \%$ \\
\hline Cs-134(604,7) & 1501 & 1501 & $0,00 \%$ & 0,042 & 0,042 & $0,00 \%$ \\
\hline $\mathrm{Ag}-110 \mathrm{~m}(657,76)$ & 8501 & 8501 & $0,00 \%$ & 0,236 & 0,236 & $0,00 \%$ \\
\hline Cs-134(795,85) & 1710 & 1710 & $0,00 \%$ & 0,047 & 0,048 & $2,08 \%$ \\
\hline Sc-46(889,28) & 51601 & 51415 & $0,36 \%$ & 1,433 & 1,428 & $0,35 \%$ \\
\hline Rb-86(1076,6) & 2007 & 2007 & $0,00 \%$ & 0,056 & 0,056 & $0,00 \%$ \\
\hline $\mathrm{Fe}-59(1099,25)$ & 15677 & 15677 & $0,00 \%$ & 0,435 & 0,435 & $0,00 \%$ \\
\hline Zn-65(1115,55) & 52100 & 52106 & $0,01 \%$ & 1,447 & 1,447 & $0,00 \%$ \\
\hline Sc-46 $(1120,5)$ & 43631 & 43560 & $0,16 \%$ & 1,212 & 1,210 & $0,17 \%$ \\
\hline Co-60(1173,24) & 9883 & 9883 & $0,00 \%$ & 0,275 & 0,275 & $0,00 \%$ \\
\hline $\mathrm{Fe}-59(1291,6)$ & 10357 & 10357 & $0,00 \%$ & 0,288 & 0,288 & $0,00 \%$ \\
\hline Co-60(1332,5) & 9015 & 9015 & $0,00 \%$ & 0,250 & 0,250 & $0,00 \%$ \\
\hline Eu-152(1408,0) & 875 & 875 & $0,00 \%$ & 0,024 & 0,024 & $0,00 \%$ \\
\hline
\end{tabular}


Tabela 13 - Comparação do espectro: MT4-B.CHN

\begin{tabular}{|c|c|c|c|c|c|c|}
\hline \multirow{2}{*}{$\begin{array}{l}\text { Padrão: MT4-B } \\
\text { Elementos }\end{array}$} & \multicolumn{3}{|c|}{ Área } & \multicolumn{3}{|c|}{ Atividade (CPS) } \\
\hline & $\begin{array}{l}\text { Vispect/ } \\
\text { Versão } 2\end{array}$ & SAANI & $\begin{array}{l}\text { Dif. } \\
\text { (\%) }\end{array}$ & $\begin{array}{l}\text { Vispect/ } \\
\text { Versão } 2\end{array}$ & SAANI & $\begin{array}{l}\text { Dif. } \\
\text { (\%) }\end{array}$ \\
\hline Eu-152(121,8) & 3322 & 3322 & $0,00 \%$ & 0,092 & 0,092 & $0,00 \%$ \\
\hline Se-75 $(136,01)$ & 9259 & 9259 & $0,00 \%$ & 0,257 & 0,257 & $0,00 \%$ \\
\hline Sc-47 $(159,4)$ & 10531 & 10531 & $0,00 \%$ & 0,293 & 0,293 & $0,00 \%$ \\
\hline Se-75 $(264,66)$ & 7469 & 7469 & $0,00 \%$ & 0,207 & 0,207 & $0,00 \%$ \\
\hline $\operatorname{Cr}-51(320,08)$ & 1671 & 1671 & $0,00 \%$ & 0,046 & 0,046 & $0,00 \%$ \\
\hline Se-75 $(400,7)$ & 2081 & 2081 & $0,00 \%$ & 0,058 & 0,058 & $0,00 \%$ \\
\hline Cs-134(604,7) & 531 & 531 & $0,00 \%$ & 0,015 & 0,015 & $0,00 \%$ \\
\hline Sc-46(889,28) & 3598 & 3598 & $0,00 \%$ & 0,100 & 0,100 & $0,00 \%$ \\
\hline $\mathrm{Rb}-86(1076,6)$ & 1659 & 1658 & $0,06 \%$ & 0,046 & 0,046 & $0,00 \%$ \\
\hline $\mathrm{Fe}-59(1099,25)$ & 4037 & 4037 & $0,00 \%$ & 0,112 & 0,112 & $0,00 \%$ \\
\hline Zn-65(1115,55) & 60137 & 60135 & $0,00 \%$ & 1,670 & 1,670 & $0,00 \%$ \\
\hline Sc-46 $(1120,5)$ & 3535 & 3535 & $0,00 \%$ & 0,098 & 0,098 & $0,00 \%$ \\
\hline Co-60 $(1173,24)$ & 7405 & 7405 & $0,00 \%$ & 0,206 & 0,206 & $0,00 \%$ \\
\hline $\mathrm{Fe}-59(1291,6)$ & 2838 & 2838 & $0,00 \%$ & 0,079 & 0,079 & $0,00 \%$ \\
\hline Co-60(1332,5) & 6611 & 6611 & $0,00 \%$ & 0,184 & 0,184 & $0,00 \%$ \\
\hline Eu-152(1408,0) & 169 & 169 & $0,00 \%$ & 0,005 & 0,005 & $0,00 \%$ \\
\hline
\end{tabular}

$\mathrm{Na}$ Tabela 12 são comparadas as áreas e as atividades para 19 fotopicos presentes no espectro da amostra "112-1B", sendo que para 15 fotopicos não apresentaram nenhuma diferença e 4 deles apresentaram uma pequena diferença no cálculo da área e da atividade. Esta diferença ocorre devido à precisão do cálculo realizado pelos softwares no algoritmo de busca da região onde estão os picos. Esta é uma diferença percentual muito pequena, que não é relevante, pois a localização das energias é efetuada com sucesso.

$\mathrm{Na}$ Tabela 13 são comparados 16 fotopicos presentes no padrão "MT4B.CHN" e não foram encontradas diferenças significativas em nenhuma área ou atividade.

Os resultados obtidos com o processamento dos espectros nos dois softwares foram excelentes, pois ambos apresentaram resultados satisfatórios, validando as rotinas dos cálculos desenvolvidas no novo software. 


\subsection{2 - Resultados do cálculo das concentrações}

O cálculo de concentrações dos elementos presentes nas amostras pode ser feito através de planilhas do Excel. Este é um dos procedimentos utilizados para este cálculo pelos pesquisadores do LAN-IPEN, conforme mencionado anteriormente. Estas planilhas contêm as fórmulas para os cálculos das concentrações dos elementos. Neste ponto, os usuários através dos relatórios dos resultados dos espectros do software VISPECT/VERSÃO 2 e dos dados referentes as datas das contagens, alimentam as planilhas do Excel para obter os resultados das concentrações.

Os dados foram alimentados na planilha do Excel e comparados com os resultados obtidos pelo novo software SAANI. Na Tabela 14, são mostrados os resultados obtidos através dos dois procedimentos.

Tabela 14 - Comparação das concentrações dos elementos

\begin{tabular}{|c|c|c|c|c|c|c|}
\hline \multicolumn{7}{|c|}{ Amostra: 112-1B } \\
\hline \multirow{2}{*}{$\begin{array}{c}\text { Elementos } \\
\text { Padrão: MT4-B }\end{array}$} & \multicolumn{3}{|c|}{ Concentração $\left(\mathrm{mg} \mathrm{Kg}^{-1}\right)$} & \multicolumn{3}{|c|}{ Desvio Padrão } \\
\hline & Excel & SAANI & Dif. (\%) & $1 \mathrm{~s}(\%)$ & $1 \mathrm{~s}(\%)$ & Dif. (\%) \\
\hline Se-75 $(136,01)$ & 3,92 & 3,92 & $0,00 \%$ & 0,42 & 0,42 & $0,00 \%$ \\
\hline Se-75 $(264,66)$ & 3,57 & 3,56 & $0,28 \%$ & 0,35 & 0,35 & $0,00 \%$ \\
\hline $\operatorname{Cr}-51(320,08)$ & 0,88 & 0,87 & $1,15 \%$ & 0,31 & 0,31 & $0,00 \%$ \\
\hline Se-75 $(400,7)$ & 3,29 & 3,45 & $4,64 \%$ & 0,44 & 0,46 & $4,35 \%$ \\
\hline Sc-46 $(889,28)$ & 0,18 & 0,18 & $0,00 \%$ & 0,01 & 0,01 & $0,00 \%$ \\
\hline $\mathrm{Rb}-86(1076,6)$ & 4,33 & 4,30 & $0,70 \%$ & 0,28 & 0,28 & $0,00 \%$ \\
\hline Fe-59(1099,25) & 581,00 & 581,07 & $0,01 \%$ & 21,78 & 21,66 & $0,55 \%$ \\
\hline Zn-65(1115,55) & 105,00 & 105,01 & $0,01 \%$ & 9,99 & 9,96 & $0,30 \%$ \\
\hline Co-60 $(1173,24)$ & 0,72 & 0,72 & $0,00 \%$ & 0,03 & 0,03 & $0,00 \%$ \\
\hline Fe-59(1291,6) & 545,43 & 546,00 & $0,10 \%$ & 20,92 & 20,87 & $0,24 \%$ \\
\hline Co-60(1332,5) & 0,74 & 0,74 & $0,00 \%$ & 0,03 & 0,03 & $0,00 \%$ \\
\hline Eu-152(1408,0) & 0,01 & 0,01 & $0,00 \%$ & 0,00 & 0,00 & $0,00 \%$ \\
\hline
\end{tabular}

Comparando os resultados da amostra obtidos pelo SAANI e pelos cálculos no programa Excel, observa-se que foram localizados 12 fotopicos em comum 
entre estes espectros. Houve uma maior variação da concentração no elemento Se-75 na energia de 400,7keV, que teve sua área e atividade com diferença na precisão do cálculo dos resultados do espectro. As demais concentrações ficaram abaixo de $1,15 \%$ de diferença.

$\mathrm{Na}$ comparação dos resultados das concentrações, verificou-se que os resultados foram satisfatórios nos dois processos de cálculos, validando os cálculos do novo software SAANI. 


\section{CAPÍTULO 7 - CONCLUSÕES}

A proposta deste trabalho foi criar um software livre para as análises que são realizadas pelo Laboratório de Análise por Ativação com Nêutrons (LAN) do Instituto de Pesquisas Energéticas e Nucleares (IPEN).

Para o desenvolvimento do software foi realizado um levantamento de todos os processos e softwares que envolvem a AAN e foi elaborado um projeto utilizando diversas metodologias durante o seu desenvolvimento.

A implantação deste software propicia um crescimento de produtividade, padronização dos procedimentos e uma interface gráfica amigável para os usuários do LAN-IPEN.

O objetivo inicialmente proposto foi alcançado, agregando os dois processos: a obtenção dos resultados do software VISPECT/VERSÃO 2 e os cálculos das concentrações em um só software.

Para efeito de validação dos resultados foram executados vários testes, nos quais os resultados gerados pelo novo software SAANI foram comparados com os resultados e procedimentos atualmente utilizados no LAN-IPEN, comprovando assim as rotinas de cálculos implementadas no novo software SAANI, bem como a interface gráfica.

Este trabalho ainda poderá ser explorado, tornando-se base para novas implementações ou extensões de métodos matemáticos e estatísticos, execução em ambiente de rede, através de interface WEB ou modelo Cliente/Servidor, entre outras melhorias que possam surgir, pois toda a documentação e programas fontes desenvolvidos estarão disponíveis para este fim. 
ANEXOS 


\title{
Anexo A - Listagem do software SAANI: espectro MT4-B.CHN
}

\author{
Resultados Arquivo: MT4-B,CHN - Padrão qua, 16/jul/08
}

Tempo Total: 36398,46 seg, Massa: 1 Data contagem: 18/6/2008 16:25:00

Tempo Vivo : $36000 \mathrm{seg}$,

\begin{tabular}{|c|c|c|c|c|c|c|c|c|}
\hline Energia & Area & BG & Resol, & Can, Final & Can, Inic & LP & CPS & $1 S\left(\frac{\circ}{0}\right)$ \\
\hline 5,20 & -1028 & 133861 & $-11,20$ & 24,67 & 51,00 & 8 & 0,0286 & $-50,2$ \\
\hline 72,33 & 1390 & 164368 & 1,44 & 294,16 & 287 & 13 & 0,0386 & 41,3 \\
\hline 75,00 & 3221 & 144370 & 1,18 & 304,84 & 299 & 11 & 0,0895 & 16,8 \\
\hline 121,26 & 3322 & 189293 & 1,57 & 490,55 & 484 & 16 & 0,0923 & 18,6 \\
\hline 136,10 & 9259 & 142051 & 1,35 & 550,11 & 544 & 14 & 0,2572 & 5,8 \\
\hline 144,72 & 71 & 18341 & 0,10 & 584,73 & 585 & 2 & 0,0020 & 268,8 \\
\hline 145,83 & 1809 & 98842 & 1,58 & 589,17 & 586 & 11 & 0,0502 & 24,7 \\
\hline 159,51 & 10531 & 122408 & 1,29 & 644,09 & 637 & 16 & 0,2925 & 4,8 \\
\hline 238,72 & 1641 & 37380 & 1,30 & 962,02 & 956 & 12 & 0,0456 & 16,8 \\
\hline 264,78 & 7469 & 44394 & 1,52 & 1066,62 & 1058 & 19 & 0,2075 & 4,2 \\
\hline 279,64 & 4022 & 37095 & 1,61 & 1126,27 & 1117 & 18 & 0,1117 & 7,0 \\
\hline 300,59 & 386 & 15342 & 0,84 & 1210,39 & 1206 & 9 & 0,0107 & 45,7 \\
\hline 320,13 & 1671 & 21715 & 1,62 & 1288,81 & 1281 & 15 & 0,0464 & 12,7 \\
\hline 338,48 & 667 & 15034 & 1,93 & 1362,45 & 1358 & 12 & 0,0185 & 26,3 \\
\hline 352,00 & 1083 & 15629 & 1,39 & 1416,74 & 1409 & 14 & 0,0301 & 16,6 \\
\hline 400,74 & 2081 & 15324 & 1,67 & 1612,36 & 1604 & 19 & 0,0578 & 8,7 \\
\hline 411,71 & 630 & 8323 & 1,60 & 1656,40 & 1652 & 11 & 0,0175 & 20,9 \\
\hline 511,01 & 6428 & 7274 & 1,32 & 2055,00 & 2041 & 35 & 0,1785 & 2,3 \\
\hline 514,00 & 3311 & 6982 & 1,32 & 2067,00 & 2041 & 35 & 0,0920 & 4,0 \\
\hline 554,54 & 3176 & 6378 & 1,60 & 2229,74 & 2222 & 17 & 0,0882 & 4,0 \\
\hline 583,40 & 1546 & 6365 & 1,65 & 2345,56 & 2337 & 19 & 0,0429 & 7,7 \\
\hline 604,44 & 531 & 5982 & 1,68 & 2430,04 & 2425 & 19 & 0,0148 & 21,0 \\
\hline 609,52 & 1594 & 5295 & 1,72 & 2450,41 & 2443 & 18 & 0,0443 & 6,9 \\
\hline 619,39 & 1801 & 4637 & 1,62 & 2490,03 & 2482 & 16 & 0,0500 & 5,8 \\
\hline 626,70 & 179 & 2813 & 1,43 & 2519,38 & 2515 & 10 & 0,0050 & 42,6 \\
\hline 698,73 & 753 & 4276 & 1,35 & 2808,49 & 2801 & 17 & 0,0209 & 12,8 \\
\hline 727,49 & 253 & 2569 & 0,98 & 2923,95 & 2919 & 11 & 0,0070 & 29,1 \\
\hline 756,53 & 162 & 2786 & 0,85 & 3040,50 & 3036 & 13 & 0,0045 & 46,8 \\
\hline 776,79 & 2709 & 4088 & 1,72 & 3121,86 & 3113 & 19 & 0,0752 & 3,9 \\
\hline 828,13 & 748 & 4148 & 2,01 & 3327,91 & 3319 & 19 & 0,0208 & 12,7 \\
\hline 860,84 & 254 & 2534 & 1,63 & 3459,21 & 3454 & 11 & 0,0071 & 28,7 \\
\hline 889,59 & 3598 & 5047 & 1,79 & 3574,62 & 3566 & 21 & 0,0999 & 3,3 \\
\hline 911,58 & 1806 & 3983 & 1,83 & 3662,90 & 3654 & 21 & 0,0502 & 5,5 \\
\hline 965,26 & 152 & 1876 & 0,79 & 3878,36 & 3873 & 12 & 0,0042 & 41,1 \\
\hline 969,46 & 1179 & 2653 & 1,75 & 3895,21 & 3888 & 21 & 0,0328 & 6,8 \\
\hline 1044,40 & 719 & 1503 & 1,77 & 4196,03 & 4187 & 18 & 0,0200 & 8,5 \\
\hline 1077,23 & 1658 & 1761 & 1,82 & 4327,79 & 4317 & 21 & 0,0461 & 4,3 \\
\hline 1090,57 & 96 & 623 & 0,74 & 4381,37 & 4378 & 9 & 0,0027 & 38,3 \\
\hline 1099,67 & 4037 & 1852 & 1,83 & 4417,88 & 4407 & 23 & 0,1121 & 2,2 \\
\hline 1115,89 & 60135 & 1817 & 1,93 & 4483,00 & 4469 & 47 & 1,6704 & 0,0 \\
\hline 1120,88 & 3535 & 1448 & 1,84 & 4503,00 & 4469 & 47 & 0,0982 & 0,0 \\
\hline 1173,66 & 7405 & 1202 & 1,95 & 4714,87 & 4700 & 27 & 0,2057 & 1,3 \\
\hline 1201,98 & 82 & 427 & 0,88 & 4828,53 & 4824 & 11 & 0,0023 & 37,4 \\
\hline
\end{tabular}




\begin{tabular}{|c|c|c|c|c|c|c|c|c|}
\hline 1238,54 & 288 & 669 & 1,77 & 4975,32 & 4969 & 17 & 0,0080 & 14,0 \\
\hline 1280,67 & 38 & 305 & 1,35 & 5144,41 & 5140 & 8 & 0,0010 & 67,6 \\
\hline 1291,92 & 2838 & 656 & 2,10 & 5189,56 & 5178 & 24 & 0,0788 & 2,3 \\
\hline 1297,40 & 867 & 605 & 2,19 & 5211,58 & 5201 & 21 & 0,0241 & 5,3 \\
\hline 1318,11 & 682 & 616 & 2,03 & 5294,72 & 5284 & 21 & 0,0189 & 6,4 \\
\hline 1333,00 & 6611 & 743 & 2,06 & 5354,48 & 5342 & 27 & 0,1836 & 1,4 \\
\hline 1378,15 & 119 & 394 & 1,57 & 5535,69 & 5529 & 13 & 0,0033 & 25,4 \\
\hline 1402,27 & 50 & 282 & 0,81 & 5632,51 & 5628 & 11 & 0,0014 & 49,9 \\
\hline 1408,72 & 169 & 390 & 1,70 & 5658,41 & 5652 & 15 & 0,0047 & 18,2 \\
\hline 1432,46 & 23 & 170 & 1,67 & 5753,69 & 5750 & 7 & 0,0006 & 84,1 \\
\hline 1461,39 & 2176 & 549 & 2,17 & 5869,83 & 5855 & 27 & 0,0604 & 2,6 \\
\hline 1475,33 & 291 & 390 & 2,09 & 5925,78 & 5917 & 18 & 0,0081 & 11,2 \\
\hline 1496,42 & 16 & 170 & 0,73 & 6010,42 & 6008 & 6 & 0,0004 & 117,9 \\
\hline 1501,56 & 30 & 201 & 0,68 & 6031,06 & 6027 & 9 & 0,0008 & 69,3 \\
\hline 1509,54 & 135 & 339 & 1,81 & 6063,09 & 6054 & 16 & 0,0038 & 21,1 \\
\hline 1516,37 & 67 & 174 & 1,16 & 6090,51 & 6086 & 11 & 0,0019 & 30,5 \\
\hline 1588,87 & 370 & 340 & 1,92 & 6381,51 & 6373 & 17 & 0,0103 & 8,8 \\
\hline 1593,00 & 424 & 509 & 2,22 & 6398,11 & 6389 & 19 & 0,0118 & 9,0 \\
\hline 1621,64 & 166 & 243 & 1,60 & 6513,09 & 6507 & 14 & 0,0046 & 15,3 \\
\hline 1638,84 & 42 & 187 & 1,32 & 6582,12 & 6577 & 11 & 0,0012 & 48,6 \\
\hline 1661,52 & 15 & 173 & 0,24 & 6673,14 & 6669 & 9 & 0,0004 & 130,8 \\
\hline 1730,14 & 223 & 222 & 2,50 & 6948,59 & 6941 & 18 & 0,0062 & 11,6 \\
\hline 1758,82 & 45 & 81 & 0,85 & 7063,73 & 7060 & 8 & 0,0012 & 32,2 \\
\hline 1765,32 & 1040 & 357 & 2,19 & 7089,81 & 7079 & 23 & 0,0289 & 4,0 \\
\hline 1848,37 & 136 & 190 & 1,96 & 7423,17 & 7416 & 15 & 0,0038 & 16,7 \\
\hline 1871,76 & 10 & 59 & 0,84 & 7517,03 & 7515 & 5 & 0,0003 & 115,1 \\
\hline 1872,94 & 49 & 100 & 1,08 & 7521,78 & 7519 & 8 & 0,0014 & 32,4 \\
\hline 1994,89 & 518 & 795 & 2,03 & 8011,27 & 8004 & 16 & 0,0144 & 8,9 \\
\hline
\end{tabular}




\section{Anexo B - Listagem do software VISPECT/VERSAO 2: espectro MT4- B.CHN}

\begin{tabular}{|c|c|c|c|c|c|c|c|c|c|c|}
\hline \multicolumn{2}{|c|}{$\begin{array}{l}\text { Tempo } \\
\text { Tempo }\end{array}$} & \multirow{2}{*}{ 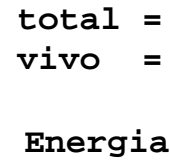 } & \multirow{2}{*}{$\begin{array}{c}36398.5 \\
36000.0 \\
\text { Área }\end{array}$} & \multicolumn{2}{|c|}{$\begin{array}{ll}5 & \text { segundos } \\
0 & \text { segundos }\end{array}$} & \multirow[b]{2}{*}{ Canal } & \multirow[b]{2}{*}{ Cini } & \multirow[b]{2}{*}{ LP } & \multirow[b]{2}{*}{ Cps } & \multirow[b]{2}{*}{$15 \%$} \\
\hline $\mathbf{P k}$ & It & & & BG & Resol & & & & & \\
\hline 1 & 0 & 17,55 & -296 & 133129 & 10,30 & 74,25 & 51 & 8 & $-0,008$ & $-174,0$ \\
\hline 2 & 0 & 13,09 & -942 & 243607 & $-0,50$ & 56,34 & 58 & 17 & $-0,026$ & $-74,0$ \\
\hline 3 & 0 & 72,79 & 1390 & 16 & 58 & 295 & 7 & 13 & 0,039 & 1,3 \\
\hline 4 & 0 & 75,00 & 3221 & 14 & 8 & 30 & & 11 & 9 & 6,8 \\
\hline 5 & 0 & 121,26 & 3322 & 18 & 1,57 & 49 & 4 & 16 & 92 & 18,6 \\
\hline 6 & 0 & 136,10 & 9259 & 51 & 1,35 & 1 & 4 & 14 & 7 & 5,8 \\
\hline 7 & 0 & 144,79 & 1 & & , & 58 & & 2 & 2 & 268,8 \\
\hline 8 & 0 & 145,83 & 809 & & 1, & 58 & & 11 & & 24,7 \\
\hline 9 & 0 & 159,51 & 10531 & 12 & 1,29 & 64 & 7 & 16 & 3 & 4,8 \\
\hline 10 & 0 & 238,72 & 41 & 80 & 1,30 & 962,02 & & 12 & 6 & 6,8 \\
\hline 11 & 0 & 264,78 & 69 & & 1,52 & 1066,62 & & 19 & ， & 4,2 \\
\hline 12 & 0 & 279,64 & 22 & & 1,61 & 1126,27 & & 18 & , & 7,0 \\
\hline 13 & 0 & 300,59 & 36 & & 0,84 & 1210,39 & 12 & 9 & 0, & 45,7 \\
\hline 14 & 0 & 320,13 & 71 & & 2 & 81 & & 15 & & 2,7 \\
\hline 15 & 0 & 338,48 & 67 & & 1,93 & 1362,45 & & 12 & , & 26,3 \\
\hline 16 & 0 & 352,00 & 33 & & 1,39 & 1416,74 & 14 & 14 & 0, & 16,6 \\
\hline 17 & 0 & 400,74 & 2081 & & 1,67 & 1612,36 & 1 & 19 & 0 , & 8,7 \\
\hline 18 & 0 & 411,71 & & & 0 & 40 & & 11 & & 20,9 \\
\hline 19 & 3 & 511,08 & 54 & 66 & 1,32 & 29 & 2 & 35 & 0 & 2,2 \\
\hline 20 & 3 & 514,04 & 3314 & 78 & 1,32 & 2067,17 & 2041 & 35 & 0, & 4,0 \\
\hline 21 & 0 & 554,54 & 3176 & 78 & 1,60 & 2229,74 & 2222 & 17 & 0, & 4,0 \\
\hline 22 & 0 & 0 & & & & 56 & & 19 & 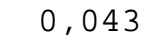 & 7,7 \\
\hline 23 & 0 & 605,02 & 31 & 32 & 2,15 & 36 & & 19 & 0, & 21,0 \\
\hline 24 & 0 & 609,52 & 1594 & 295 & 1,72 & 2450,41 & 2443 & 18 & 0,044 & 6,9 \\
\hline 25 & 0 & 619,39 & 1801 & 4637 & 1,62 & 2490,03 & 2482 & 16 & 0,050 & 5,8 \\
\hline 26 & 0 & 626,70 & & & 3 & 38 & & 10 & 5 & 2,6 \\
\hline 27 & 0 & 8,73 & & & 1,35 & 2808,49 & & 17 & 0, & 12,8 \\
\hline 28 & 0 & 727,49 & 253 & 569 & 0,98 & 2923,95 & 2919 & 11 & 0,007 & 29,1 \\
\hline 29 & 0 & 756,53 & 62 & 786 & 0,85 & 3040,50 & 3036 & 13 & 0,004 & 46,8 \\
\hline 30 & 0 & 76,79 & 109 & & 72 &, 86 & & 19 &, 075 & 3,9 \\
\hline 31 & 0 & 828,13 & 8 & & 2,01 & 3327,91 & & 19 & 0, & 12,7 \\
\hline 32 & 0 & 860,84 & 54 & 534 & 1,63 & 3459,21 & 3454 & 11 & 0,007 & 28,7 \\
\hline 33 & 0 & 889,59 & 3598 & 047 & 1,79 & 3574,62 & 3566 & 21 & 0,100 & 3,3 \\
\hline 34 & 0 & 11,58 & 1806 & 83 & 1,83 & 3662,90 & 4 & 21 & 0,050 & 5,5 \\
\hline 35 & 0 & 965,26 & 2 & & 0,79 & 3878,36 & & 12 & 0,004 & 41,1 \\
\hline 36 & 0 & 969,46 & 1179 & 2653 & 1,75 & 3895,21 & 3888 & 21 & 0,033 & 6,8 \\
\hline 37 & 0 & 1044,40 & 719 & 03 & 1,77 & 4196,03 & 4187 & 18 & 0,020 & 8,5 \\
\hline 38 & 0 & 1077,23 & 659 & 1761 & 1,82 & 4327,79 & 4317 & 21 & 0,046 & 4,3 \\
\hline 39 & 0 & 090,57 & 96 & 623 & 0,74 & 4381,37 & 4378 & 9 & 0,003 & 38,3 \\
\hline 40 & 0 & 1099,67 & 37 & 852 & 1,83 & 4417,88 & 4407 & 23 & 0,112 & 2,2 \\
\hline
\end{tabular}




\begin{tabular}{|c|c|c|c|c|c|c|c|c|c|}
\hline 41 & 41115,96 & 60137 & 1802 & 1,92 & 4483,28 & 4469 & 47 & 1,670 & 0,4 \\
\hline 42 & 41120,93 & 3535 & 1441 & 1,83 & 4503,21 & 4469 & 47 & 0,098 & 2,3 \\
\hline & 01173,66 & 7405 & 202 & 1,95 & 4714,87 & 4700 & 27 &, 206 & 1,3 \\
\hline 4 & $0 \quad 1201,98$ & 82 & 427 & 0,88 & 4828,53 & 4824 & 11 & 0,002 & 37,4 \\
\hline & 01238,54 & 288 & 669 & 1,77 & 4975,32 & 4969 & 17 & 0,008 & 14,0 \\
\hline & 01280,67 & 38 & 305 & 1,35 & 5144,41 & 5140 & 8 & 0,001 & 67,6 \\
\hline & $0 \quad 1292,11$ & 2838 & 656 & 2,15 & 190,35 & 5178 & 24 & 0,079 & 2,3 \\
\hline & $0 \quad 1297,40$ & 867 & 605 & 2,19 & 5211,58 & 5201 & 21 & 0,024 & 5,3 \\
\hline & 01318,11 & 682 & 616 & 2,02 & 5294,72 & 5284 & 21 & 0,019 & 6,4 \\
\hline & 01333,00 & 6611 & 743 & 2,06 & 5354,48 & 5342 & 27 & 0,184 & 1,4 \\
\hline & 01378,15 & 119 & 394 & 1,57 & 5535,69 & 5529 & 13 & 0,003 & 25,4 \\
\hline & $0 \quad 1402,27$ & 50 & 282 & 0,81 & 5632,51 & 5628 & 11 & 0, & 49,9 \\
\hline 3 & 01408,72 & 169 & 390 & 1,70 & 5658,41 & 5652 & 15 & 0,005 & 18,2 \\
\hline & 1432,46 & 23 & 170 & 1,67 & 5753,69 & 5750 & 7 & 0 , & 84,1 \\
\hline & 01461,39 & 2176 & 549 & 2,17 & 5869,83 & 5855 & 27 & 0,060 & 2,6 \\
\hline & 01475,33 & 291 & 390 & 2,09 & 5925,78 & 5917 & 18 & 0,008 & 11,2 \\
\hline & 01496,42 & 16 & 170 & 0,73 & 6010,42 & 6008 & 6 & 0,000 & 117,9 \\
\hline 8 & 1501,56 & 30 & 201 & 0,68 & 6031,06 & 6027 & 9 & & 69,3 \\
\hline 9 & 01509,54 & 135 & 339 & 1,81 & 6063,09 & 6054 & 16 & 0,004 & 21,1 \\
\hline 6 & $0 \quad 1516,37$ & 67 & 174 & 1,16 & 6090,51 & 6086 & 11 & 0,002 & 30,5 \\
\hline & 1588,88 & 370 & 340 & 1,95 & 6381,56 & 6373 & 17 & 0,010 & 8,8 \\
\hline & 1593,00 & 424 & 509 & 2,22 & 6398,11 & 6389 & 19 & 0,012 & 9,0 \\
\hline & 01621,64 & 166 & 243 & 1,60 & 6513,09 & 6507 & 14 & 0,005 & 15,3 \\
\hline & 01638,84 & 42 & 187 & 1,32 & 6582,12 & 6577 & 11 & 0,001 & 48,6 \\
\hline 6 & 01661,52 & 15 & 173 & 0,24 & 6673,14 & 6669 & 9 & 0,000 & 130,8 \\
\hline 6 & 1730,14 & 223 & 222 & 2,50 & 6948,59 & 6941 & 18 & 0,006 & 11,6 \\
\hline & 01758,82 & 45 & 81 & 0,85 & 7063,73 & 7060 & 8 & 0,001 & 32,2 \\
\hline & 01765,32 & 1040 & 357 & 2,19 & 7089,81 & 7079 & 23 & 0,029 & 4,0 \\
\hline 69 & 01848,37 & 136 & 190 & 1,96 & 7423,17 & 7416 & 15 & 0,004 & 16,7 \\
\hline & 01871,94 & 10 & 59 & 0,57 & 7517,75 & 7515 & 5 & 0,000 & 115,1 \\
\hline & $0 \quad 1872,94$ & 49 & 100 & 1,08 & 7521,78 & 7519 & 8 & 0,001 & 32,4 \\
\hline & 01994,89 & 518 & 795 & 2,03 & 8011,27 & 8004 & 16 & 0,014 & 8,9 \\
\hline
\end{tabular}




\title{
Anexo C - Listagem do software SAANI: espectro 112-1B.CHN
}

\author{
Resultados Arquivo: 112-1B, CHN - Padrão qua, 16/jul/08
}

Tempo Total: 36716,86 seg, Massa: 0,14848 Data contagem: 17/6/2008 19:41:00 Tempo Vivo : $36000 \mathrm{seg}$, Nível sensibilidade: 15

\begin{tabular}{|c|c|c|c|c|c|c|c|c|c|}
\hline Seq, & Energia & Area & BG & Resol, & Can, Final & $\begin{array}{r}\text { Can, I } \\
\text { nic }\end{array}$ & LP & CPS & $15\left(\frac{\circ}{\circ}\right)$ \\
\hline 1 & 7,36 & -2481 & 236093 & $-7,44$ & 33,35 & 51 & 8 & $-0,0689$ & $-27,6$ \\
\hline 2 & 75,09 & 2755 & 261811 & 1,03 & 305,20 & 300 & 11 & 0,0765 & 26,3 \\
\hline 3 & 98,67 & 3307 & 355115 & 1,24 & 399,85 & 395 & 14 & 0,0919 & 25,5 \\
\hline 4 & 121,52 & 12549 & 343192 & 1,61 & 491,59 & 484 & 16 & 0,3486 & 6,7 \\
\hline 5 & 136,11 & 22825 & 274915 & 1,34 & 550,15 & 543 & 15 & 0,6340 & 3,3 \\
\hline 6 & 145,51 & 11231 & 263704 & 1,33 & 587,89 & 581 & 16 & 0,3120 & 6,5 \\
\hline 7 & 159,48 & 5598 & 179296 & 1,28 & 643,95 & 638 & 13 & 0,1555 & 10,8 \\
\hline 8 & 192,49 & 3101 & 139803 & 1,23 & 776,47 & 771 & 15 & 0,0862 & 17,1 \\
\hline 9 & 238,83 & 2177 & 83670 & 1,70 & 962,47 & 956 & 15 & 0,0605 & 18,9 \\
\hline 10 & 264,78 & 16753 & 89726 & 1,53 & 1066,65 & 1058 & 21 & 0,4654 & 2,6 \\
\hline 11 & 279,59 & 9015 & 74523 & 1,54 & 1126,09 & 1115 & 20 & 0,2504 & 4,4 \\
\hline 12 & 299,91 & 2851 & 56367 & 2,56 & 1207,65 & 1199 & 18 & 0,0792 & 11,9 \\
\hline 13 & 312,03 & 10116 & 61538 & 1,58 & 1256,28 & 1245 & 22 & 0,2810 & 3,6 \\
\hline 14 & 320,22 & 3357 & 40028 & 1,53 & 1289,18 & 1282 & 15 & 0,0932 & 8,6 \\
\hline 15 & 340,50 & 586 & 18303 & 0,86 & 1370,58 & 1367 & 8 & 0,0163 & 32,9 \\
\hline 16 & 344,41 & 3001 & 37278 & 1,62 & 1386,28 & 1379 & 17 & 0,0834 & 9,3 \\
\hline 17 & 351,78 & 242 & 16823 & 0,77 & 1415,87 & 1413 & 8 & 0,0067 & 76,0 \\
\hline 18 & 400,56 & 4520 & 30908 & 1,56 & 1611,66 & 1604 & 21 & 0,1255 & 5,7 \\
\hline 19 & 404,39 & 480 & 13918 & 1,45 & 1627,04 & 1624 & 10 & 0,0133 & 35,1 \\
\hline 20 & 447,06 & 322 & 12478 & 0,92 & 1798,32 & 1794 & 11 & 0,0090 & 49,3 \\
\hline 21 & 482,37 & 1308 & 13960 & 1,55 & 1940,04 & 1932 & 15 & 0,0363 & 13,1 \\
\hline 22 & 497,61 & 318 & 7893 & 0,84 & 2001,21 & 1997 & 9 & 0,0088 & 39,9 \\
\hline 23 & 510,99 & 6961 & 22960 & 2,46 & 2054,93 & 2042 & 24 & 0,1934 & 3,3 \\
\hline 24 & 554,55 & 4693 & 14410 & 1,66 & 2229,76 & 2219 & 21 & 0,1303 & 3,9 \\
\hline 25 & 569,97 & 546 & 8487 & 1,71 & 2291,68 & 2285 & 13 & 0,0152 & 24,2 \\
\hline 26 & 583,44 & 1454 & 11403 & 1,72 & 2345,72 & 2337 & 18 & 0,0404 & 10,7 \\
\hline 27 & 604,99 & 1501 & 10083 & 1,53 & 2432,25 & 2425 & 16 & 0,0417 & 9,8 \\
\hline 28 & 609,52 & 1110 & 9087 & 1,58 & 2450,41 & 2443 & 15 & 0,0308 & 12,5 \\
\hline 29 & 619,49 & 2569 & 11520 & 1,86 & 2490,45 & 2481 & 20 & 0,0714 & 6,2 \\
\hline 30 & 658,04 & 8501 & 11645 & 1,76 & 2645,17 & 2635 & 21 & 0,2361 & 2,1 \\
\hline 31 & 676,89 & 147 & 3260 & 0,65 & 2720,86 & 2718 & 6 & 0,0041 & 55,5 \\
\hline 32 & 677,90 & 207 & 3370 & 0,50 & 2724,89 & 2723 & 6 & 0,0057 & 40,3 \\
\hline 33 & 687,09 & 570 & 8355 & 1,91 & 2761,79 & 2754 & 16 & 0,0158 & 23,0 \\
\hline 34 & 698,61 & 1327 & 7735 & 2,05 & 2808,04 & 2800 & 17 & 0,0369 & 9,8 \\
\hline 35 & 707,11 & 1448 & 8967 & 1,68 & 2842,16 & 2833 & 20 & 0,0402 & 9,6 \\
\hline 36 & 727,60 & 217 & 3951 & 1,00 & 2924,38 & 2921 & 9 & 0,0060 & 41,5 \\
\hline 37 & 744,92 & 559 & 5845 & 1,89 & 2993,90 & 2987 & 15 & 0,0155 & 19,8 \\
\hline 38 & 764,26 & 2208 & 7517 & 2,08 & 3071,54 & 3062 & 20 & 0,0613 & 5,9 \\
\hline 39 & 776,85 & 3368 & 8393 & 1,78 & 3122,08 & 3111 & 20 & 0,0935 & 4,2 \\
\hline 40 & 796,12 & 1710 & 7676 & 2,10 & 3199,44 & 3188 & 21 & 0,0475 & 7,6 \\
\hline 41 & 802,04 & 38 & 1903 & 1,85 & 3223,18 & 3223 & 5 & 0,0010 & 164,6 \\
\hline 42 & 819,04 & 383 & 5495 & 2,40 & 3291,45 & 3285 & 15 & 0,0106 & 27,8 \\
\hline
\end{tabular}




\begin{tabular}{|c|c|c|c|c|c|c|c|c|c|}
\hline 43 & 828,14 & 1196 & 7213 & 1,97 & 3327,96 & 3318 & 20 & 0,0332 & 10,5 \\
\hline 44 & 861,08 & 172 & 3833 & 0,67 & 3460,17 & 3456 & 10 & 0,0048 & 51,6 \\
\hline 45 & 879,70 & 275 & 4609 & 1,53 & 3534,91 & 3530 & 11 & 0,0076 & 35,4 \\
\hline 6 & 884,95 & 5319 & 9906 & 2,09 & 3556,00 & 3544 & 44 & 0,1478 & 3,0 \\
\hline 47 & 889,44 & 51415 & 9458 & 1,97 & 3574,00 & 3544 & 44 & 1,4282 & 0 , \\
\hline 8 & 911,70 & 1992 & 6261 & 1,83 & 3663,38 & 3653 & 19 & 0,0553 & 6,0 \\
\hline 49 & 937,95 & 2038 & 5467 & 1,84 & 3768,72 & 3759 & 20 & 0,0566 & 5,6 \\
\hline 50 & 969,65 & 908 & 3584 & 1,73 & 3895,96 & 3890 & 16 & 0,0252 & 9,9 \\
\hline 51 & 1044,50 & 851 & 2476 & 2,00 & 4196,42 & 4187 & 17 & 0,0236 & 9， \\
\hline 52 & 1077,32 & 2007 & 2514 & 2,04 & 4328,18 & 4319 & 19 & 0,0557 & 4,2 \\
\hline 53 & 1099,80 & 15677 & 3625 & 2,10 & 4418,39 & 4402 & 30 & 0,4355 & 1,0 \\
\hline 54 & 1115,89 & 52106 & 3693 & 2,22 & 4483,00 & 4466 & 54 & 1,4474 & 0,0 \\
\hline 55 & 1120,88 & 43560 & 2987 & 2,18 & 4503,00 & 4466 & 54 & 1,2100 & 0 ， \\
\hline 56 & 1173,81 & 9883 & 2330 & 2,19 & 4715,48 & 4700 & 30 & 0,2745 & 1,2 \\
\hline 57 & 1221,57 & 123 & 768 & 1,52 & 4907,19 & 4902 & 12 & 0,0034 & 33,1 \\
\hline 58 & 1238,78 & 130 & 908 & 1,14 & 4976,27 & 4969 & 13 & 0,0036 & 33,9 \\
\hline 59 & 1272,41 & 102 & 539 & 1,37 & 5111,26 & 5106 & 11 & 0,0028 & 33, \\
\hline 60 & 1281,87 & 68 & 456 & 0,92 & 5149,21 & 5145 & 9 & 0,0019 & 46,0 \\
\hline 61 & 1292,24 & 10357 & 1515 & 2,32 & 5190,87 & 5176 & 30 & 0,2877 & 1,1 \\
\hline 62 & 1298,16 & 96 & 638 & 1,50 & 5214,63 & 5210 & 10 & 0,0027 & 38,7 \\
\hline 63 & 1318,12 & 952 & 1092 & 2,35 & 5294,73 & 5283 & 26 & 0,0264 & 5, \\
\hline 64 & 1333,18 & 9015 & 1300 & 2,37 & 5355,18 & 5341 & 30 & 0,2504 & 1,2 \\
\hline 65 & 1349,54 & 80 & 335 & 1,12 & 5420,86 & 5417 & 10 & 0,0022 & 34,2 \\
\hline 66 & 1377,41 & 4 & 160 & 0,12 & 5532,73 & 5532 & 3 & 0,0001 & 450,0 \\
\hline 67 & 1378,52 & 111 & 438 & 1,45 & 5537,17 & 5534 & 10 & 0,0031 & 28, \\
\hline 68 & 1384,95 & 1555 & 873 & 2,51 & 5562,97 & 5550 & 27 & 0,0432 & 3,7 \\
\hline 69 & 1408,81 & 875 & 725 & 2,25 & 5658,76 & 5649 & 21 & 0,0243 & 5,5 \\
\hline 70 & 1461,60 & 2154 & 873 & 2,41 & 5870,67 & 5858 & 27 & 0,0598 & 2,9 \\
\hline 71 & 1475,97 & 713 & 700 & 2,72 & 5928,34 & 5917 & 25 & 0,0198 & 6, \\
\hline 72 & 1505,82 & 588 & 755 & 2,44 & 6048,17 & 6038 & 23 & 0,0163 & 7,8 \\
\hline 73 & 1510,85 & 60 & 315 & 0,96 & 6068,36 & 6064 & 10 & 0,0017 & 43,8 \\
\hline 74 & 1543,25 & 124 & 450 & 1,64 & 6198,43 & 6189 & 15 & 0,0034 & 25,8 \\
\hline 75 & 1588,58 & 387 & 500 & 2,54 & 6380,36 & 6369 & 21 & 0,0107 & 9,6 \\
\hline 76 & 1593,34 & 412 & 720 & 2,30 & 6399,48 & 6389 & 20 & 0,0114 & 10,4 \\
\hline 77 & 1621,86 & 89 & 348 & 1,64 & 6513,96 & 6508 & 12 & 0,0025 & 31,5 \\
\hline 78 & 1630,84 & 23 & 578 & 1,94 & 6550,00 & 6543 & 18 & 0,0006 & 151,0 \\
\hline 79 & 1631,59 & 103 & 572 & 1,94 & 6553,00 & 6543 & 18 & 0,0029 & 34,2 \\
\hline 80 & 1662,89 & 19 & 155 & 0,41 & 6678,65 & 6676 & 6 & 0,0005 & 95,5 \\
\hline 81 & 1730,15 & 114 & 397 & 2,12 & 6948,62 & 6939 & 16 & 0,0032 & 26,5 \\
\hline 82 & 1765,55 & 1085 & 490 & 2,58 & 7090,71 & 7078 & 26 & 0,0301 & 4, \\
\hline 83 & 1849,32 & 44 & 203 & 1,21 & 7426,97 & 7423 & 10 & 0,0012 & 48,6 \\
\hline 84 & 1949,61 & 34 & 121 & 1,02 & 7829,53 & 7823 & 11 & 0,0009 & 48,9 \\
\hline 85 & 1994,64 & 484 & 847 & 1,65 & 8010,29 & 8005 & 14 & 0,0134 & 9, \\
\hline
\end{tabular}




\title{
Anexo D - Listagem do software VISPECT/VERSAO 2: espectro 112- 1B.CHN
}

\author{
112-1b.chn desde 0 canal 0 ate o canal 8191
}

\begin{tabular}{|c|c|c|c|c|c|c|c|c|c|c|}
\hline \multicolumn{5}{|c|}{ Contagem - inicio...: 17JUN08 } & \multicolumn{6}{|l|}{$19: 41$} \\
\hline \multicolumn{2}{|c|}{$\begin{array}{l}\text { Tempo } \\
\text { Tempo }\end{array}$} & $\begin{array}{l}\text { total } \\
\text { vivo }\end{array}$ & $\begin{array}{l}=36398.5 \\
=36000.0 \mathrm{~s}\end{array}$ & $\begin{array}{l}\text { egundos } \\
\text { egundos }\end{array}$ & \multirow[b]{2}{*}{ Resol } & \multirow[b]{2}{*}{ Canal } & \multirow[b]{2}{*}{ Cini } & \multirow[b]{2}{*}{ LP } & \multirow[b]{2}{*}{ Cps } & \multirow[b]{2}{*}{$1 S \%$} \\
\hline $\mathbf{P k}$ & It & Energia & Área & BG & & & & & & \\
\hline 1 & 0 & 7,36 & -2481 & 236093 & $-7,44$ & 33,35 & 51 & 8 & $-27,669$ & \\
\hline 2 & 0 & 75,09 & 2755 & 261811 & 1,03 & 305,20 & 300 & 11 & 0,077 & 26,3 \\
\hline 3 & 0 & 98,67 & 3307 & 355115 & 1,24 & 399,85 & 395 & 14 & 0,092 & 25,5 \\
\hline 4 & 0 & 121,52 & 12549 & 343192 & 1,61 & 491,59 & 484 & 16 & 0,349 & 6,7 \\
\hline 5 & 0 & 136,11 & 22825 & 274915 & 1,34 & 550,15 & 543 & 15 & 0,634 & 3,3 \\
\hline 6 & 0 & 145,51 & 11231 & 263704 & 1,33 & 587,89 & 581 & 16 & 0,312 & 6,5 \\
\hline 7 & 0 & 159,48 & 5598 & 179296 & 1,28 & 643,95 & 638 & 13 & 0,156 & 10,8 \\
\hline 8 & 0 & 192,49 & 3102 & 139803 & 1,23 & 776,47 & 771 & 15 & 0,086 & 17,1 \\
\hline 9 & 0 & 238,83 & 2177 & 83670 & 1,70 & 962,47 & 956 & 15 & 0,060 & 18,9 \\
\hline 10 & 0 & 264,78 & 16753 & 89726 & 1,53 & 1066,65 & 1058 & 21 & 0,465 & 2,6 \\
\hline 11 & 0 & 279,59 & 9015 & 74523 & 1,54 & 1126,09 & 1115 & 20 & 0,250 & 4,4 \\
\hline 12 & 0 & 299,91 & 2851 & 56367 & 2,56 & 1207,65 & 1199 & 18 & 0,079 & 11,9 \\
\hline 13 & 0 & 312,03 & 10116 & 61538 & 1,58 & 1256,28 & 1245 & 22 & 0,281 & 3,6 \\
\hline 14 & 0 & 320,22 & 3357 & 40028 & 1,53 & 1289,18 & 1282 & 15 & 0,093 & 8,6 \\
\hline 15 & 0 & 340,50 & 586 & 18303 & 0,86 & 1370,58 & 1367 & 8 & 0,016 & 32,9 \\
\hline 16 & 0 & 344,41 & 3001 & 37278 & 1,62 & 1386,28 & 1379 & 17 & 0,083 & 9,3 \\
\hline 17 & 0 & 351,78 & 242 & 16823 & 0,77 & 1415,87 & 1413 & 8 & 0,007 & 76,0 \\
\hline 18 & 0 & 400,76 & 4328 & 29697 & 1,58 & 1612,44 & 1604 & 20 & 0,120 & 5,8 \\
\hline 19 & 0 & 447,06 & 322 & 12478 & 0,92 & 1798,32 & 1794 & 11 & 0,009 & 49,3 \\
\hline 20 & 0 & 482,37 & 1308 & 13960 & 1,55 & 1940,04 & 1932 & 15 & 0,036 & 13,1 \\
\hline 21 & 0 & 497,61 & 318 & 7893 & 0,84 & 2001,21 & 1997 & 9 & 0,009 & 39,9 \\
\hline 22 & 0 & 510,99 & 6961 & 22960 & 2,46 & 2054,93 & 2042 & 24 & 0,193 & 3,3 \\
\hline 23 & 0 & 554,55 & 4693 & 14410 & 1,66 & 2229,76 & 2219 & 21 & 0,130 & 3,9 \\
\hline 24 & 0 & 569,97 & 546 & 8487 & 1,71 & 2291,68 & 2285 & 13 & 0,015 & 24,2 \\
\hline 25 & 0 & 583,44 & 1454 & 11403 & 1,72 & 2345,72 & 2337 & 18 & 0,040 & 10,7 \\
\hline 26 & 0 & 604,99 & 1501 & 10083 & 1,53 & 2432,25 & 2425 & 16 & 0,042 & 9,8 \\
\hline 27 & 0 & 609,52 & 1110 & 9088 & 1,58 & 2450,41 & 2443 & 15 & 0,031 & 12,5 \\
\hline 28 & 0 & 619,49 & 2569 & 11520 & 1,86 & 2490,45 & 2481 & 20 & 0,071 & 6,2 \\
\hline 29 & 0 & 658,04 & 8501 & 11645 & 1,76 & 2645,17 & 2635 & 21 & 0,236 & 2,1 \\
\hline 30 & 0 & 676,99 & 147 & 3260 & 0,72 & 2721,23 & 2718 & 6 & 0,004 & 55,5 \\
\hline 31 & 0 & 677,90 & 207 & 3370 & 0,50 & 2724,89 & 2723 & 6 & 0,006 & 40,3 \\
\hline 32 & 0 & 687,09 & 570 & 8355 & 1,91 & 2761,79 & 2754 & 16 & 0,016 & 23,0 \\
\hline 33 & 0 & 698,61 & 1327 & 7735 & 2,05 & 2808,04 & 2800 & 17 & 0,037 & 9,8 \\
\hline 34 & 0 & 707,11 & 1448 & 8967 & 1,68 & 2842,16 & 2833 & 20 & 0,040 & 9,6 \\
\hline 35 & 0 & 727,60 & 217 & 3951 & 1,00 & 2924,38 & 2921 & 9 & 0,006 & 41,5 \\
\hline 36 & 0 & 744,92 & 559 & 5845 & 1,89 & 2993,90 & 2987 & 15 & 0,016 & 19,8 \\
\hline 37 & 0 & 764,26 & 2208 & 7517 & 2,08 & 3071,54 & 3062 & 20 & 0,061 & 5,9 \\
\hline 38 & 0 & 776,85 & 3368 & 8393 & 1,78 & 3122,08 & 3111 & 20 & 0,094 & 4,2 \\
\hline 39 & 0 & 796,12 & 1710 & 7676 & 2,10 & 3199,44 & 3188 & 21 & 0,047 & 7,6 \\
\hline 40 & 0 & 802,04 & 38 & 1903 & 1,85 & 3223,18 & 3223 & 5 & 0,001 & 164,6 \\
\hline
\end{tabular}




\begin{tabular}{|c|c|c|c|c|c|c|c|c|c|c|}
\hline 41 & 0 & 819,04 & 383 & 5495 & 2,40 & 3291,45 & 3285 & 15 & 0,011 & 27,8 \\
\hline 42 & 0 & 828,14 & 1196 & 7213 & 1,97 & 3327,96 & 3318 & 20 & 0,033 & 10,5 \\
\hline 43 & 0 & 861,08 & 172 & 3833 & 0,67 & 3460,17 & 3456 & 10 & 0,005 & 51,6 \\
\hline 44 & 0 & 879,70 & 275 & 4609 & 1,53 & 3534,91 & 3530 & 11 & 0,008 & 35,4 \\
\hline 45 & 5 & 885,15 & 4934 & 7990 & 1,68 & 3556,80 & 3544 & 44 & 0,137 & 2,9 \\
\hline 46 & 5 & 889,67 & 51601 & 9047 & 1,88 & 3574,95 & 3544 & 44 & 1,433 & 0,5 \\
\hline 47 & 0 & 911,70 & 1992 & 6261 & 1,83 & 3663,39 & 3653 & 19 & 0,055 & 6,0 \\
\hline 48 & 0 & 937,95 & 2038 & 5467 & 1,84 & 3768,72 & 3759 & 20 & 0,057 & 5,6 \\
\hline 49 & 0 & 969,65 & 908 & 3584 & 1,73 & 3895,96 & 3890 & 16 & 0,025 & 9,9 \\
\hline 50 & 0 & 1044,50 & 851 & 2476 & 2,00 & 4196,42 & 4187 & 17 & 0,024 & 9,0 \\
\hline 51 & 0 & 1077,32 & 2007 & 2514 & 2,04 & 4328,18 & 4319 & 19 & 0,056 & 4,2 \\
\hline 52 & 0 & 1099,80 & 15677 & 3625 & 2,10 & 4418,39 & 4402 & 30 & 0,435 & 1,0 \\
\hline 53 & 5 & 1116,09 & 52100 & 3526 & 2,14 & 4483,80 & 4466 & 54 & 1,447 & 0,5 \\
\hline 54 & 5 & 1121,10 & 43631 & 2882 & 2,12 & 4503,90 & 4466 & 54 & 1,212 & 0,5 \\
\hline 55 & 0 & 1173,81 & 9883 & 2330 & 2,19 & 4715,48 & 4700 & 30 & 0,275 & 1,2 \\
\hline 56 & 0 & 1221,57 & 123 & 768 & 1,52 & 4907,19 & 4902 & 12 & 0,003 & 33,1 \\
\hline 57 & 0 & 1238,78 & 130 & 908 & 1,14 & 4976,27 & 4969 & 13 & 0,004 & 33,9 \\
\hline 58 & 0 & 1272,41 & 102 & 539 & 1,37 & 5111,26 & 5106 & 11 & 0,003 & 33,7 \\
\hline 59 & 0 & 1281,87 & 68 & 456 & 0,92 & 5149,21 & 5145 & 9 & 0,002 & 46,0 \\
\hline 60 & 0 & 1292,24 & 10357 & 1515 & 2,32 & 5190,87 & 5176 & 30 & 0,288 & 1,1 \\
\hline 61 & 0 & 1298,16 & 96 & 638 & 1,50 & 5214,63 & 5210 & 10 & 0,003 & 38,7 \\
\hline 62 & 0 & 1318,12 & 952 & 1092 & 2,35 & 5294,73 & 5283 & 26 & 0,026 & 5,9 \\
\hline 63 & 0 & 1333,18 & 9015 & 1300 & 2,37 & 5355,18 & 5341 & 30 & 0,250 & 1,2 \\
\hline 64 & 0 & 1349,54 & 80 & 335 & 1,12 & 5420,86 & 5417 & 10 & 0,002 & 34,2 \\
\hline 65 & 0 & 1377,47 & 4 & 160 & 0,24 & 5532,95 & 5532 & 3 & 0,000 & 450,0 \\
\hline 66 & 0 & 1378,52 & 111 & 438 & 1,45 & 5537,17 & 5534 & 10 & 0,003 & 28,2 \\
\hline 67 & 0 & 1384,94 & 1555 & 873 & 2,51 & 5562,97 & 5550 & 27 & 0,043 & 3,7 \\
\hline 68 & 0 & 1408,81 & 875 & 725 & 2,25 & 5658,76 & 5649 & 21 & 0,024 & 5,5 \\
\hline 69 & 0 & 1461,60 & 2154 & 873 & 2,41 & 5870,67 & 5858 & 27 & 0,060 & 2,9 \\
\hline 70 & 0 & 1475,97 & 713 & 700 & 2,72 & 5928,34 & 5917 & 25 & 0,020 & 6,4 \\
\hline 71 & 0 & 1505,82 & 588 & 755 & 2,44 & 6048,17 & 6038 & 23 & 0,016 & 7,8 \\
\hline 72 & 0 & 1510,85 & 60 & 315 & 0,96 & 6068,36 & 6064 & 10 & 0,002 & 43,8 \\
\hline 73 & 0 & 1543,25 & 124 & 450 & 1,64 & 6198,43 & 6189 & 15 & 0,003 & 25,8 \\
\hline 74 & 0 & 1588,87 & 387 & 500 & 2,64 & 6381,54 & 6369 & 21 & 0,011 & 9,6 \\
\hline 75 & 0 & 1593,34 & 412 & 720 & 2,30 & 6399,48 & 6389 & 20 & 0,011 & 10,4 \\
\hline 76 & 0 & 1621,86 & 89 & 348 & 1,64 & 6513,96 & 6508 & 12 & 0,002 & 31,5 \\
\hline 77 & 10 & 1631,03 & 23 & 576 & 1,94 & 6550,77 & 6543 & 18 & 0,001 & 150,8 \\
\hline 78 & 10 & 1631,66 & 103 & 572 & 1,94 & 6553,28 & 6543 & 18 & 0,003 & 34,2 \\
\hline 79 & 0 & 1662,89 & 19 & 155 & 0,41 & 6678,65 & 6676 & 6 & 0,001 & 95,5 \\
\hline 80 & 0 & 1730,15 & 114 & 397 & 2,12 & 6948,62 & 6939 & 16 & 0,003 & 26,5 \\
\hline 81 & 0 & 1765,55 & 1085 & 490 & 2,58 & 7090,71 & 7078 & 26 & 0,030 & 4,2 \\
\hline 82 & 0 & 1849,32 & 44 & 203 & 1,21 & 7426,97 & 7423 & 10 & 0,001 & 48,6 \\
\hline 83 & 0 & 1949,61 & 34 & 121 & 1,02 & 7829,53 & 7823 & 11 & 0,001 & 48,9 \\
\hline 84 & 0 & 1994,64 & 484 & 847 & 1,65 & 8010,29 & 8005 & 14 & 0,013 & 9,6 \\
\hline
\end{tabular}




\section{REFERÊNCIAS BIBLIOGRÁFICAS}

ALFASSI, Activation Analysis, Boca Raton, Fla.: CRC Press, 1990, v.1.

BAEDECKER, P. A. Digital methods of photopeak integration in activation analysis. Anal. Chem., v.43, n.3, p.405-410, 1971

BONA, C. Avaliação de Processos de Software: Um estudo de caso em XP e Iconix. Dissertação (Mestrado) - Universidade Federal de Santa Catarina, 2002. Disponível em: <http://teses.eps.ufsc.br/defesa/pdf/10816.pdf>. Acesso em: Novembro 2004.

CANBERRA: Genie-2000. Disponível em <http://www.canberra.com>. Acesso em: Janeiro 2006.

COSTA, M. T. C. da. Processo de Desenvolvimento de Software com UML. São José, SC: [s.n.], 2001. Apud in (7).

GUSTAFSON, D. A. Teoria e Problemas de Engenharia de Software. Porto Alegre: Bookman, 2003. (Coleção Schaum). Trad. Fernanda Cláudia Alves Campos.

IAEA. Guidelines for radioelement mapping using gamma ray spectrometry data. Viena, Austria, IAEA-TECDOC-1363, July 2003.

IAEA. Intercomparison of Gamma Ray Analysis Software Packages. Viena, Austria, IAEA-TECDOC-1011, April 1998.

Joseph Feller, Brian FitzGerald - Understanding Open Source Software Development. 2002.

PRESSMAN, R. Engenharia de Software. 5a. ed. [S.I.]: McGraw-Hill Interame, 2002. 872 pág, ISBN 8586804258.

Open Source Initiative - Disponível em: <http://www.opensource.org >. Acesso em: 29/07/2007.

ORTEC: GammaVision-32. Disponível em <http://www.ortec-online.com>. Acesso em: Janeiro 2006.

PYTHON Programming Language. Disponível em: <http://www.python.org>. Acesso em: Setembro 2004. 
RAYMOND, E. S. The Cathedral and The Bazaar. In: The Cathedral and TheBazaar. 1st ed. Sebastopol: O'Reilly and Associates, 1999. p. 27-78. Disponível em: <http://www.tuxedo.org/ esr/writings/cathedral-bazaar/>. Acesso em 07 de Abril de 2007.

REZENDE, D. A. Engenharia de Software e Sistemas de Informação. [S.I.]: Basport, 2002. 358 pág, ISBN 8574520942.

RIVERBANK: PyQt. Disponível em: http://www.riverbankcomputing.co.uk/pyqt/index.php>. Acesso em: Dezembro 2005.

SIMONITS A. et al. Hyperlab: A new concept in gamma-ray spectrum analysis. Jornal of Radioanalytical and Nuclear Chemistry, v. 257, n. 3, p. 589-595, 2003.

SOLÉ, V.A.; PAPILLON, E.; COTTE, M.; WALTER, PH.; SUSINI, J. A multiplatform code for the analysis of energy-dispersive $\mathrm{X}$-ray fluorescence spectra, Spectrochim. Acta Part B 62 (2007) 63-68.

SOMMERVILLE, I. Engenharia de Software. 6a. ed. [S.I.]: Prentice Hall Brasil, 2003. 608 pág, ISBN 8588639076.

TROLLTECH. Disponível em: <http://www.trolltech.com>. Acesso em: Dezembro 2005. 